Review

\title{
Design Strategies for Functionalized Poly(2-oxazoline)s and Derived Materials
}

\section{Elisabeth Rossegger ${ }^{1,2}$, Verena Schenk ${ }^{1,2}$ and Frank Wiesbrock ${ }^{1,2, *}$}

1 Polymer Competence Center Leoben GmbH, Roseggerstrasse 12, Leoben 8700, Austria; E-Mails: elisabeth.rossegger@pccl.at (E.R.); verena.schenk@pccl.at (V.S.)

2 Institute for Chemistry and Technology of Materials, Graz University of Technology, Stremayrgasse 9/V, Graz 8010, Austria

* Author to whom correspondence should be addressed; E-Mail: frank.wiesbrock@pccl.at; Tel.: +43-3842-42962-42; Fax: +43-3842-42962-6.

Received: 17 June 2013; in revised form: 1 July 2013 / Accepted: 2 July 2013 /

Published: 15 July 2013

\begin{abstract}
The polymer class of poly(2-oxazoline)s currently is under intensive investigation due to the versatile properties that can be tailor-made by the variation and manipulation of the functional groups they bear. In particular their utilization in the biomedic(in)al field is the subject of numerous studies. Given the mechanism of the cationic ring-opening polymerization, a plethora of synthetic strategies exists for the preparation of poly(2-oxazoline)s with dedicated functionality patterns, comprising among others the functionalization by telechelic end-groups, the incorporation of substituted monomers into (co)poly(2-oxazoline)s, and polymeranalogous reactions. This review summarizes the current state-of-the-art of poly(2-oxazoline) preparation and showcases prominent examples of poly(2-oxazoline)-based materials, which are retraced to the desktop-planned synthetic strategy and the variability of their properties for dedicated applications.
\end{abstract}

Keywords: poly(2-oxazoline)s; cationic ring-opening polymerization; telechelic end-group functionalization; polymeranalogous reactions 


\section{Introduction}

Since their discovery in 1966 [1-4], the class of poly(2-oxazoline)s has received great interest due to its versatility in enabling the preparation of materials with tailor-made properties. The materials are currently receiving on-going interest in particular as potential biomaterials, also benefiting from the introduction of microwave reactors dedicatedly designed for chemical syntheses in polymer chemists' and material scientists' laboratories [5].

One huge advantage of the cationic ring-opening polymerization of 2-oxazoline monomers (Scheme 1) arises from the fact that they can be performed in a manner that side-reactions such as the termination of chain growth and/or chain-coupling are suppressed (because of the control of this type of polymerization, it has been described as living or quasi-living polymerization). Concomitant with first-order kinetics of the monomer consumption, the polymers with narrow molar mass distributions, pave the way for the synthesis of block copoly(2-oxazoline)s and other copolymers containing blocks of poly(2-oxazoline)s, and enable the synthesis of telechelic and semitelechelic poly(2-oxazoline)s due to dedicated (and quantitative) termination of the polymerization. Notably, also the initiation of the polymerization is highly regioselective and can only occur at the nitrogen atom of a 2-oxazoline monomer, but not at the oxygen atom [6]. In particular potential usage in mammalian bodies and/or sanitary applications greatly benefits from the control of the cationic ring-opening polymerization CROP and the regioselective initiation. The hydrolysis of poly(2-oxazoline)s yields poly(ethylene imine)s (Scheme 1), which opens a whole new area of synthetic strategies for (polymeranalogous) polymer modification, even further expanding the "toolbox" of chemical findings for fine-tuning the poly(2-oxazoline)-based materials with numerous potential applications in the biomedical sector [7-9].

Scheme 1. Reaction scheme for the methyl tosylate-initiated cationic ring-opening polymerization CROP of 2-oxazolines for the example of the block copolymerization of 2-methyl-2-oxazoline and 2-ethyl-2-oxazoline, yielding the diblock copolymer poly(2-methyl-2-oxazoline)-block-poly(2-ethyl-2-oxazoline) after termination with water (top). Poly(2-oxzoline)s can be subjected to acid-mediated partial hydrolysis [shown for the example of poly(2-ethyl-2-oxazoline)], yielding the random copolymer poly(2-ethyl-2-oxazoline)-stat-poly(ethylene imine) (bottom) and paving the way to further polymeranalogous reactions.
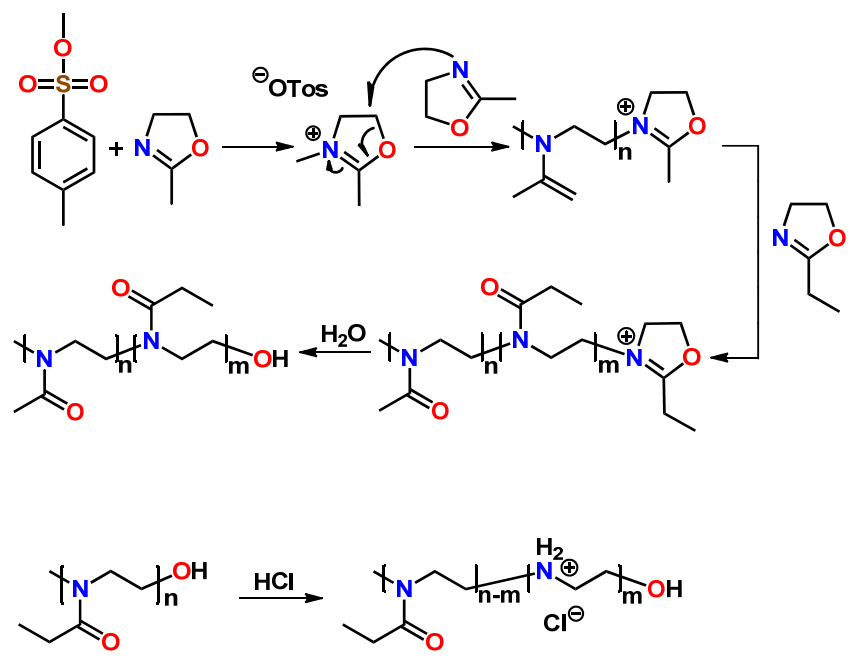
This review aims to summarize the state-of-the-art of "poly(2-oxazoline) synthesis" and in particular to correlate the targeted properties of the poly(2-oxazoline)s and the materials derived from that class of polymers with the strategies required for their synthesis. The most recent developments published in the last ten years have been focused on during the compilation of this review; crosslinked poly(2-oxazoline)s, which were reviewed in a recent publication, have been omitted from this compilation [10]. While this review focuses on the synthesis of poly(2-oxazoline)s and copoly(2-oxazoline)s as well as the derived materials, the properties of the polymers and materials themselves will be discussed only for dedicated examples, and the reader interested in more and/or more general details is referred to recent reviews in that area [11-20].

Based on the accessibility of dedicatedly substituted 2-oxazoline monomers due to the (comparably) easy and straight-forward synthesis (see Section 3.1.2), a vaste number of 2-oxazoline monomers and polymers have been investigated over the last years. The monomers described in this article have been summarized in Table 1. Notably, while there is still no commonly designed acronym to use for 2-oxazolines, they have been defined consistently throughout this review such that they meet the (XX) $\mathrm{AA}^{=} \mathrm{Ox}(\mathrm{YY})$ notation, according to which $\mathrm{AA}$ (or $\mathrm{AA}^{-}$) specifies the substituent in 2-position of the 2-oxazoline ring ( ${ }^{=}$and ${ }^{\equiv}$ are indicative of $\mathrm{C}-\mathrm{C}$ double and triple bonds of the AA substituent), $\mathrm{XX}$ specifies the substitution pattern of the AA substituent, and YY specifies the substitution pattern of the 2-oxazoline ring in its 4- and/or 5-position. In this sense, $(\mathrm{Cl}-\mathrm{Ph})^{\mathrm{c}} \mathrm{BuOx}$ is a 2-cyclo-butyl-2-oxazoline, in which the cyclobutane unit carries a chlorophenyl substituent: 2-[1'-(4"-chlorophenyl)-cyclo-butyl]2-oxazoline. The term "ethylene imine" and the corresponding acronym EI are used only for hydrolyzed poly(2-oxazoline)s with the $\left[-\mathrm{NH}-\mathrm{CH}_{2}-\mathrm{CH}_{2}-\right]$ repeating unit (Scheme 1).

Table 1. Overview of the 2-oxazoline monomers described in this review. Acronyms are defined such that they meet the style $(\mathrm{XX}) \mathrm{AA}^{=} \mathrm{Ox}(\mathrm{YY})$, according to which $\mathrm{AA}$ or $\mathrm{AA}^{=}$, respectively, specifies the substituent in 2-position of the 2-oxazoline ring $\left({ }^{\circ}\right.$ and ${ }^{\equiv}$ are indicative of $\mathrm{C}-\mathrm{C}$ double and triple bonds of the AA substituent), $\mathrm{XX}$ specifies the substitution pattern of the AA substituent, and YY specifies the substitution pattern of the 2-oxazoline ring in its 4- and/or 5-position.

\begin{tabular}{|c|c|c|}
\hline \multicolumn{3}{|c|}{ Methyl-based Substituents } \\
\hline $\begin{array}{c}\text { MeOx } \\
\text { 2-methyl-2-oxazoline }\end{array}$ & $\begin{array}{c}\text { (F3)MeOx } \\
\text { 2-trifluoromethyl- } \\
\text { 2-oxazoline }\end{array}$ & $\begin{array}{c}(\mathbf{M e S}) \mathbf{M e O x} \\
\text { 2-(methyl-thio)-methyl- } \\
\text { 2-oxazoline }\end{array}$ \\
\hline \multicolumn{3}{|c|}{ Ethyl-based Substituents } \\
\hline$\underbrace{\text { 2-ethyl-2-oxazoline }}_{\text {EtOx }}$ & 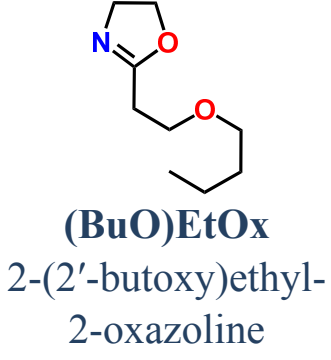 & $\begin{array}{l}\text { (Carb)EtOx } \\
\text { 2-(carbazolyl)ethyl- } \\
\text { 2-oxazoline }\end{array}$ \\
\hline
\end{tabular}


Table 1. Cont.

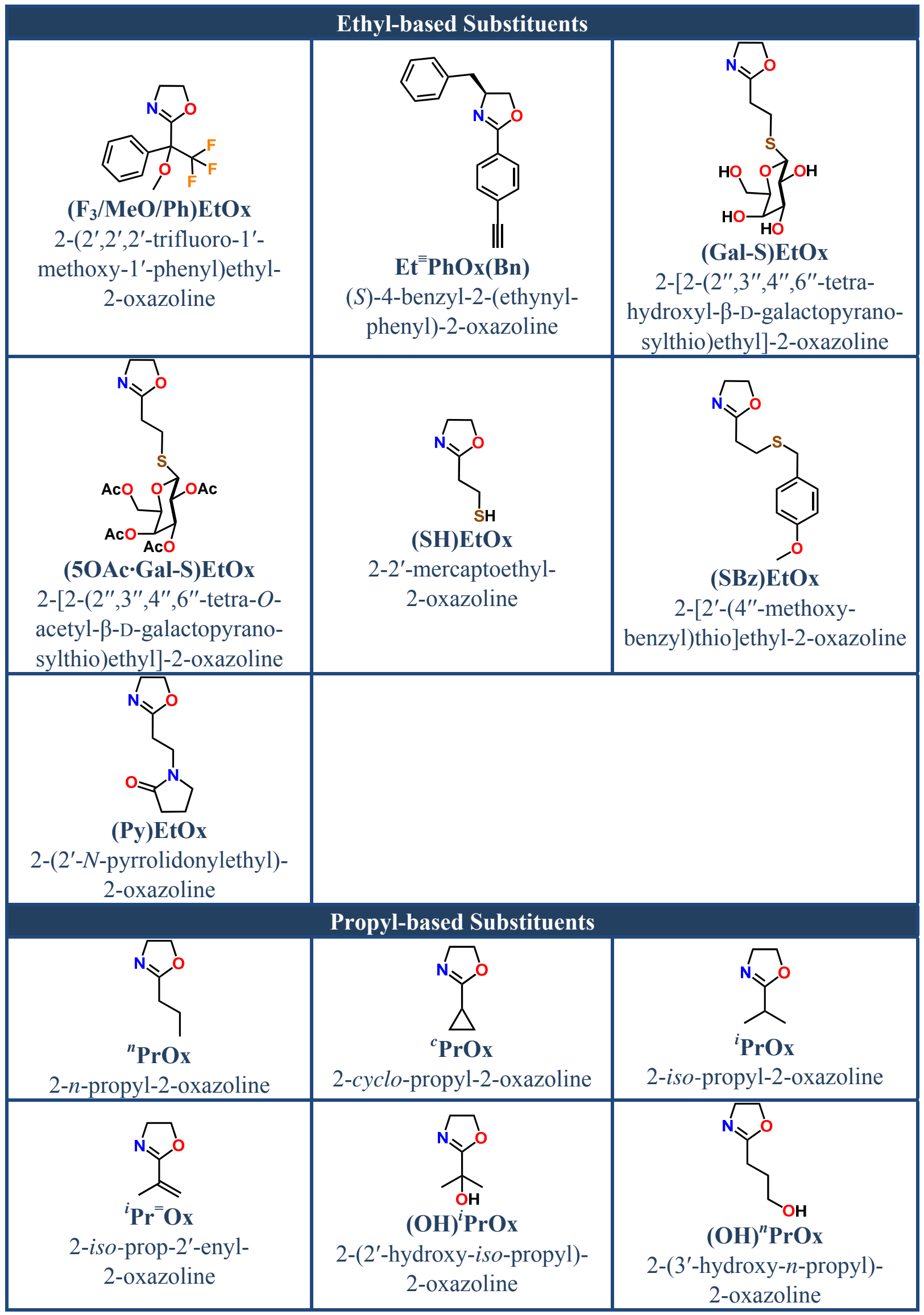


Table 1. Cont.

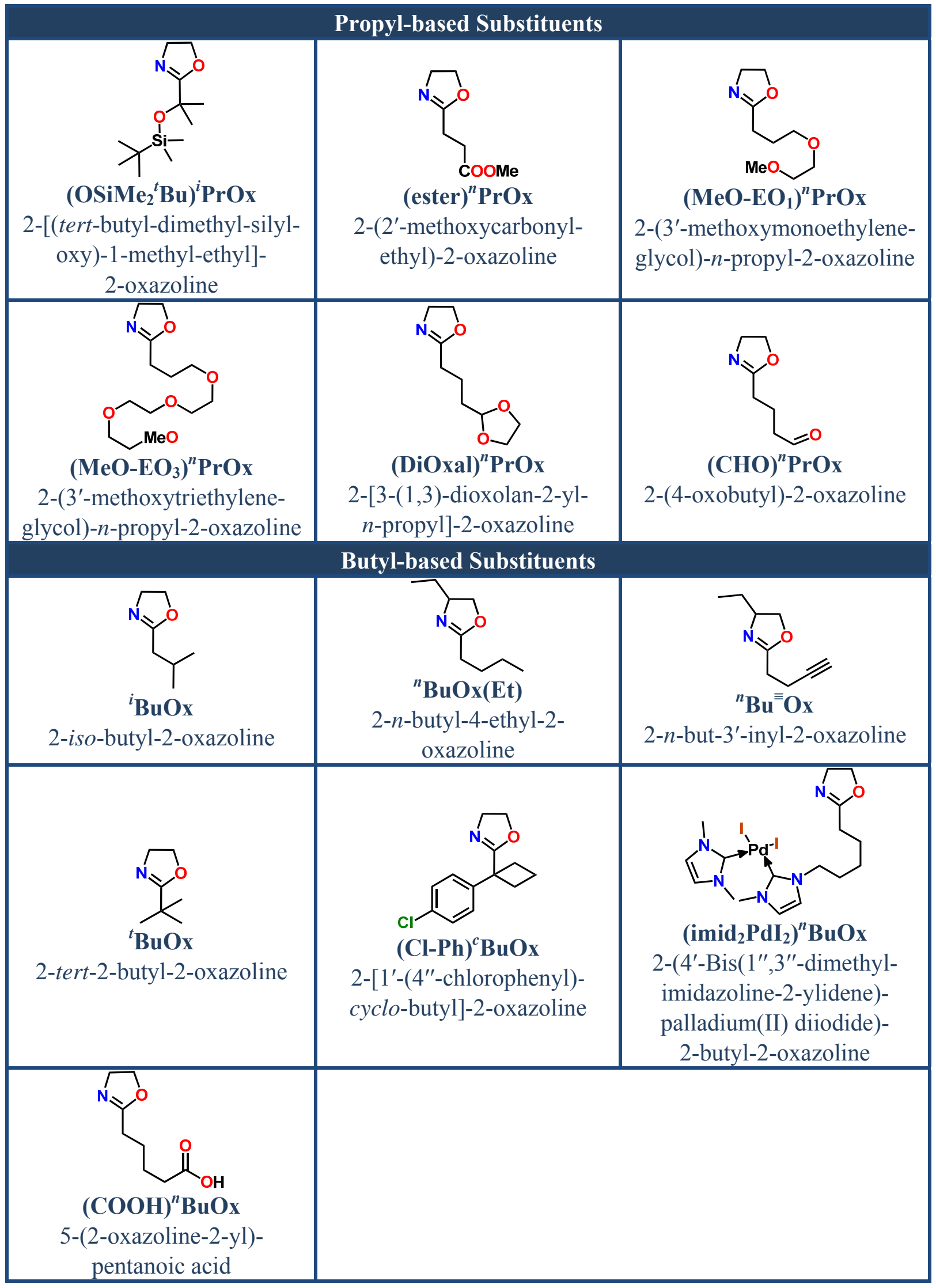


Table 1. Cont.

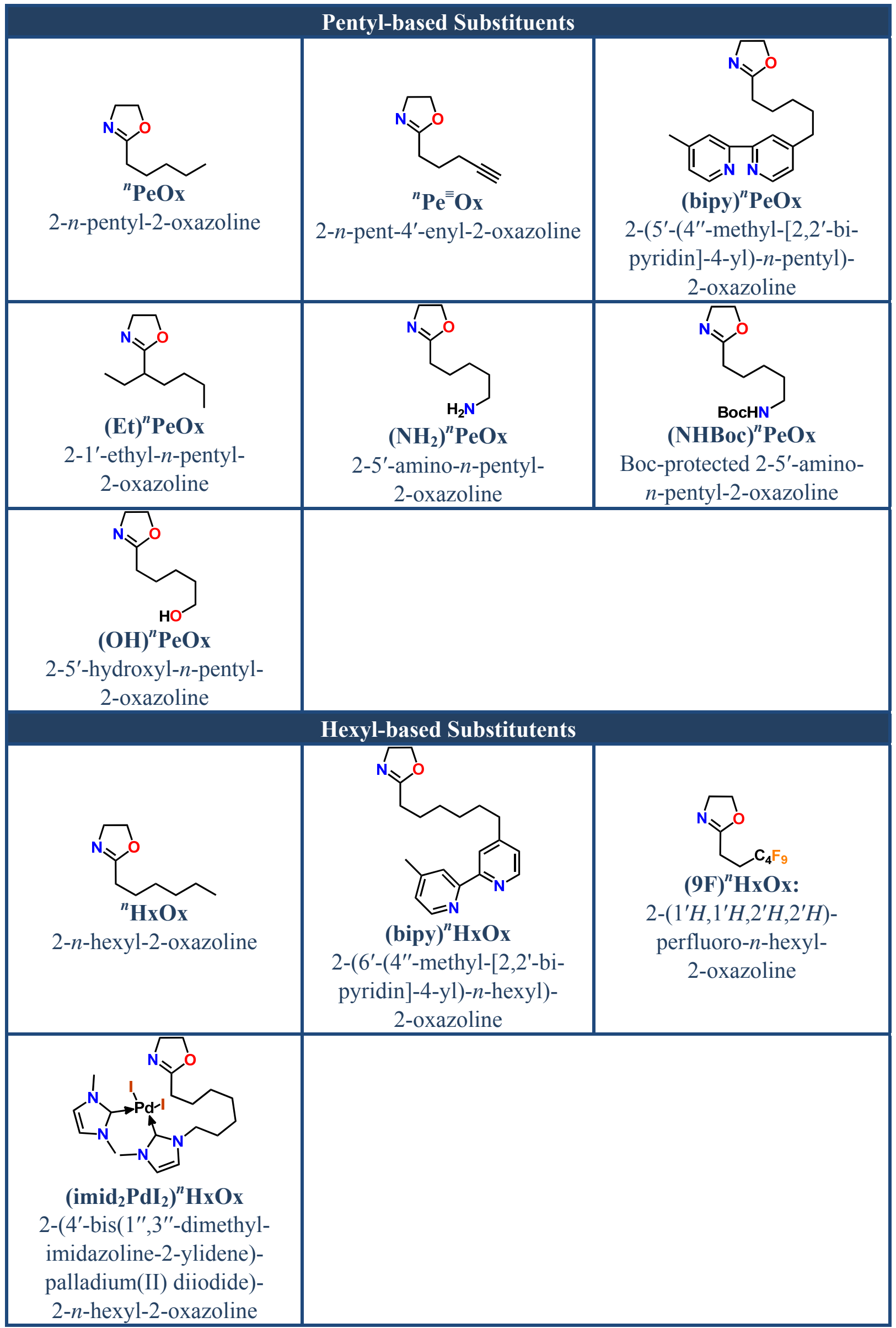


Table 1. Cont.

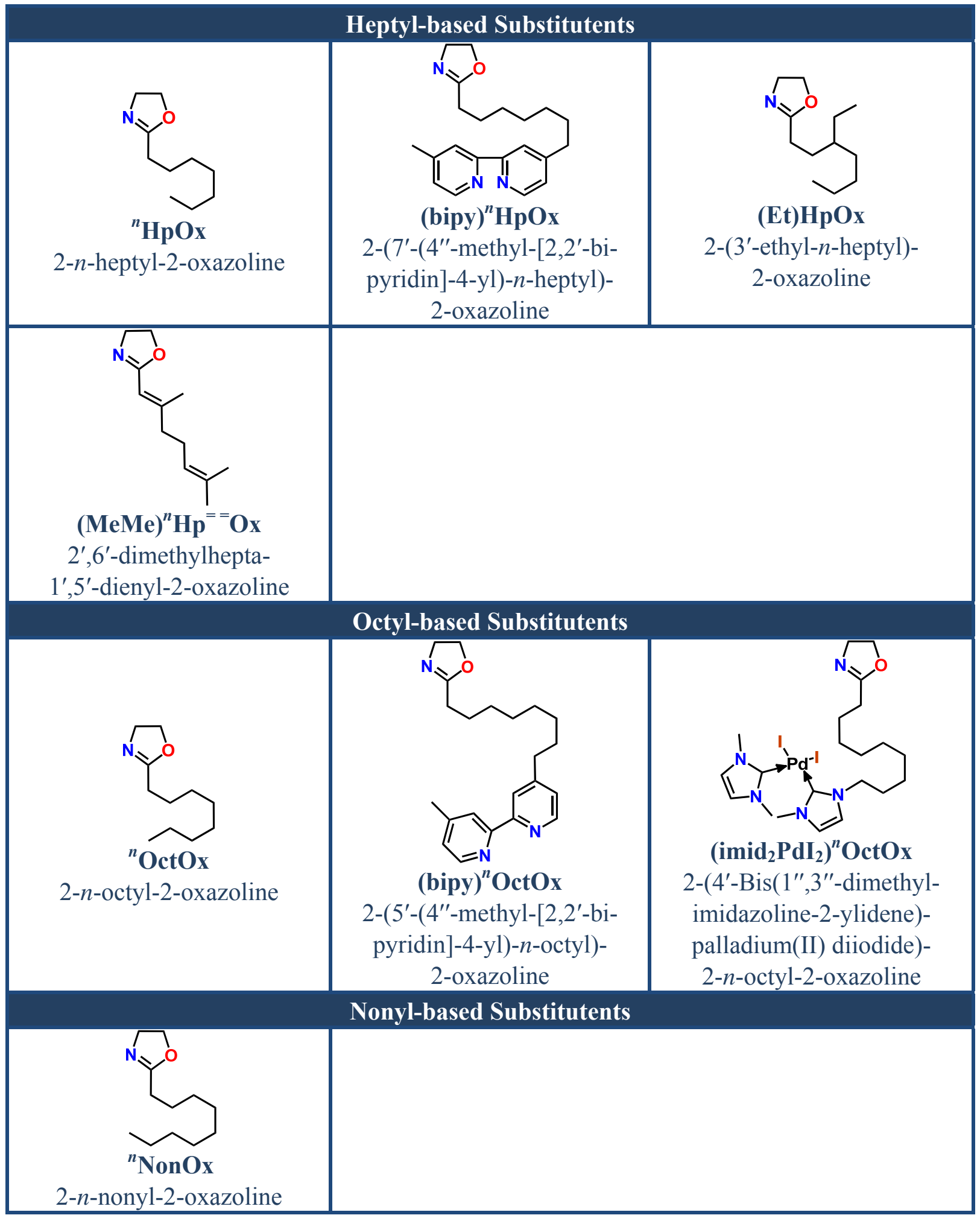


Table 1. Cont.

\begin{tabular}{|c|c|c|}
\hline \multicolumn{3}{|c|}{ Decyl-based Substitutents } \\
\hline$\overbrace{\text { 2-n-decyl-2-oxazoline }}^{{ }_{\text {DecOx }}}$ & $\begin{array}{l}\text { 2-[2-(2", } 3^{\prime \prime}, 4^{\prime \prime}, 6^{\prime \prime} \text {-tetra- } \\
\text { hydroxyl- } \beta-\mathrm{D} \text {-galacto- } \\
\text { pyranosylthio) decenyl]- } \\
\text { 2-oxazoline }\end{array}$ & $\begin{array}{l}\text { 2-[2-(2", } 3^{\prime \prime}, 4^{\prime \prime}, 6^{\prime \prime} \text {-tetra- } O \text { - } \\
\text { acetyl- } \beta \text {-D-galacto- } \\
\text { pyranosylthio) decenyl]- } \\
\text { 2-oxazoline }\end{array}$ \\
\hline 2-n-dec-9'-enyl-2-oxazolin & Decyl-based Substitutents & \\
\hline$\underbrace{c}_{\substack{{ }_{\text {Und Ox }} \\
\text { 2-n-undecyl-2-oxazoline }}}$ & ndecyl-based Substituten & \\
\hline 2-phenyl-2-oxazoline & $\begin{array}{l}\text { 2-4'-tert-butyl-2-phenyl- } \\
\text { 2-oxazoline }\end{array}$ & $\begin{array}{c}\text { 2-F)PhOx } \\
\text { 2-2',6'-difluorphenyl- } \\
\text { 2-oxazoline }\end{array}$ \\
\hline $\begin{array}{c}\text { 2-[4'-(trifluoromethyl)- } \\
\text { thio]phenyl-2-oxazoline }\end{array}$ & $\begin{array}{l}\text { (2I)PhOx(Bz) } \\
\text { 4-benzyl-2-oxazoline }\end{array}$ & $\begin{array}{l}\text { (2I)PhOx(Ph) } \\
\text { 4-phenyl-2-oxazoline }\end{array}$ \\
\hline
\end{tabular}


Table 1. Cont.

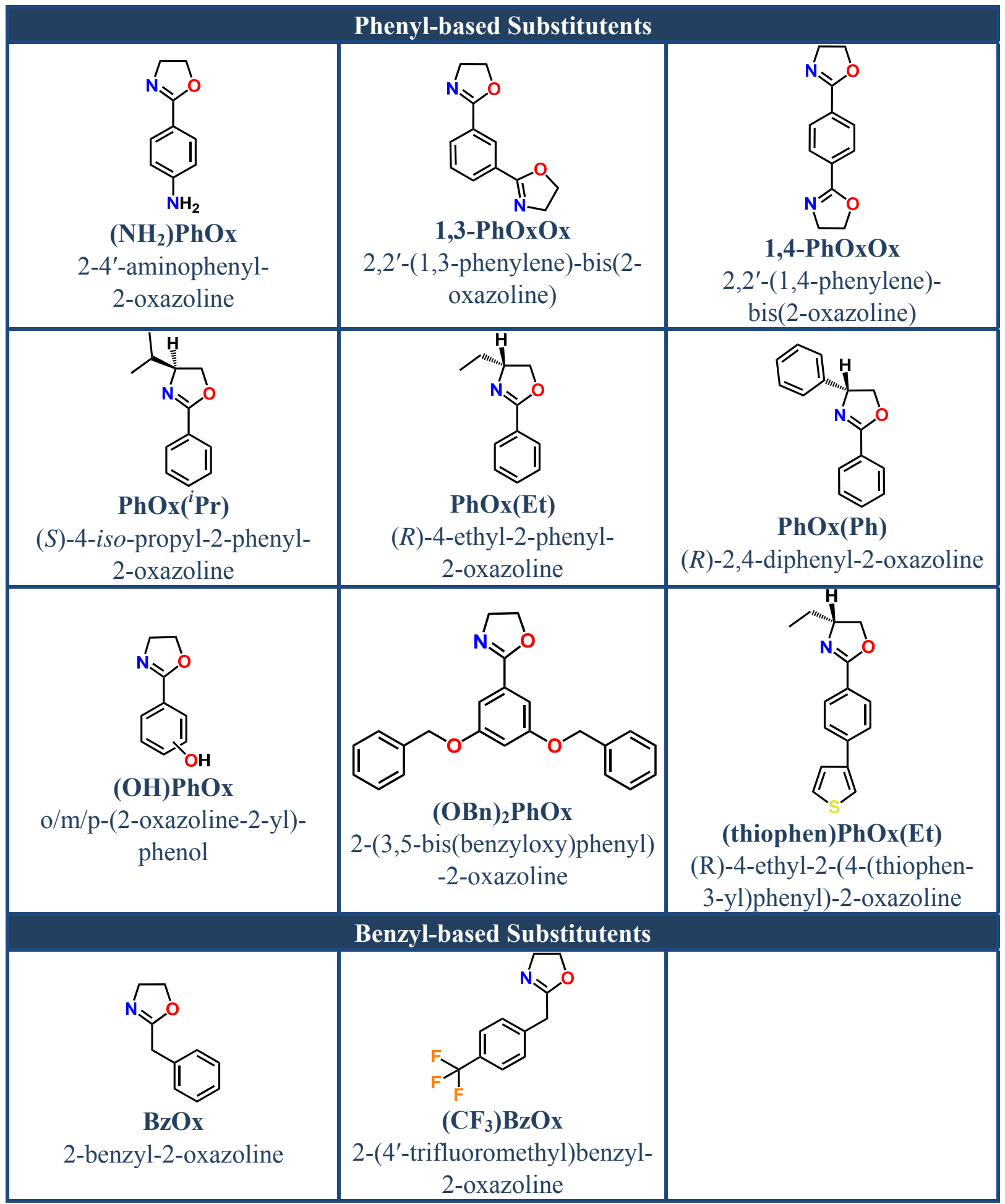


Table 1. Cont.

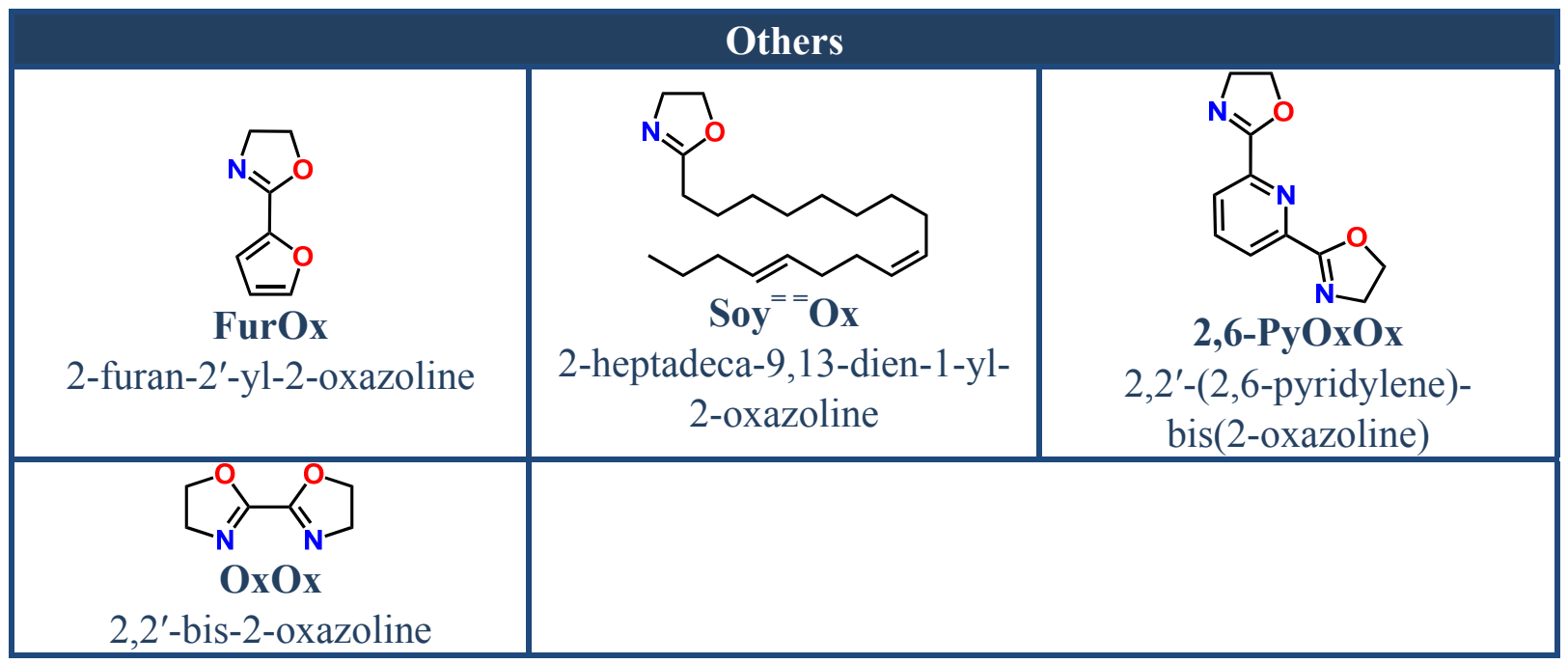

This review has been divided into three parts according to the initiators/terminating agents available (unconventional initiators, initiators and terminating agents with targeted properties, macroinitiators for the synthesis of linear (co-)poly(2-oxazoline)s, macroinitiators: grafting of brush- and comblike structures, and macroinitiators: star-shape geometries), the poly(2-oxazoline)s reported over the last ten years [homopoly(2-oxazoline)s and homopolymers with pending 2-oxazoline groups, block copoly(2-oxazoline)s), and polymeranalogous reactions of poly(2-oxazoline)s (excluding and including partial hydrolysis). The term "polymeranalogous reactions" is used for reactions altering the side-chain functionalities; reports of the usage of semitelechelic and telechelic poly(2-oxazoline)s as macroinitiators have been summarized in the "initiator" section.

\section{Initiators and Terminating Agents}

\subsection{Unconventional Initiators}

Compounds capable of delivering strongly electrophilic, almost carbocationic species are the most commonly used initiators for the CROP of 2-oxazolines. Schubert and co-workers prepared a library of 128 homopolymers of the composition pMeOx, pEtOx, pPhOx, and $\mathbf{p}^{n}$ NonOx and ranged the reactivity of four different initiators for the corresponding CROP reactions, namely benzyl bromide, methyl triflate, methyl tosylate, and methyl iodide [21]. In terms of polymerization rates, the initiators that delivered methyl cations during the initiation were ranked methyl triflate $>$ methyl tosylate $>$ methyl iodide.

\subsubsection{Metal Cations as Initiators}

The CROP of MeOx and PhOx initiated by metallocene complexes such as $\operatorname{bis}\left(\eta^{5}\right.$-cyclopentadienyl)dimethyl zirconium $\mathrm{cp}_{2} \mathrm{ZrMe}_{2}$ and bis $\left(\eta^{5}\right.$-tert-butyl-cyclopentadienyl $)$ dimethyl hafnium ( $\left.{ }^{t} \mathrm{Bu}-\mathrm{cp}\right)_{2} \mathrm{HfMe}_{2}$ was reported for the first time by Pitsikalis et al. [22]. Poly(2-oxazoline)s with narrow molar mass distributions were obtained after quantitative monomer consumption. The PhOx monomer showed lower polymerization rates than its MeOx congener; side-reactions like termination and/or chain transfer reactions were reported to occur. Kricheldorf and co-workers 
polymerized MeOx and EtOx using bismuth salts such as $\mathrm{BiCl}_{3}, \mathrm{BiBr}_{3}, \mathrm{BiI}_{3}$, and $\mathrm{Bi}(\mathrm{OTf})_{3}$ [23]. The authors revealed that the formation of cyclic oligomers was not observed, but nonetheless chain-transfer reactions limited the chain-growth of the poly(2-oxazoline)s.

\subsubsection{Iodine-Based Initiators}

In addition to well-described methyl iodide and benzyl iodide initiators, also acetyl iodine (amongst other acetyl halides) has been described as initiator for the CROP of 2-oxazolines by Schubert et al. [24]. pEtOx with low $\overline{\mathrm{M}}_{\mathrm{w}} / \overline{\mathrm{M}}_{\mathrm{n}}$ values (according to SEC) were obtained. Lapinte and co-workers investigated the applicability of molecular iodine as an initiator for the polymerization of MeOx [25]. They reported an ionic-type mechanism for the polymerization in acetonitrile, involving the dissociation of molecular iodine to the active initiating species. Volet and co-workers prepared amphiphilic poly(iso-butylvinyl ether)-block-pMeOx block copolymers using the hydrogen iodide/iodine system for the initiation of the cationic polymerizations [26]. These block copolymers formed micelles, and their adsorption behavior onto porous silica particles was investigated using different solvents showing that nonselective solvents (dichloromethane) lead to higher adsorption.

\subsubsection{Advanced Organic Initiators}

The anionic polymerization technique was the method of choice for Dumas et al. to prepare poly(ethylene oxide) and poly(tert-butyl methacrylate), induced via the carbanion derived from the reaction of MeOx with ${ }^{n} \mathrm{BuLi}$ or LDA [27]. Notably, $(\mathbf{O H})^{n} \mathbf{P r O x}$ derived from the reaction of deprotonated $\mathbf{M e O x}$ with ethylene oxide was found to be a dedicated initiator for the polymerization of $\varepsilon$-caprolactone. Starting from various tert-butyldiphenylsilyl monoprotected diols, Jordan et al. synthesized the corresponding triflates as initiators for the CROP of EtOx [28]. The polymers, which were end-capped with various cyclic amines, showed monomodal, narrow molar mass distributions. Easy cleavage of the protective groups revealed intact (lipo)polymer structures. Methacryloyl chloride, was employed as initiator for the CROP of EtOx or in polymeranalogous reactions (with $\mathrm{OH}$ end groups) after termination of the CROP of EtOx, respectively, in order to yield methacrylate- or methacrylamide-functionalized pEtOx [29]. Termination with methacryloyl chloride was performed in-situ or after the polymerization and "intermediate quenching" with alkaline aqueous solutions. Thomas et al. studied the microstructures of supramolecular-assembled star block copolymers consisting of six arms of pEtOx-block-p ${ }^{n} \mathbf{U n d O x}$ with an iron tris(bipyridine) center [30]. For the CROP, iron(II)-tris[4,4'-bis(chloromethyl)-2,2'-bipyridine] was used as initiator after exchange of the chlorine atoms by iodine. A cylindrical pEtOx conformation was observed.

\subsection{Initiators and Terminating Agents with Targeted Properties}

\subsubsection{Functionalization of Poly(2-oxazoline)s with Tracers}

Statistical copoly(2-oxazoline) nanoparticles were surface-functionalized with fluorescein dyes by Schubert and co-workers [31]. The fluorescein label enabled unambiguous monitoring of cellular uptake of the nanoparticles. Jordan, Essler et al. reported the synthesis of radiolabeled poly(2-oxazoline)s [32]. They used $N$-tert-butyloxycarbonylpiperazine as terminating agent; after 
removal of the Boc protection group, the end-group was reacted with 2-(4-iso-thiocyanatobenzyl)$N, N^{\prime}, N^{\prime \prime}, N^{\prime \prime \prime}$-tetraazacyclododecane-1,4,7,10-tetraacetic acid yielding a poly(2-oxazoline) bearing the DOTA structural motif capable of complexing, e.g., ${ }^{111}$ indium. The polymers were found to not accumulate in body tissues, and only a minimal uptake into the reticuloendothelial system was observed.

\subsubsection{Functionalization of Poly(2-oxazoline)s with Hydrophobic/Hydrophilic End-Groups}

Winnik et al. reported the self-assembly of $n$-octadecyl end-modified $\mathbf{p}^{i} \mathbf{P r O x}$ samples at the air/water interface [33]. The stability of their interfacial assemblies correlated with the molar mass of the polymer in a reciprocal way. It was also found that the telechelic (n-octadecyl group on both termini) rather than the semitelechelic ( $n$-octadecyl group on one chain-end) $\mathbf{p}^{i} \mathbf{P r O x}$ and higher temperature $\left(36^{\circ} \mathrm{C}\right.$ instead of $\left.14^{\circ} \mathrm{C}\right)$ stabilized the interfacial assembly. The poly(2-oxazoline)s were prepared using $n$-octadecyl-4-chlorobenzenesulfonate as initiator and methanolic $\mathrm{KOH}$ or $n$-octadecyl isocyanate, respectively, as terminating agent [34]. Volet and co-workers used the "initiator method" to prepare monoalkyl-terminated pMeOx and pEtOx using long-chain alkyl iodides as initiator [35-38]. The authors investigated the aggregation behavior of those amphiphilic poly(2-oxazoline)s in aqueous media. Due to preferred supramolecular assembly of the semitelechelic poly(2-oxazoline)s with $\beta$-cyclodextrin, the addition of $\beta$-cyclodextrin resulted in dissociation of the aggregates. Analogously, pMeOx addition to silica nanoparticles that were shielded by cyclodextrin resulted in the formation of a second surrounding layer. Notably, Yan and co-workers synthesized pMeOx using benzyl bromide as initiator and formed complexes with cyclodextrin [39]. Yan and co-workers showed a crystalline inclusion complex formation using $\gamma$-cyclodextrin, but none with $\alpha$ - or $\beta$-cyclodextrin due to a geometric hindrance of the methyl side-groups of $\mathbf{p M e O x}$ that, according to molecular modeling, were too voluminous for $\alpha$ - or $\beta$-cyclodextrin. In order to fine-tune the LCST of $\mathbf{p}^{i}$ PrOx, not only the initiator and/or termination method by various reactants but also the sequential block copolymerization with MeOx was investigated by Jordan et al. [40]. Telechelic groups like methyl, $n$-nonyl, piperidine, piperazine, oligo(ethylene glycol) and oligoMeOx were used. In contrast to lipophilic reactants (which decreased the LCST), hydrophilic end-groups increased the LCST.

\subsubsection{Telechelic Poly(2-oxazoline)s as Antimicrobially Active Compounds}

Aguiar-Ricardo et al. synthesized semitelechelic pMeOx, pEtOx, and pPhOx that were end-functionalized with various amines (and subjected some congeners to acid-mediated hydrolysis, yielding pEI hydrochloride) [41]. The obtained oligomers exhibited antimicrobial activity due to the quarternary ammonium groups. pMeOx and pTMBO [poly(tetramethylene-bis-2-oxazoline)] that were end-capped with $N, N$-dimethyl- $n$-dodecylamine showed high antimicrobial activity, whereas linear pEI hydrochloride displayed the lowest minimal inhibitory concentration values, but higher activity against Staphylococcus aureus and Escherichia coli. Tiller and Waschinski initiated the CROP of MeOx and EtOx with the initiator 3-[(tert-butoxycarbonyl)amino]benzyl-p-toluenesulfonate and terminated the polymerizations with tertiary amines exhibiting one long alkyl chain (dimethyl-ndodecylamine and dimethyl-n-hexadecylamine, respectively) [42]. In antimicrobial tests, the authors revealed that the satellite groups of the polymers had great influence on the bioactivity, which was verified with the example of the bacterium Staphylococcus aureus. Tiller et al. also investigated 
pMeOx with $N, N$-dimethyl-n-dodecylammonium end-groups and different "satellite" groups such as methyl, $n$-decyl, $n$-hexadecyl in terms of their biocidal behavior (groups at the distal end of the polymer are referred to as "satellite" groups) [43]. They found that there are differences in the interactions between the polymer and the phospholipid membrane due to different affinities of the polymer to the membrane. Tiller et al. proposed that not only the polymers' good adhesion to the membrane, but also their incorporation played important roles in the overall mechanism of biocidal activity. In case of the hexadecyl satellite group, the penetration of the DDA ( $N, N$-dimethyldodecylammonium) functionality is prevented. Tiller et al. examined the great influence of the satellite groups on the antimicrobial activity of poly(2-oxazoline)s in an expanded study [44] (Scheme 2). pMeOx, pEtOx, and the corresponding block copolymers with pPhOx with varying satellite groups and a dimethyl- $n$-dodecylammonium end-group were synthesized and their antibacterial activities against Staphylococcus aureus and Escherichia coli were examined. Tiller et al. postulated that the satellite groups induced destabilization of the bacterial membranes.

\subsubsection{Functionalization of Poly(2-oxazoline)s with Non-Olefinic Reactive End-Groups}

Schubert et al. reported the semitelechelic functionalization of OH-end-capped $\mathbf{p E t O x}$ by the reaction with $4^{\prime}$-chloro-2,2':6', $2^{\prime \prime}$-terpyridine [45]. This type of end-functionalized chelating macromolecule was described as a key candidate for the preparation of metallo-supramolecular polymers via metallo-terpyridine complexation. Mero et al. terminated the CROP of EtOx with methyl 3-mercaptoproprionate and subsequently reacted the semitelechelic pEtOx with 3-amino-1,2propanediol or alkylamines, yielding aldehyde or amine end-capped poly(2-oxazoline)s [46]. Both, $\mathrm{N}$-terminal reductive amination as well as transglutaminase-mediated glutamine conjugation were used as coupling techniques for granulocyte colony stimulating factors. The thus-conjugated pharmaceutical protein maintained its biological activity. Tadpole-shaped pMeOx was synthesized by Ogoshi and Nakamoto et al. employing the CROP of MeOx using 2-(6-bromo-n-hexyloxy)-3,6,7,10,11pentahexyloxytriphenylene as initiator [47]. In solution, the tadpole-shaped pMeOx formed crooked nanowires. Guis et al. investigated pMeOx-block-poly(propylene glycol)-block-pMeOx triblock copolymers as possible alternative to poly(ethylene glycol)-block-poly(propylene glycol)-blockpoly(ethylene glycol) compounds especially for the use in in vivo muscle gene transfer and found that the DNA transfection efficacy could be increased using these compounds [48]. For the synthesis, Guis et al. used ditosylated poly(propylene glycol) macroinitiators to initiate the CROP of MeOx. Meier and Stoenescu prepared poly(ethylene oxide)-block-poly(dimethyl siloxane)-block-pMeOx triblock polymers [49]. Therefore, poly(ethylene oxide) monomethyl ether was converted into the corresponding alcoholate anion and as such used for the initiation of the anionic ring-opening polymerization of octamethyltetracyclosiloxane with methacryloyloxypropyl-dimethylchlorosilane as terminating agent. After reduction of the ester end-group of the poly(ethylene oxide) block, the CROP of MeOx was carried out. These triblock copolymers aggregated to vesicles with asymmetric membranes in water. 
Scheme 2. Structural formula of telechelic pMeOx exhibiting antimicrobial activity (for details, see reference [44]).

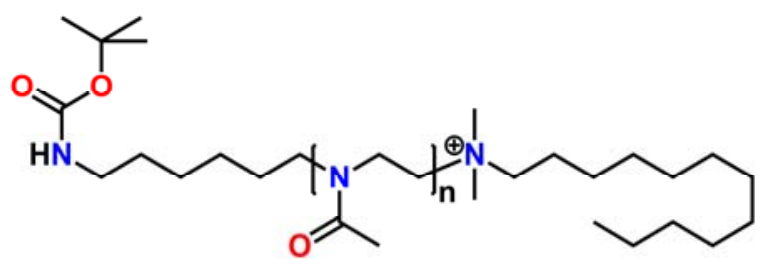

\subsubsection{Functionalization of Poly(2-oxazoline)s with End-Groups Containing Unsaturated $\mathrm{C}-\mathrm{C}$ Bonds}

Acetylene functionalized pMeOx, pEtOx, pPhOx, and $\mathbf{p}^{n}$ NonOx was prepared by Hoogenboom, Schubert et al. using propargyl toluene-4-sulfonate or 3-butynyl toluene-4-sulfonate as initiators [50]. These homo poly(2-oxazoline)s were used for click-reactions applied onto azide-terminated silicon substrates using microwave irradiation [51]. Vuluga et al. used p-chloromethyl-styrene as initiator to prepare pEtOx bearing a styryl end-group in bulk and solution [52]. Higher conversion and molar mass, nonetheless, were achieved using the solution technique. Volet and co-workers prepared telechelic and semitelechelic pMeOx by initiating the CROP of MeOx with monofunctional iodomethane or bisfunctional 1,3-diiodopropane and terminating it with sodium azide [53]. The Huisgen's cycloaddition with various alkynes yielded the corresponding triazole mono- or bis-terminated pMeOx. Poly(2-hexylthiophene)s, prepared by Stefan et al. using Grignard metathesis (GRIM) and (multi-step) termination with a triflate group, were used as macroinitiators for the CROP of EtOx [54]. Copolymers with 5, 15, and 30 mol \% pEtOx displayed nanofibrills with inverse density behavior, meaning that the lowest pEtOx content showed the highest density of nanofibrills. The same correlation behavior was shown in the field-effect mobilities. The lowest pEtOx content displayed the highest field-effect mobility, which was ascribed to the insulating properties of the pEtOx block. Barner-Kowollik, Hoogenboom, Schubert, and co-workers reported the synthesis of cyclopentadienyl end-functionalized pEtOx using sodium cyclopentadienide for the termination of the CROP [55], followed by Diels-Alder reactions between the terminal cyclopentadienyl group and $N$-substituted maleimides. Employing this one-pot synthetic strategy, they prepared pEtOx-blockpoly(ethylene glycol) block copolymers using maleimide terminated poly(ethylene glycol).

\subsubsection{Telechelic Poly(2-oxazoline)s for Biological Applications}

Jordan et al. prepared lipopolymers by using 2,3-di-O-octadecyl-1-trifluormethanesulfonyl-snglycerol as initiator for the CROP of (Py)EtOx, $\left(\mathbf{M e O}-\mathbf{E O}_{1}\right)^{n} \operatorname{PrOx}$, and $\left(\mathbf{M e O}-\mathbf{E O}_{3}\right)^{n}{ }^{n} \operatorname{PrOx}$ [56] (Scheme 3). The influence of the side-chain functionalities in terms of $2 \mathrm{D}$-gel formation was investigated. This novel type of lipopolymers did not exhibit rheological transitions, and Jordan et al. correspondingly claimed jammed surface micelles to be responsible for the gelation. Hoogenboom, Veronese et al. compared pEtOx conjugates with low molar mass biomolecules such as trypsin with their poly(ethylene glycol) analogues, in order to prove if pEtOx is a suitable alternative polymer for poly(ethylene glycol) [57]. They converted the $\mathrm{OH}$ end-group of semitelechelic pEtOx to a carboxylic acid end-group (reaction with potassium tert-butoxide, addition of tert-butyl bromoacetate, and deprotection of the acid), subsequent activation with $N$-hydroxysuccinimide, and the reaction with 
amino groups of proteins, yielding their covalent linkage by amide bonds. For both systems, the poly(ethylene glycol)- as well as the pEtOx-based one, similar results were obtained in terms of preserving the enzymatic activity, increasing the drug hydrodynamic volume and being protein-repellant.

Scheme 3. Structural formula of telechelic $\left(\mathbf{M e O}-\mathbf{E O}_{1}\right)^{n} \operatorname{PrOx}$ mimicking a lipopolymer structure (for details, see reference [56]).

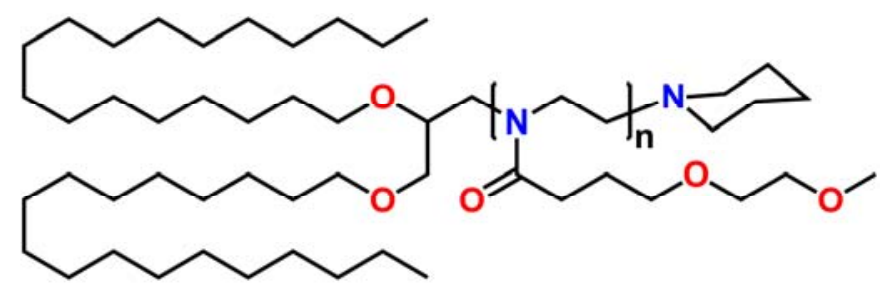

Kabanov et al. conjugated pMeOx and pMeOx-block-p ${ }^{n} \mathbf{B u O x}$ via amide bonds to horseradish peroxidase with different linkers [58]. The synthetic routine comprised end-capping of the poly(2-oxazoline)s with piperazine, reaction of its remaining secondary amine with either di-succinimidyl proprionate or dithiobis(succinimidyl proprionate), and the reaction of amine groups of horseradish peroxidase with the succinimide-activated carboxylic acid at the poly(2-oxazoline)s' end-groups. The conjugates correspondingly consisted of one to two polymer chains per enzyme and retained $70 \%-90 \%$ of the enzymatic activity. Notably, usage of dithiobis(succinimidyl proprionate) introduced a redox-labile disulfide linker into the conjugates. Tiller et al. reported on the conjugation of the proteins hen-egg white lysozyme, RNase A, and $\alpha$-chymotrypsin with pEtOx with the aim to render the enzymes organosoluble while retaining their activity [59]. The synthesis was accomplished by terminating the CROP of EtOx with ethylene diamine and subsequent reaction with pyromellitic acid dianhydride as bifunctional reagent for the coupling between the amino groups of the proteins and pEtOx. Tiller et al. reported a two-step termination strategy for the CROP of MeOx and EtOx, comprising the reaction with ethylene diamine and (subsequently) with pyromellitic acid dianhydride [59]. The semitelechelic poly(2-oxazoline) could be coupled to enzymes by the reaction of the second anhydride group of the former pyromellitic acid "di"anhydride, rendering the polymer enzyme conjugates organosoluble while the enzymes were retaining their activity. Ulijn et al. coupled alkyne-functionalized $\mathbf{p}^{i} \mathbf{P r O x}$ (obtained from the CROP of ${ }^{i} \mathbf{P r O x}$ using propargyl toluene-4-sulfonate as initiator) with azide functionalized Fmoc- $p Y$ (obtained from the reaction of Fmoc-pY with 11-azido-3,6,9-trioxaundecan-1-amine) by click-reactions using $\mathrm{CuSO}_{4}$ as catalyst and ascorbic acid as reducing agent [60]. These polymer "bio"conjugates displayed double responsiveness, on the one hand to temperature changes ( $\mathbf{p}^{i} \mathbf{P r O x}$ ) and on the other to phosphatases present (phosphate group-carrying Fmoc- $p Y$ ).

\subsection{Macroinitiators for the Synthesis of Linear (co-) Poly(2-oxazoline)s and Usage of} End-Functionalized Poly(2-oxazoline)s as Macroinitiators

\subsubsection{Poly(2-oxazoline)-co-poly( $\varepsilon$-caprolactone)s}

Hwang, Hsiue et al. used hydroxyl end-capped pEtOx (from the CROP of EtOx and end-capping with water) as macroinitiator to synthesize the amphiphilic diblock copolymer pEtOx-block-poly(\&- 
caprolactone) [61]. To yield a thermosensitive triblock copolymer of the composition pEtOx-blockpoly(E-caprolactone)-block-pEtOx, the diblock copolymers were coupled with hexamethylene diisocyanate. In aqueous solution, the triblock polymer formed a hydrogel, which was used as an intraocular carrier for the antibody bevacizumab. Tarvainen et al. prepared poly( $\varepsilon$-caprolactone)-blockpoly(2-oxazoline) copolymers via a linking reaction of carboxyl-terminated poly(e-caprolactone) prepolymers and OxOx [62]. Copolymers loaded with various compounds were evaluated regarding degradation and erosion in phosphate buffer solution; films of the copolymer showed faster degradation, while erosion could not be detected for both types of films (polymer and copolymer). Both types of microparticles released low molar mass drugs similarly fast, while fluorescein isothiocyanate was released faster from copolymer particles. OxOx-linked poly(e-caprolactone) copolymers were synthesized by Pulkkinen et al. [63]. The in-vitro erosion of films of these compounds was investigated, and lipase was found to be mainly responsible for that process, which can be controlled by the length of the poly( $\varepsilon$-caprolactone) blocks. In another study, Tarvainen et al. produced injection molded bars and films using the same type of polymers and copolymers [64]. The performance of the films and bars in simulated gastric fluid and simulated intestinal fluid was investigated. Simulated gastric fluid had no influence on the films or bars, while pancreatin-containing simulated intestinal fluid led to an elevated weight loss of the copolymer preparations. Jeong and co-workers synthesized pEtOx-block-poly(E-caprolactone) that formed micelles in aqueous environment [65]. During loading of these micelles with paclitaxel, a positive correlation of the loading efficacy and the content of the hydrophobic block was observed.

\subsubsection{Poly(2-oxazoline)-co-poly(lactid)s}

Liu and co-workers reported that coupling of a similar type of semitelechelic diblock copolymer, namely OH-endcapped pEtOx-block-poly(lactic acid), with adipoyl chloride as a coupling agent yielded pEtOx-block-poly(lactic acid)-block-pEtOx triblock copolymers that showed temperature-dependent sol-gel-sol transition in water and possessed low cytotoxicity and good biocompatibility [66]. Similarly, Tarvainen and co-workers used OxOx for the coupling of two equivalents of poly(lactic acid), yielding poly(ester amide) copolymers that showed faster hydrolytic degradation for drug release compared to poly(lactic acid) homopolymers [67] (Scheme 4). Hsiue et al. reported on doxorubicin-loaded pEtOx-block-poly(L-lactide) diblock copolymer-based micelles with a diameter of around $170 \mathrm{~nm}$ [68]. The copolymer was synthesized using OH-end-capped pEtOx as macroinitiator for the tin octanoate-catalyzed ring-opening polymerization of L-lactide. Doxorubicin was released $\mathrm{pH}$-dependent. Hsiue and Wang synthesized poly(L-lactic acid)-block-pEtOx-blockpoly(L-lactic acid) triblock copolymers according to a synthetic strategy involving a telechelic pEtOx macroinitiator that was obtained by initiating the CROP of EtOx with bisfunctional 1,4-dibromo-2butene [69] (Scheme 5). Subsequently, the OH-groups of the pEtOx macroinitiator initiated the tin octanoate-catalyzed polymerization of L-lactide. These $\mathrm{pH}$ - and thermo-sensitive triblock copolymers were claimed to be good candidates for drug delivery applications, since Hsiue and Wang expect anionic drugs to have an extended release time because of binding to the poly(L-lactic acid)-blockpEtOx-block-poly(L-lactic acid) micelles. Micelles of those triblock copolymers that were loaded 
with doxorubicin showed in in-vitro tests that inhibition of the compound release occurred at $\mathrm{pH} 7.4$, with a faster release under acidic conditions [70].

Scheme 4. Scheme of the reaction of a carboxylic acid-end-capped telechelic (bio)polyester with $\mathbf{O x O x}$.

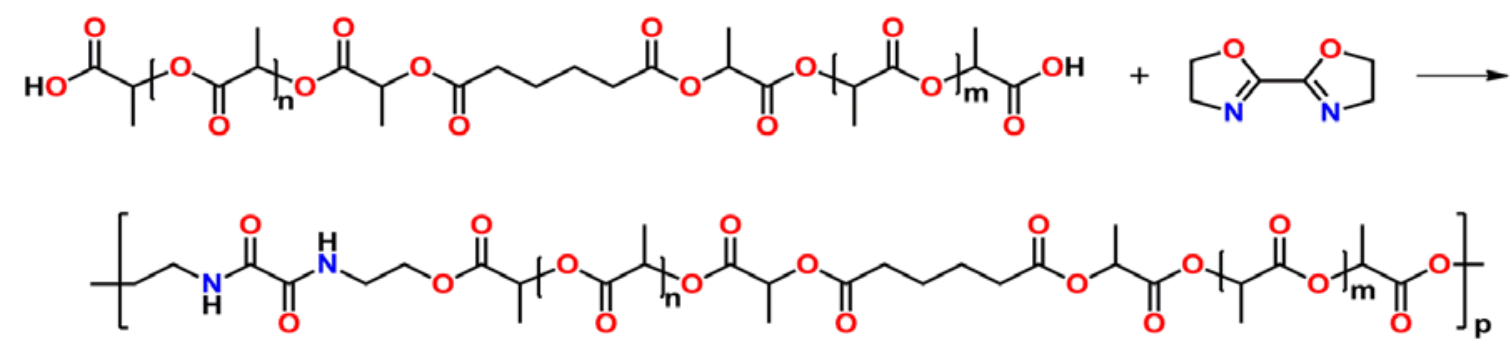

Scheme 5. Reaction scheme for the synthesis of poly(L-lactic acid)-block-pEtOx-blockpoly(L-lactic acid) triblock copolymers from telechelic pEtOx macroinitiators, derived from the CROP of EtOx initiated with bisfunctional 1,4-dibromo-2-butene (for details, see reference [69]).

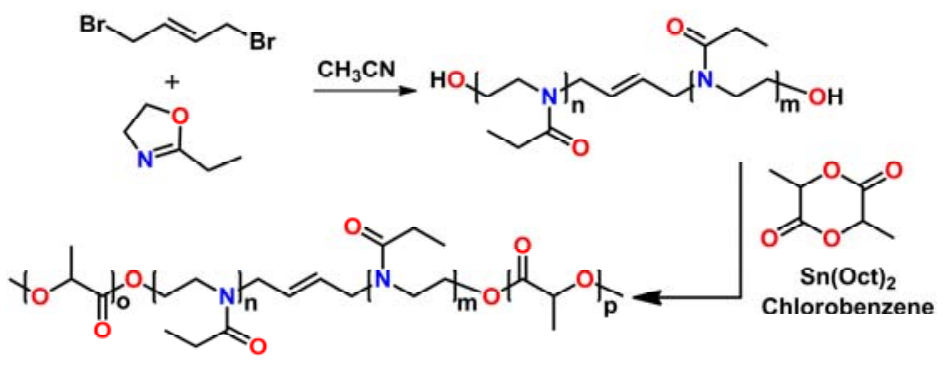

\subsubsection{Copoly(2-oxazoline)-co-poly(amino acid)s}

Using $N$-[2-(p-toluenesulfonyloxy)ethyl]phthalimide as initiator, Scholz et al. prepared semitelechelic linear $\mathbf{p M e O x}$ that could be reacted with hydrazine in order to yield $\omega$-amino- $\alpha$-hydroxy-pMeOx that carried a primary amino end-group [71]. This macroinitiator was used for the polymerization of $\mathrm{N}$-carboxyanhydride protected amino acids, yielding amphiphilic diblock copolymers of the composition pMeOx-block-pAA that self-assembled in aqueous solutions.

Kuo and co-workers reported the Mitsunobu reaction of OH-end-capped pEtOx, yielding phthalimide-end-capped pEtOx [72], that subsequently could be reacted with hydrazine monohydrate for the preparation of primary amine-end-capped pEtOx. Using this macroinitiator, $N$-carboxyanhydride derivatives of amino acids could be polymerized, yielding amphiphilic diblock copolymers such as pEtOx-block-poly( $\gamma$-benzyl-L-glutamate) (Scheme 6). Responsive to the solvent, the diblock copolymers self-assembled into various aggregates. Another way of preparing amino-end-capped $\mathbf{p}^{i} \mathbf{P r O x}$ was reported by Schlaad et al. [73], namely the usage of 4-( $N$-Boc-amino)-piperidine as terminating agent and subsequent cleavage of the protection group by trifluoroacetic acid. The thermoresponsive diblock copolymer $\mathbf{p}^{i}$ PrOx-block-poly(L-glutamate) was obtained using amino-end-capped $\mathbf{p}^{i} \mathbf{P r O x}$ as macroinitiator for the polymerization of the $N$-carboxyanhydride derivative of $\gamma$-benzyl L-glutamate and subsequent alkaline cleavage of the protection group. 
Scheme 6. Synthesis of the diblock copolymer p $^{i}$ PrOx-block-poly(L-glutamate) involving amine-functionalized $\mathbf{p}^{i} \mathbf{P r O x}$ macroinitiators and $N$-carboxyanhydride protected L-glutamic acid (for details, see reference [73]).
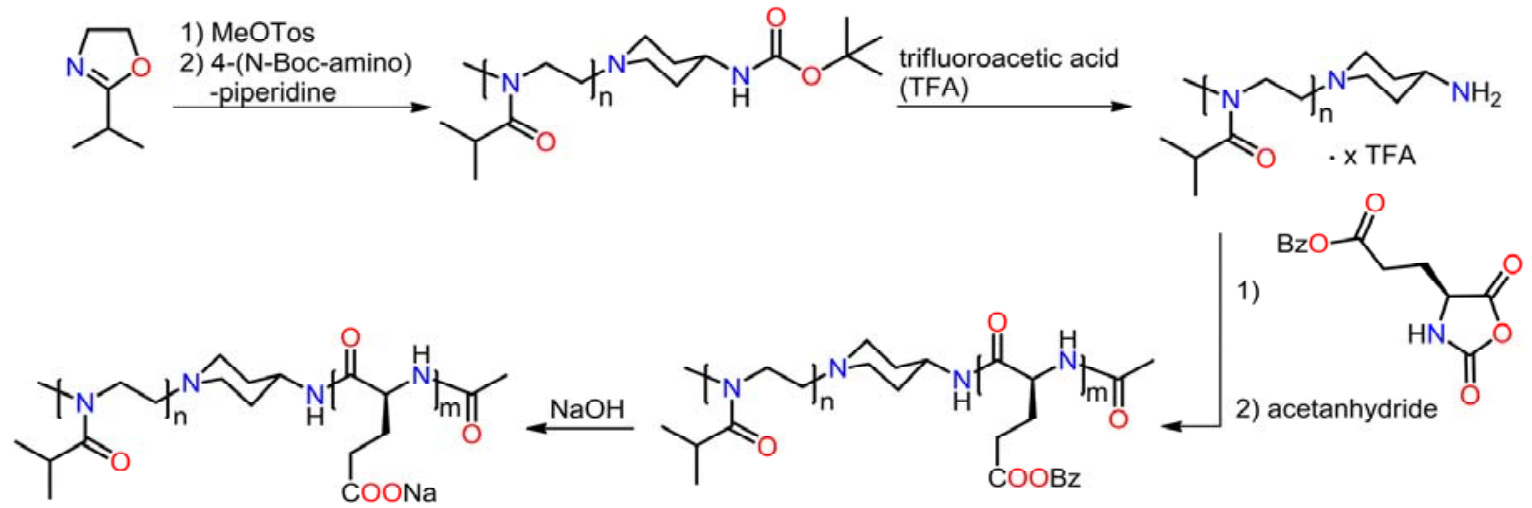

Winnik et al. used $\mathrm{N}$-[2-(p-toluenesulfonyloxy)-ethyl]phthalimide as initiator for the CROP of EtOx and subsequent reaction with hydrazine for the synthesis of primary amine-end-capped pEtOx [74]. The polymeranalogous reaction with polymeric hyaluronic acid (HA) yielded a diblock copolymer of the composition pEtOx-block-HA as potential candidates for drug delivery. Hsiue and co-workers used amino-pEtOx (obtained from quenching the CROP of EtOx with ammonia) as macroinitiator for the synthesis of the block copolymer pEtOx-block-poly(aspartic acid) [75]; aspartic acid was used as $\mathrm{N}$-carboxyanhydride protected amino acid during the polymerization. Amphotericin B could be encapsulated into the polyion complex micelles while a clear core-shell structure was formed.

\subsubsection{Other Copolymers Containing Blocks of Copoly(2-oxazoline)s}

Poly(3-hydroxyalkanoate)s pHAs bearing an alkyne end-group (from the reaction of bacterially-produced pHA with propargyl alcohol) were reacted in a Huisgen cycloaddition click-reaction with azido-semitelechelic pMeOx to yield pHA-block diblock copolymers soluble in water by Langlois and co-workers [76]. Telechelic linear poly(arylene ether sulfone)s (pSFs) that were functionalized by tosylate groups were used as bivalent macroinitiators for the CROP of EtOx yielding amphiphilic pEtOx-block-pSF-block-pEtOx triblock copolymers [77]. Subsequently, the triblock copolymers were partially hydrolyzed to yield polyelectrolytes of the composition (pEtOx-co-pEI)block-pSF-block-(pEtOx-co-pEI); due to increased polarity, water uptake at room temperature increased. Theogarajan et al. obtained ABA triblock copolymers employing the azide-alkyne cycloaddition reactions catalyzed via copper nanoparticles [78]. The amphiphilic triblock polymer based on an alkyne-terminated pMeOx A-block and a telechelic azide-terminated polysiloxane B-block displayed self-aggregation into vesicles. Halacheva and co-workers synthesized comblike linear pEI/linear pEtOx graft copolymers by terminating the CROP of EtOx with linear pEI. These copolymers were shown to yield comblike linear pEI/linear pEI homopolymers upon hydrolysis [79]. The pEI-comb-pEtOx particles featured bimodal distributions; polymers with low grafting densities formed elongated aggregates, whereas high grafting densities induced the formation of spherical core-shell structures. Fradet and co-workers coupled carboxyl-terminated polyamide-12 or carboxyl-terminated 
poly(butane-1,4-diyl adipate) with several aromatic bis(2-oxazoline)s, namely 1,3-PhOxOx, 1,4-PhOxOx, and 2,6-PyOxOx, yielding AB-type condensation copolymers [80]. Notably, no side-reactions were detected; 2,6-PyOxOx exhibited the highest reactivity.

\subsubsection{Covalent Attachment to/Supramolecular Assembly with Cyclodextrins and other Cavitands}

Supramolecular (thermoresponsive) diblock copolymers composed of two water-soluble polymers were obtained by Voit et al. from $\beta$-cyclodextrin-functionalized poly $(N$-isopropylacrylamide $)$ and adamantine-end-capped pMeOx (Scheme 7) [81]. The telechelic pMeOx was synthesized using adamantan-1-ylmethyl 4-(bromomethyl)-benzoate as initiator and 2-(iso-propylamino)ethanol as terminating agent. The diblock copolymers formed by self-assembly in aqueous solution. The double hydrophilic block assembly showed thermoresponsive behavior with heat-induced hydrophilic-hydrophobic switching. Azido-semitelechelic pEtOx was coupled to a (former octaol) alkyne-functionalized "deep-cavity cavitand" using azide-alkyne click-coupling by Grayson et al. [82]. The resulting macromolecular cavitand exhibited tuneable solubility, while its ability to encapsulate guest molecules was maintained.

Scheme 7. Diblock copolymers formed by the supramolecular assembly of $\beta$-cyclodextrinfunctionalized poly( $N$-isopropylacrylamide) and adamantine-end-capped $\mathbf{p M e O x}$ (for details, see reference [81]).

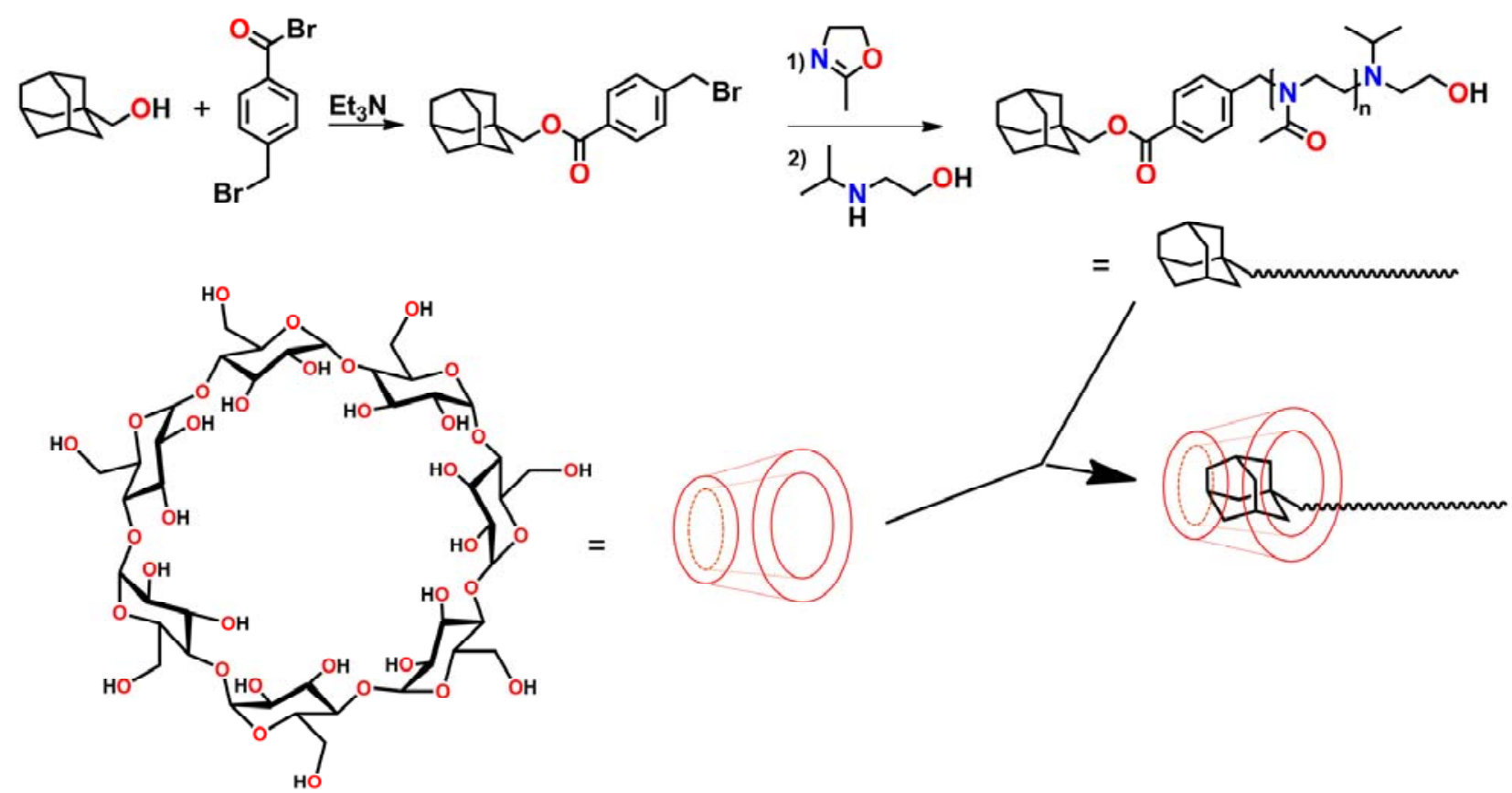

\subsubsection{Combination of CROP and Controlled-Radical Polymerizations}

An alkoxyamine-functionalized pMeOx macroinitiator was synthesized via the CROP of MeOx using $N$-\{1-[4-(chloromethyl)phenyl]ethoxy $\}$ - $N$-tert-butyl-2-methyl-1-phenylpropane-1-amine as initiator by Ibrahim and Voit [83]. This macroinitiator could be successfully employed in the subsequent nitroxide-mediated polymerization of styrene, yielding pEtOx-block-polystyrenes with well-defined molar mass. Schubert and co-workers described the employment of $\alpha$-bromoisobutyrylbromide as initiator 
for the CROP of EtOx, yielding pEtOx macroinitiators for the synthesis of pEtOx-block-polystyrene diblock copolymers from subsequent copper-mediated ATR polymerizations [84]. The amphiphilic diblock copolymer formed micelles in solution. Becer, Schubert and co-workers managed to combine both, CROP and RAFT techniques, for the synthesis of various diblock copolymers of the composition poly(2-oxazoline)-block-poly(vinylic monomer)s [85,86]; the monomers employed were MeOx, EtOx and ${ }^{n}$ NonOx on the one hand, and styrene, methyl methacrylate, tert-butyl acrylate, acrylic acid, $N, N$-dimethyl acrylamide, and $N, N$-dimethylaminoethylacrylate on the other. The diblock copolymer synthesis was realized as two-step routine with intermediate end-capping of the pEtOx-2-ethyl-2oxazolinium cation with 2-(butylthiocarbonothioylthio)propanoic acid. Usage of the end-capping reagents 2,2,5-trimethyl-3-[1-(4'-chloromethyl)-phenylethoxy)-4-phenyl-3-azahexane, its corresponding iodine derivative, and 2,2,5-trimethyl-3-(1'-p-aminomethylphenylethoxy)-4-phenyl-3-azahexane after the CROP of MeOx was reported by Marx, Volet and Amiel [87]. Semitelechelic pMeOx was subsequently used as macroinitiator for the RAFT polymerization of styrene. Vuluga et al. used methylvinyldichlorosilane as bifunctional initiator for the CROP of EtOx, yielding pEtOx bearing a center-vinyl group [88]. This macromer was used in free-radical dispersion copolymerizations with styrene, yielding monodisperse microspheres. The CROP of EtOx using $\alpha$-bromoisobutyryl bromide and 2-bromopropionyl bromide, respectively, as initiators and subsequent use of telechelic pEtOx as macroinitiator for the single electron transfer living radical polymerization (SET-LRP) of methyl acrylate, ethylene glycol methyl ether acrylate and 2-(dimethylamino)ethyl methacrylate was described by Becer and coworkers [89]. Due to pronouncedly low initiator efficiency, the block copolymers exhibited high molar masses.

\subsection{Grafting of Brush- and Comblike Structures}

\subsubsection{Grafting from Pending 2-oxazoline Units}

A substituted 2-aminoalcohol, namely 2-amino-2-ethyl-1,3-propanediol, was reacted with the nitrile groups of poly(acrylonitrile)s by Schmidt-Naake et al., yielding 2-oxazoline moieties attached to the polyolefin backbone [90]. The modified poly(acrylonitrile) particle surfaces were subsequently reacted with methyl triflate in order to graft pEtOx on those surfaces. Schmidt-Naake and Cabrera functionalized the nitrile groups of polystyrene-co-poly(acrylonitrile) and poly(butadiene)-copoly(acrylonitrile) to oxazoline groups by the reaction with 1,3-aminoethylpropanediol [91]. The as-functionalized copolymers were reacted with methyl triflate and acted as macroinitiators for the CROP grafting of EtOx and PhOx. Jordan and co-workers used the living anionic ${ }^{n}$ BuLi-initiated polymerization of ${ }^{i} \mathbf{P r}^{=} \mathbf{O} \mathbf{x}$ to prepare linear polyolefin chains with pending oxazoline moieties (Scheme 8) [92]. After the reaction with methyl triflate, these polyelectrolytes were used as macroinitiators for the CROP of ${ }^{i} \mathbf{P r O x}$ or ${ }^{n} \mathbf{P r O x}$, yielding thermoresponsive molecular brushes with defined cloud points. Kinetic investigations of the grafting step showed that there was no correlation between the polymerization rate and the number of initiator functions per initiator molecule. Jordan and co-workers showed that the olefinic side-chains of ${ }^{i}{ }^{1}{ }^{=} \mathbf{O x}$ can be polymerized by either the free-radical or anionic polymerization technique, yielding polyolefins with pending un-reacted 2-oxazoline moieties [93]. Hence, this 2-oxazoline monomer enables the synthesis of brush-shaped 
polymers in a straight-forward manner due to its two orthogonal reaction sites. Goh and co-workers modified poly(styrene-co-acrylonitrile) with 2-aminoethanol in order to convert the cyano groups (partly) into 2-oxazoline groups [94]. Subsequently, acid-functionalized multiwalled carbon nanotubes were grafted onto the polymer by the reaction of the 2-oxazolines with the carboxylic acid groups. Jerca and co-workers performed the free-radical copolymerization of ${ }^{i} \mathbf{P r}{ }^{=} \mathbf{O x}$ and methyl methacrylate; the copolymer's pending 2-oxazoline groups were subsequently reacted with carboxylic acid-functionalized dyes, yielding polymers with tuneable fluorescent properties [95]. The homo- and random copolymerization of ${ }^{i} \mathbf{P r}^{=} \mathbf{O x}$ (and methyl methacrylate or $N$-iso-propylacrylamide) via RAFT polymerization was investigated by Becer and co-workers [96]. The copolymers exhibited thermoresponsive properties in aqueous solution and phosphate buffered saline at elevated temperatures. The pending 2-oxazoline moieties could be reacted in ring-opening fashion with thiols and carboxylic acids such as thiophenol, benzoic acid and 4-azidobenzoic acid.

\subsubsection{Grafting from Surfaces}

The synthesis of tailored poly(2-oxazoline) polymer brushes on glassy carbon was described by Jordan et al. [97], describing the end-functionalization of the grafted-from pEtOx chains by sterically demanding molecules such as rhodamine B isothiocyanate. Pompe, Jordan and co-workers successfully applied the synthetic routine to 3-aminopropyltrimethoxysilane-modified substrates, onto which ${ }^{i} \mathbf{P r}^{=} \mathbf{O}$ was polymerized via self-initiated photografting and photopolymerization involving the double bonds of ${ }^{i} \mathbf{P r}^{=} \mathbf{O x}$ exclusively, yielding polymer chains covalently attached to modified silicon substrates (Scheme 8) [98]. Subsequently, after initiation by methyl triflate, the CROP of different 2-oxazolines was performed. Those poly(2-oxazoline)s were grafted from the surface-bound macroinitiators in order to build bottle-brush architectures. The chemical composition and architecture of these types of brushes was correlated with the adsorption and adhesion of proteins. Garrido, Jordan et al. prepared structured poly(2-oxazoline) bottle-brush brushes also on nanocrystalline diamond (NCD) surfaces, where covalent attachment during photografting was observed to the oxidized NCD areas selectively [99]. After the reaction with methyl triflate, the thus-generated macroinitiators started by the CROP of EtOx or CarbOx, bottle-brush brushes containing hole-conducting moieties such as carbazole units were described as potential amperometric biosensing systems. Kim, Lim, and co-workers grafted $\mathbf{M e O x}$ from $\mathrm{SiO}_{2} / \mathrm{SiOH}-$ based tips after its precedent surface reaction with a bromoalkyl-substituted trichlorosilane (Figure 1) [100]. The tip surface had pore sizes from 30-100 $\mathrm{nm}$ and correspondingly could absorb large-molecular-weight (bio-)molecules, capable of fast protein nanostructure generation during dip-pen nanolithography. The suspension copolymerization of methyl methacrylate, 2-bromoethyl methacrylate, and ethylene glycol dimethacrylate yielded crosslinked microspheres, the surfaces of which bore bromoalkyl groups [101]. MeOx was grafted onto the microspheres' surfaces, covalently binding the pMeOx chains. 
Scheme 8. Performance of the living anionic ${ }^{n} \mathrm{BuLi}$-initiated polymerization of ${ }^{i} \mathbf{P r}^{=} \mathbf{O x}$ and subsequent graft polymerization of 2-oxazolines from the pending oxazoline moieties (top; for details, see reference [92]). Grafting of poly(2-oxazoline)s from dedicatedly equipped silicon surfaces (for details, see reference [98]).

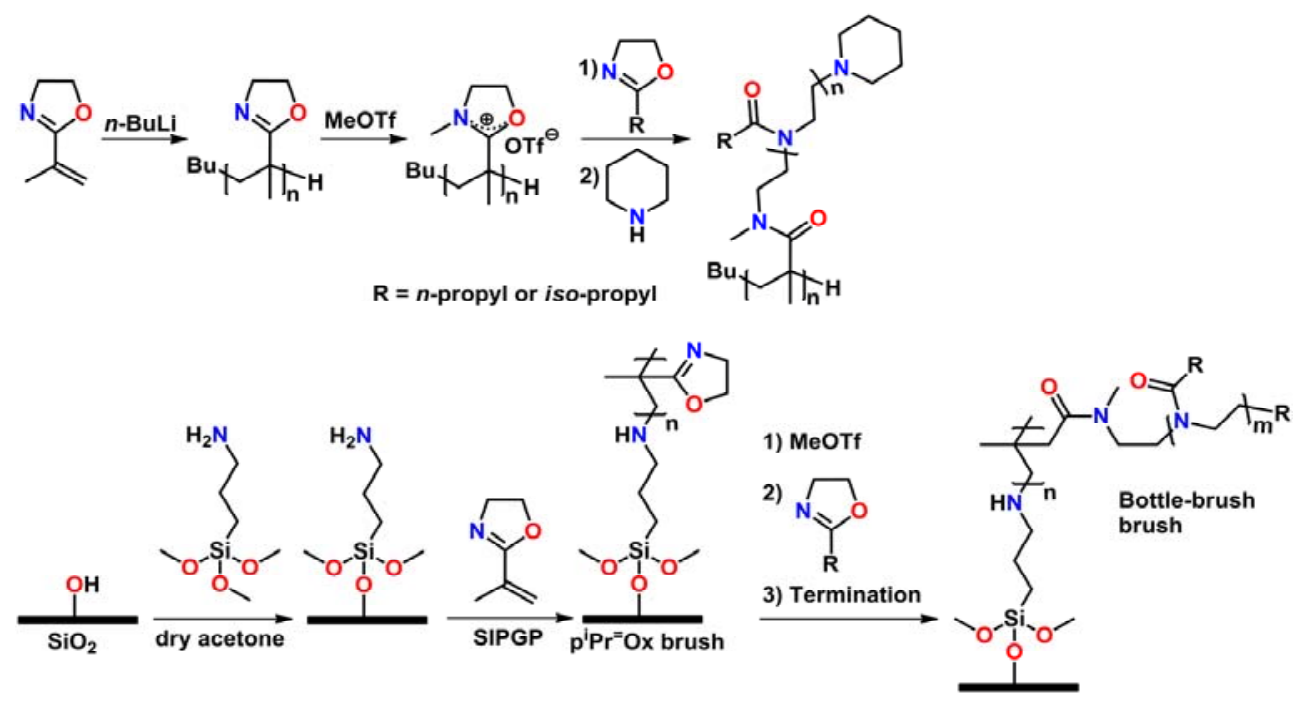

Figure 1. SEM images of a $\mathrm{SiO}_{2} / \mathrm{SiOH}$-based tip before (left) and after (right) grafting of pMeOx on the surface (for details, see reference [100]).
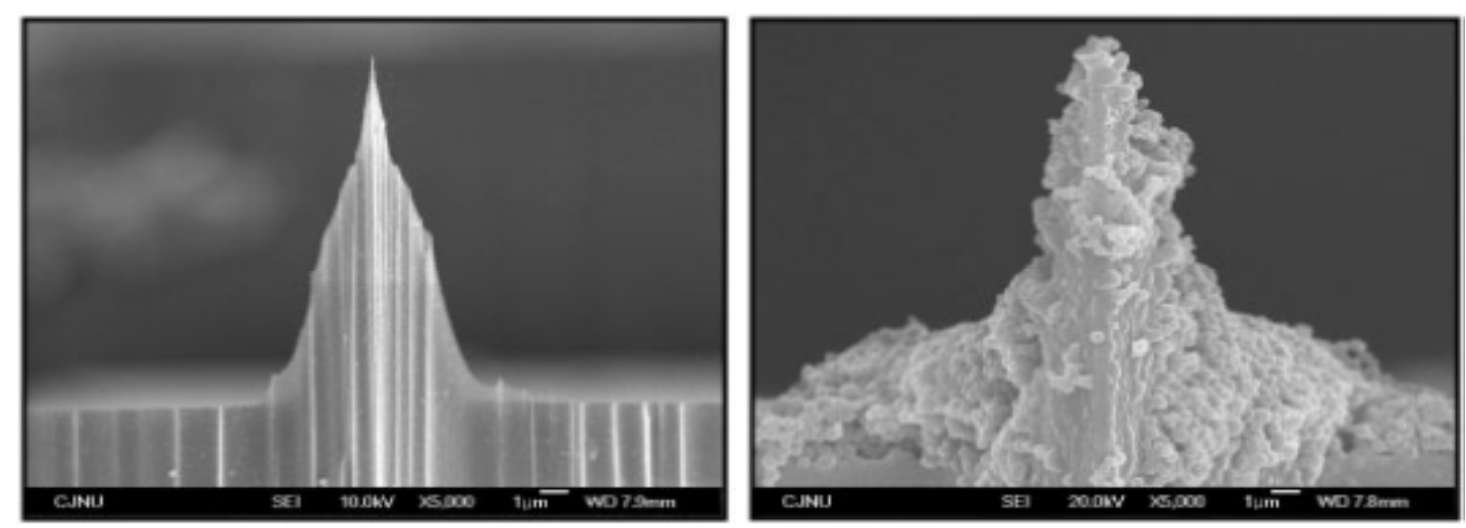

\subsubsection{Grafting from Heteropolymer Side-Chains}

Yuan, Schlaad and co-workers reported that commercially available 1,2-poly(butadiene) could be quantitatively brominated and used as macroinitiator for the CROP of EtOx, yielding polymer brushes composed of a polyolefinic backbone with grafted pEtOx side-chains [102]. Voit et al. prepared thermo-sensitive graft copolymers based on poly( $N$-isopropyl-acrylamide)-co-poly(chloromethyl styrene) as the backbone, onto which MeOx and EtOx were grafted as chains of random or block copoly(2-oxazoline)s [103]. The CROP of 2-oxazolines was initiated by the benzyl chloride groups of the backbone copolymer. Phase transition could be altered not only via side-chain composition or structure, but also by hydrolysis of the methyl ester groups and subsequent carboxylic acid functionalization. Tailoring of the polymer properties was also reported to be feasible by the parameters macroinitiator and hydrophilic/hydrophobic segments [104]. An increasing quantity of chloromethylstyrene in the backbone lowered the LCST, while an increasing content of $\mathbf{p M e O x}$ or 
pEtOx (relative to the backbone) raised the transition temperature. Voit et al. employed the random copolymer composed of $\mathrm{N}$-isopropylacrylamide and chloromethylstyrene, which they used as macroinitiator for the graft polymerization of (ester) ${ }^{n} \operatorname{PrOx}$ (the chloromethylstyrene units acted as initiators after dissociation of the chloride anions) [105]. In solution, core-shell nanogels with micellar shape and reproducible thermo- and $\mathrm{pH}$-dependent swelling behavior formed, which could be stabilized by electron-beam crosslinking. Grafting of pEtOx from the copolymer composed of $N$-isopropylacrylamide and chloromethylstyrene yielded thermoresponsive nanogels (in solution) that responded with volume changes to temperature changes [106].

\subsubsection{Grafting-onto Polymers}

Monge et al. functionalised polymer brushes by grafting alkyne-end-capped $\mathbf{p M e O x}$ chains onto poly $(\alpha$-azido- $\varepsilon$-caprolactone- $c o-\varepsilon$-caprolactone) [107]. The Huisgen cycloaddition click-reaction was mediated by $\mathrm{CuSO}_{4} \cdot 5 \mathrm{H}_{2} \mathrm{O}$ (0.1 equiv) and sodium ascorbate; the corresponding pMeOx chains were prepared from the CROP of MeOx using propargyl tosylate as initiator. The graft copolymers formed micelles in water and were considered as potential drug carriers. Preceded by correlating the LCST with the poly(methacrylic acid) content of copolymers prepared by grafting pEtOx onto linear poly(methacrylic acid) [108], Hoogenboom, Schubert and co-workers described a convenient procedure to synthesize graft copolymers composed of poly(methacrylic acid) as backbone with side-chains consisting of pEtOx. Two different methods were used [109]: (i) the macroinitiator method (end-capping of pEtOx-2-ethyl-2-oxazolinium with methacrylic acid, recovery, and subsequent RAFT copolymerization with methacrylic acid) as well as (ii) the grafting-onto method (RAFT polymerization of methacrylic acid and grafting of $\mathrm{OH}$-functionalized pEtOx by reaction with carboxylic acids). Hence, both strategies combined CRO and RAFT polymerizations, but differed in the synthetic orders. Konradi et al. also prepared several poly(L-lysine)-graft-pMeOx comb copolymers with different grafting densities by reacting hydroxyl-terminated $\mathbf{p M e O x}$ with bisfunctional glutaric anhydride and subsequent grafting onto poly(L-lysine) by the unreacted carboxylic group of glutaric anhydride [110]. Linear poly(methacrylic acid) was reacted with $\mathrm{OH}$-end-capped pEtOx to form graft copolymers (linkage by ester bonds) [111]. Covalently attached pEtOx enhanced intramolecular complexation at low ionization levels and led to elevated poly(methacrylic acid) expansion at high ionization. Zheng and Li prepared poly(ethylene imine)graft-poly(ethylene oxide) copolymers from the Michael addition polymerization of acryl-terminated poly(ethylene oxide) methyl ether and poly(ethylene imine) [112]. The poly(ethylene oxide) side-chains of the semicrystalline copolymers showed inclusion complexation with $\alpha$-cyclodextrin.

\subsubsection{Grafting onto Surfaces}

Textor and co-workers prepared poly(L-lysine)-graft-pMeOx copolymers by attaching carboxyl-terminated pMeOx copolymers to poly(L-lysine) polymers using EDC/sulfo-NHS-assisted coupling [113]. This graft copolymer was used to form surface platforms on $\mathrm{Nb}_{2} \mathrm{O}_{5}$ [114] to investigate the adhesion mechanism of Escherichia coli and in particular the influence of fimbriae expression. Expressing type 1 fimbriae bacteria adhered due to van der Waals forces and hydrophobic interactions. Only films with a grafting density of $\mathbf{p M e O x}$ of 0.33 (highest density with a surface potential close to 
zero) were able to inhibit the adhesion of bacteria. Stamm, Agrawal and co-workers synthesized p(ester) ${ }^{n}$ PrOx-block-p ${ }^{i}$ PrOX block copolymers that were grafted (after alkaline deprotection of the carboxylic acids of the first block) onto poly(glycidyl methacrylate)-coated silicon wafers [115]. The chemical reaction between the carboxylic acid groups and the epoxy units of the poly(glycidyl methacrylate) layer provided chemical attachment of the poly(2-oxazoline)s on the silicon wafers in brush-like conformation. These brushes could be used to stabilize inorganic nanoparticles on their surfaces. Jordan, Tanaka and co-workers synthesized pMeOx and pEtOx with trimethoxysilane groups on their chain-ends and subsequently grafted them onto silicon/silicon dioxide substrates [116]. Characterization of these films was carried out by ellipsometry. Carboxyl-functionalized block copoly(2-oxazoline)s were synthesized by Agrawal, Stamm and co-workers after alkaline cleavage of the carboxylic acid protection groups of $\mathbf{p}\left({ }^{n} \mathbf{P r}\right.$-ester $) \mathbf{O x}_{4}-\boldsymbol{b l o c k}-\mathbf{p}^{i} \mathbf{P r O} \mathbf{x}_{100}$ [115]. These copoly(2-oxazoline)s were subsequently grafted onto poly(glycidyl methacrylate) spincoated on a silicon substrate. Covalent attachment was verified by contact-angle measurements; inorganic nanoparticles were stabilized on these macroscopic surfaces.

\subsection{Star-Shaped Polymers Obtained from Using Macroinitiators}

\subsubsection{Multifunctional Tosylate and Triflate Initiators}

Jordan et al. investigated the polymerization rates of the CROP of MeOx initiated by pluritriflates, namely by methyl triflate as well as its higher homologues bis-, tris-, and tetrakistriflate [117]. Unlike in other multivalent initiators, the functional groups of this type of multifunctional initiator proved to be of comparable reactivity, and the polymerization rate correlated linearly with the number of functional groups. Hence, this class of initiators enables the rational design of star-shaped poly(2-oxazoline)s. The preparation of well-defined polymer architectures using CROP of 2-oxazolines was the aim of Hoogenboom, Schubert et al. (Scheme 9) [118]. They synthesized various multifunctional tosylates of dendritic shape by esterification of alcohols with tosyl chloride. The alcohols investigated in their study comprised 1,4-butanediol, pentaerythritol, dipentaerythritol, and 5,10,15,20-tetrakis(4-hydroxyphenyl)porphyrin. In the group of tetra- or hexavalent initiators, the best results were achieved using the porphyrin-cored tetra-tosylate initiator, whereas tetra- and hexa-tosylates lead to slow initiation and ill-defined polymers. Dworak and co-workers used dipentaerythrityl hexakis (4-nitrobenzenesulfonate) and tosylated hyperbranched polymers of glycidol (the latter with 13 initiating groups) as initiators for the CROP of EtOx [119]. The monomer consumption in the range 0-70\% followed first-order kinetics [initiator: dipentaerythrityl hexakis (4-nitrobenzenesulfonate)]. The prepared star-shaped polymers were spherical and thermosensitive.

\subsubsection{Star-Shaped Poly(2-oxazoline) Structures Comprising Cyclodextrins}

Adeli and co-workers reported on the synthesis and characterization of multiarm star copolymers consisting of a $\beta$-cyclodextrin core with pEtOx arms [120]. $\beta$-Cyclodextrin was reacted with iodine and triphenyl phosphine (substitution of the primary $\mathrm{OH}$ groups by iodine) in order to yield a heptavalent cyclodextrin macroinitiator that initiated the CROP of EtOx. End-capping with aniline or diethanolamine yielded 1st generation dendrimers that, using diethanolamine as capping agent, could 
be used for the synthesis of higher generation dendrimers. The polymers with aniline or diethanolamine end-groups formed supramolecular dendritic aggregates in aqueous solutions. Host-guest interactions were investigated and proved the ability to incorporate small molecules on the head of the arms or form inclusion complexes. In another study, star copolymers with a poly(ethylene glycol) core and pEtOx arms bearing hydroxyl or aromatic end-groups were prepared [121]. Telechelic $\mathrm{OH}$-end-capped poly(ethylene glycol) was reacted with cyanuric chloride and subsequently used as a tetravalent initiator. The CROP of EtOx was terminated with diethanolamine or $O$-methoxyaniline. Adeli et al. used a tosylated $\beta$-cyclodextrin, which bore two types of functional groups (hydroxyl and tosylate groups), to prepare amphiphilic block copolymers with star-shape geometry. First, the hydroxyl groups served as initiator for the ROP of lactide, and second, the tosyl groups served as initiator for CROP of EtOx [122]. Model compounds such as Congo red could be (reversibly) loaded into the copolymers.

Scheme 9. Structural formulae of a hexatosylate initiator and the corresponding star-shaped pEtOx (for details, see reference [118]).
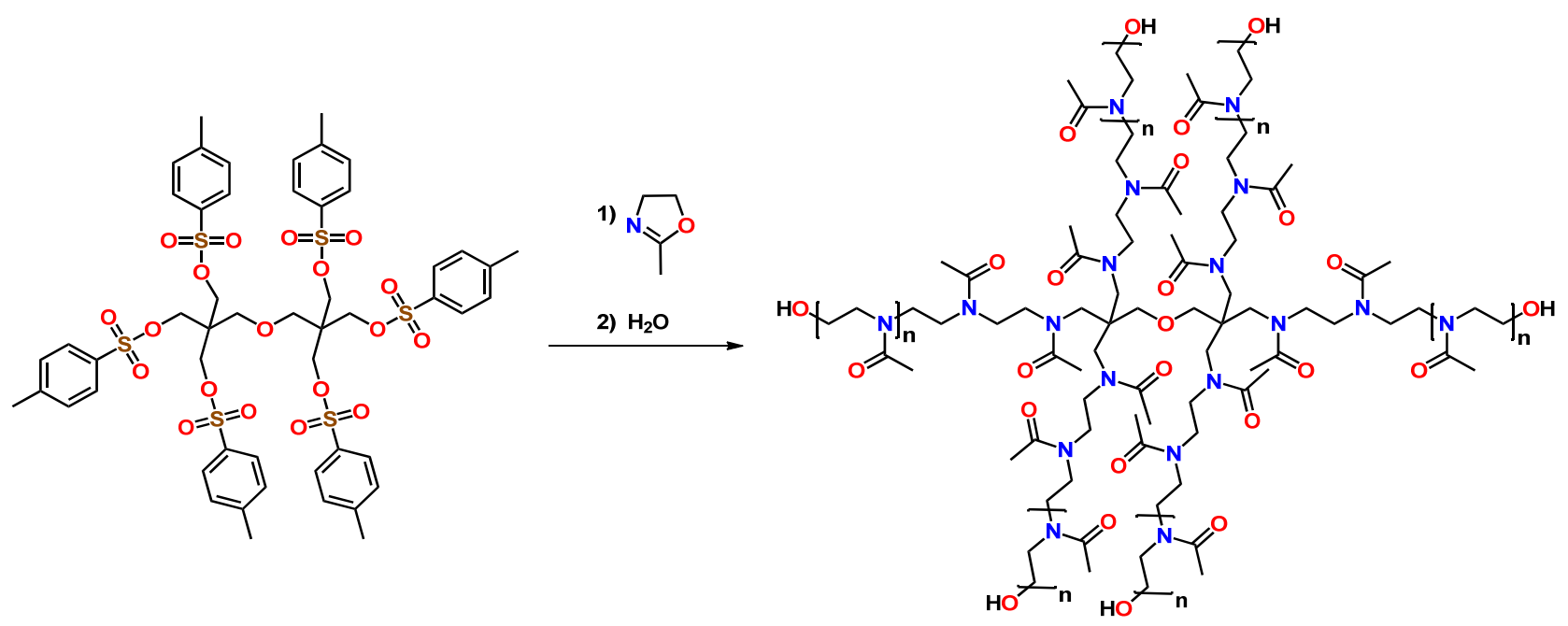

\subsubsection{Further Multifunctional Initiators}

Schubert and Heller reported that terpyridine-based supramolecular initiators of the composition bis(5,5"-bis(bromomethyl)-2,2':6',2"'-terpyridine and bis-4'-(4-bromomethylphenyl)-2,2':6',2"-terpyridine can be applied as four- and bisvalent initiators for the CROP of EtOx [123]. Fraser et al. synthesized a Ruthenium(II) tris(bipyridine)-centered pEI for gene delivery by using $\left[\mathrm{Ru}\left\{\mathrm{bpy}\left(\mathrm{CH}_{2} \mathrm{Cl}\right)_{2}\right\}_{3}\right]^{2+}$ as $3 \times 2=$ hexafunctional initiator for the CROP of EtOx (catalyst activation by heterolytic dissocation of the chloride anions) and subsequently hydrolyzing the pEtOx [124]. Schubert, Hoogenboom et al. reported the reaction of pEtOx-2-ethyl-2-oxazolinium cations with 1 st and 2 nd generation propylene imine dendrimers (four and eight primary amines, respectively), yielding star-shaped pEtOx (Scheme 10) [125]. The reaction rate of end-capping decreased with increasing pEtOx-2-ethyl-2oxazolinium chain lengths and increasing dendrimer generation. In addition to tadpole-shaped pMeOx (see above), Ogoshi and Nakamoto et al. also reported six-arm star-shaped $\mathbf{p M e O x}$ with a triphenylene core [47], which was synthesized using 2,3,6,7,10,11-hexa(6-bromohexyloxy)triphenylene as initiator. In aqueous solution, the star-shaped $\mathbf{p M e O x}$ formed straight columnar stacks. Eight-arm dendrimers of 
pMeOx were prepared using a macroinitiator derived from the reaction of the phenolic groups of calix[4]rescorcinarene with 3-bromo-propanoic acid chloride [126]. Notably, in order to prepare multifunctional hyperbranched thioxanthone photoinitiators, Yin, Jiang and Wen modified hyperbranched pEI with 2-(2,3-epoxypropyloxy) thioxanthone and poly(ethylene glycol) monoethyl ether glycidyl ether [127]. These photoinitiators were soluble in water and showed high potential for preparing coatings, inks and photo-curing hydrogels.

Scheme 10. Reaction scheme for the usage of 2 nd generation propylene imine dendrimers as terminating agents during the CROP of EtOx (for details, see reference [125]).

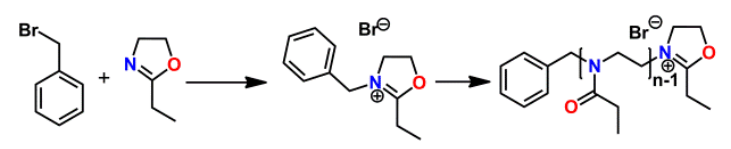

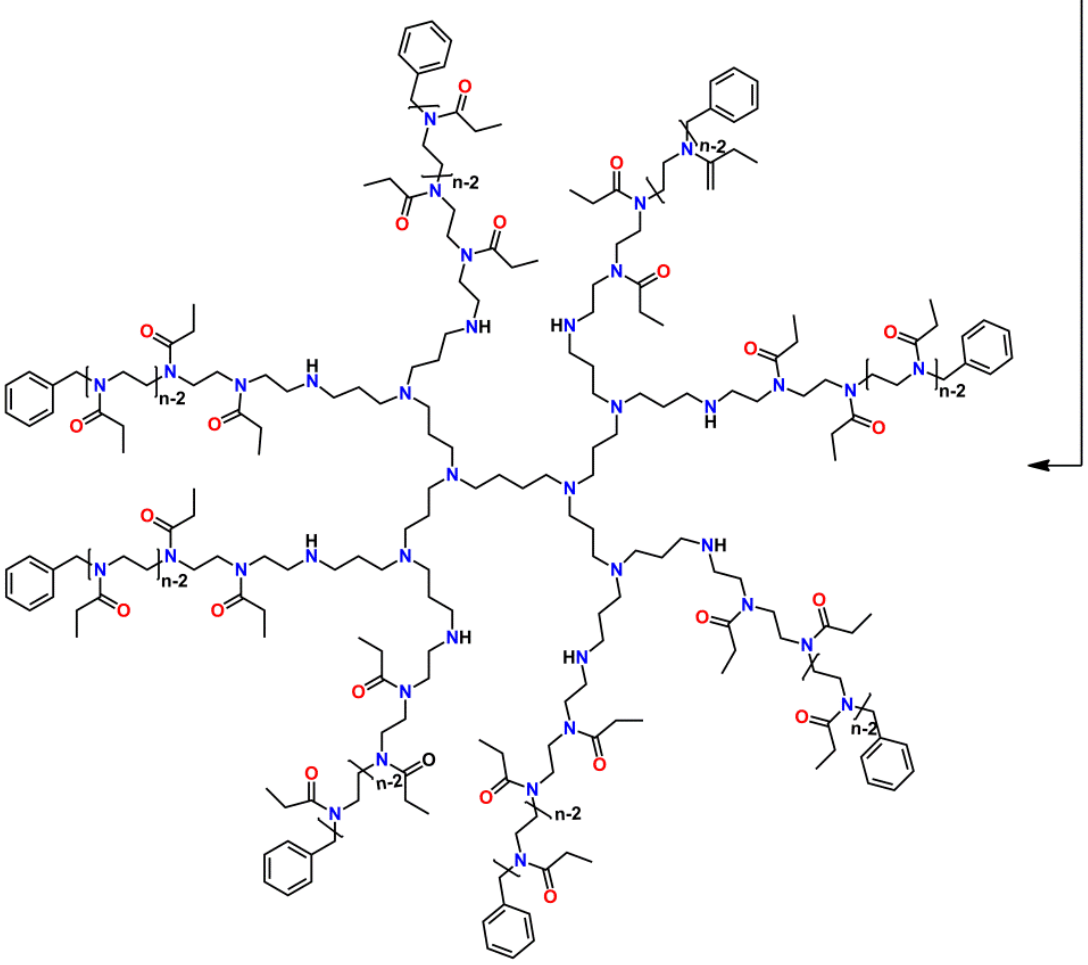

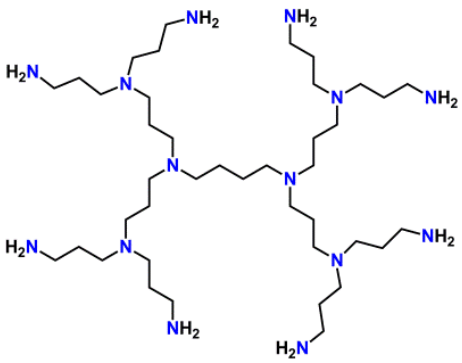

\subsubsection{Hyperstar Polymers and Second Generation Star Geometries}

Voit et al. prepared dendrimers starting from benzene-1,3,5-triol that was reacted with $(\mathbf{O B n})_{2} \mathbf{P h O x}$, yielding the first generation dendrimer [128]. Removal of the benzyl protecting groups by hydrogenation $(\mathrm{Pd} / \mathrm{C})$ enabled the recovery of $\mathrm{OH}$ functionalities, which were subsequently reacted (again) with (OBn) $2 \mathbf{P h O x}$ in order to yield aliphatic-aromatic poly(ether amide) dendrimers. Hyperstar polymers, the name of which refers to the usage of a hyperbranched core as macroinitiator, were reported by Voit et al. [129]. Hyperbranched poly(vinylbenzylchloride) could be successfully employed as initiator for the CROP of EtOx and ${ }^{i} \mathbf{P r O x}$; $\left(\mathbf{O S i M e}_{2}{ }^{t} \mathbf{B u}\right)^{i} \mathbf{P r O x}$ was incorporated into the hyperstars in order to reproducibly fine-tune the amount of $\mathrm{OH}$ groups per poly(2-oxazoline) arm by trifluoroacetic acid-mediated cleavage. The hyperbranched poly(vinylbenzylchloride)-graft-[pEtOxblock-p(OH) $\left.{ }^{i} \mathbf{P r O x}\right]$ particles are potential crosslinking agents in epoxy resins. 


\section{Synthesis of Poly(2-oxazoline)-Based Homo- and Copolymers}

\subsection{Homopoly(2-oxazoline)s and Homopolymers with Pending 2-Oxazoline Groups}

\subsubsection{Unconventional Solvents for the Performance of the CROP of 2-oxazolines}

Notably, Schubert and colleagues verified that the microwave-assisted CROP of PhOx and (2F)PhOx can be performed in water-soluble ionic liquids [130]. As additional advantage, this polymerization medium was found to exhibit a more efficient heating profile and a green approach for hydrophobic polymer synthesis. Aguiar-Ricardo and co-workers polymerized MeOx, EtOx, and PhOx in supercritical $\mathrm{CO}_{2}$, employing $\mathrm{BF}_{3}$ etherate as initiator [131]. The polymers displayed $\mathrm{CO}_{2}$ insertion $(10 \%-25 \%)$ in segments of polymer chains, giving rise to a polymer with a carboxylate end-group.

\subsubsection{Synthesis of Monomers and the Corresponding Poly(2-oxazoline)s}

Schubert and co-workers screened the synthesis of 2-oxazolines from nitriles with 2-aminoethanol (Scheme 11), yielding 2-substituted-2-oxazolines in order to optimize the reaction conditions [132]. The best results were achieved using chlorobenzene as solvent and zinc acetate as catalyst. Furthermore, the optimized conditions also confirmed the feasibility in larger-scale syntheses. This study comprised the successful syntheses of the monomers (MeS)MeOx, ${ }^{n} \mathrm{UndOx},(\mathbf{M e M e})^{n} \mathbf{H p}{ }^{=}=\mathbf{O x}$, ${ }^{n} \mathrm{HpOx},{ }^{n}$ OctOx, ( $\left.{ }^{t} \mathrm{Bu}\right) \mathrm{PhOx},(\mathrm{Cl}-\mathrm{Ph})^{c} \mathrm{BuOx},\left(\mathrm{F}_{3} / \mathrm{MeO} / \mathrm{Ph}\right) \mathrm{EtOx},{ }^{i} \mathrm{BuOx},{ }^{i} \mathrm{Pr}^{=} \mathrm{Ox},\left(\mathrm{CF}_{3}\right) \mathrm{BzOx}$, $\left(\mathbf{F}_{3} \mathbf{C S}\right)$ PhOx, FurOx, ${ }^{t} \mathbf{B u O x}$, MeOx, and (3F)MeOx. The CROP of several of these 2-oxazoline monomers (yielding homopolymers) was described in a later publication [133]. An 8-membered library of poly(2-n-alkyl-2-oxazoline)s, comprising pMeOx, pEtOx, ${ }^{n} \operatorname{PrOx}, \mathbf{p}^{n} \mathbf{B u O x}, \mathbf{p}^{n} \operatorname{PeOx}$, $\mathbf{p}^{n} \mathbf{H x O x}, \mathbf{p}^{n} \mathbf{H p O x}$, and $\mathbf{p}^{n}$ NonOx was prepared by Schubert et al. [134]. The thermal and mechanical properties of these homopolymers could be correlated with the present phases in the material. While the E moduli decreased linearly with an increasing number of carbon-atoms in the side-chain of amorphous polymers, semicrystalline polymers by contrast do not display any correlation between the E modulus and the length of the side-chain. Schubert, Hoogenboom and co-workers also reported on the solubility transitions in ethanol-water binary mixtures for a series of homopoly(2-oxazoline)s, comprising the eight congeners of the just-above mentioned study as well as $\mathbf{p}^{i} \mathbf{P r O x}, \mathbf{p}^{i} \mathbf{B u O x}$, $\mathbf{p}^{\mathbf{n} O c t O x}$, pPhOx, and pBzOx [135]. As expected, the solubility of the polymers correlated with the length of the side-chain. Side-chains with more than three carbon atoms only dissolved during the first heating run, which was correlated to the melting transition of the polymers. Grayson et al. described the employment of thiol-ene click-functionalized ${ }^{i} \mathbf{P r}^{=} \mathbf{O x}$ monomers in CROP, yielding poly(2-oxazoline)s with aryl, ester, protected amine, and protected carboxylic acid side-chain functionalities [136]. After deprotection of the amine and carboxylic acid functionalities, respectively, poly(2-oxazoline)s with properties interesting for biological applications were obtained. 2-Oxazoline monomers bearing S-galactosyl substituents, namely $(50 A c \cdot G a l-S) E t O x$ and $(50 A c \cdot G a l-S){ }^{n}$ DecOx, were synthesized by Takasu et al. [137]. Subsequent homo- and statistical copolymerization, the latter with MeOx and BzOx, yielded (co-)poly(2-oxazoline)s with narrow molar mass distributions if 2-methyl-2-oxazolinium triflate was used as initiator. Deprotection could be performed quantitatively yielding polymers and copolymers containing $\mathbf{p}\left(\mathbf{G a l - S ) E t O x}\right.$ and $\mathbf{p}(\mathbf{G a l - S})^{n} \mathbf{D e c O} \mathbf{x}$ units; the binding constants for the 
$\mathrm{RCA}_{120}$ lectin with the polymer were higher by a factor of 100 compared with that of the monosaccharide.

Scheme 11. Three common strategies for the synthesis of 2-oxazoline monomers: from nitriles according to Witte and Seeliger (top), from carboxylic acids and esters according to the Henkel patent (middle), and the three-step synthesis from carboxylic acids involving activation by $N$-hydroxysuccinimide.
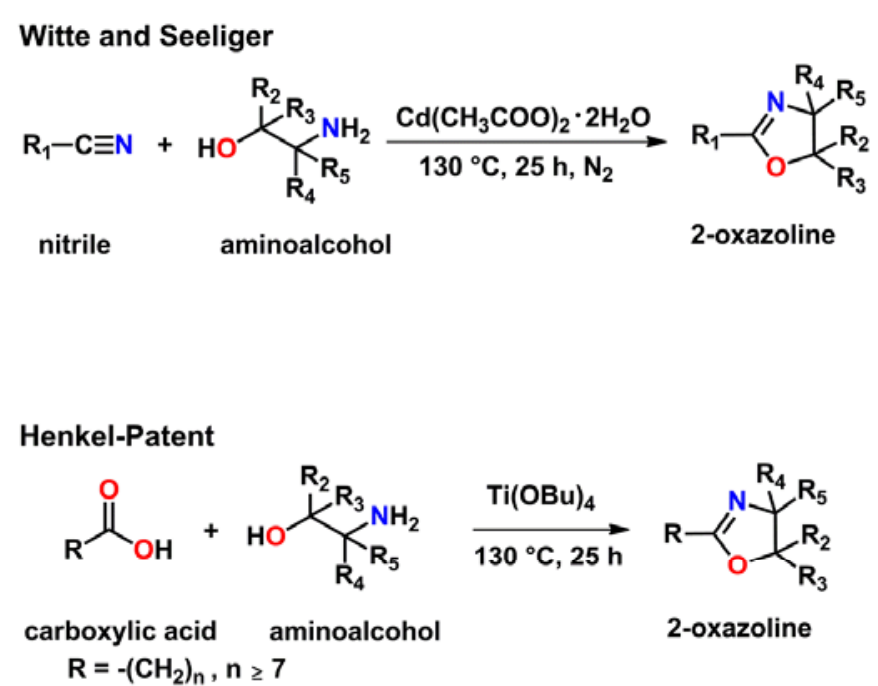

\section{3 step synthesis}
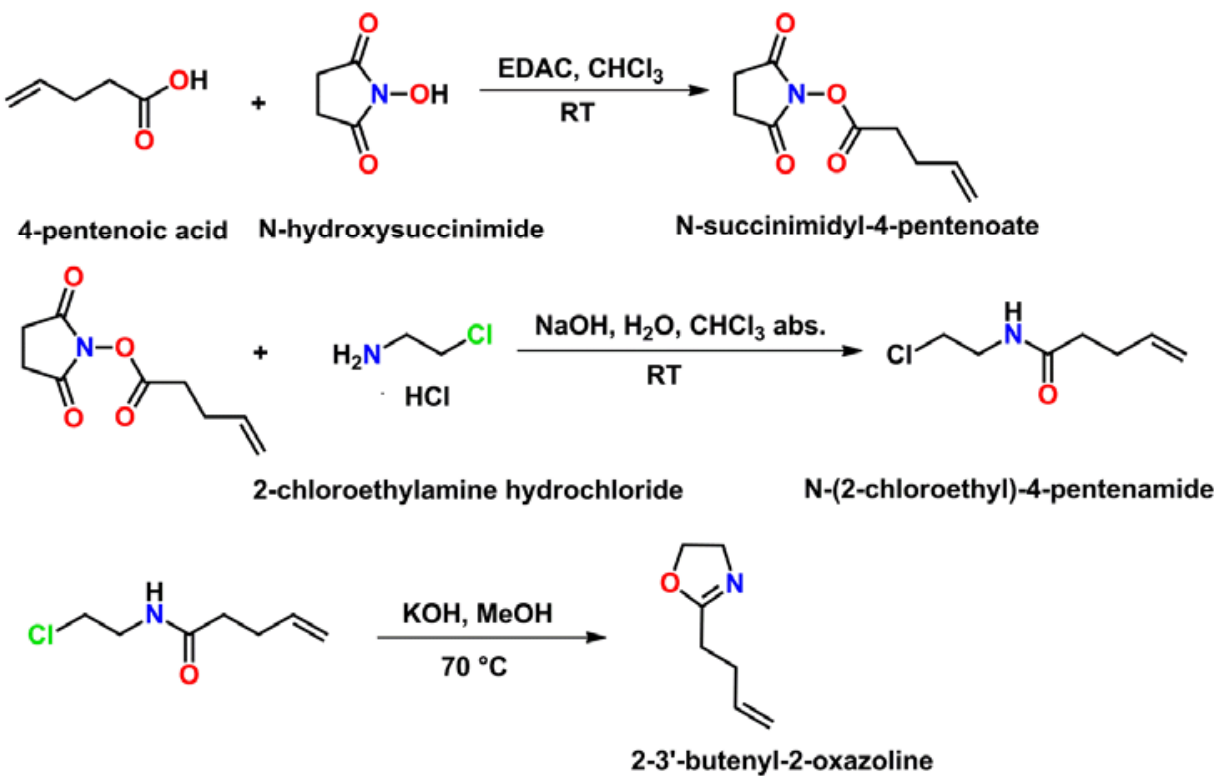

\subsubsection{LCST, UCST, and Glass-Transition Temperature of Homo Poly(2-oxazoline)s in Solution}

Winnik et al. prepared aqueous solutions of various $\mathbf{p}^{i} \mathbf{P r O x}$ to investigate the effects of temperature [138]: The transition temperature correlated with the molar mass and was higher in $\mathrm{H}_{2} \mathrm{O}$ than in $\mathrm{D}_{2} \mathrm{O}$, which are opposite observations to those made with aqueous solutions of poly( $N$-isopropylacrylamide). Katsumoto, Winnik et al. found that $\mathbf{p}^{i} \operatorname{PrOx}$ undergoes irreversible 
crystallization and phase separation after extended heat treatment in aqueous solution [139]. This observation was referred to as gradual dehydration of the amide bonds in the temperature range from room temperature to the cloud point. Irreversible conformational transitions of the polymer backbone upon prolonged exposure to elevated temperatures facilitated the crystallization by a nucleation/growth mechanism in the polymer-rich phase, similar to the crystallization of proteins from solution. Demirel, Schlaad et al. reported that $\mathbf{p}^{i} \mathbf{P r O X}$, mimicking a thermoresponsive pseudopeptides, crystallized into nanoribbons in aqueous solution above its LCST as a result of hydrophobic and dipolar interactions [140]. Solvation was found to be especially important in lowering the kinetic barriers in the crystallization process, similar to the self-organization of polypeptides and proteins.

Polymerization rate acceleration was reported by Hoogenboom, Schubert and co-workers during the CROP of ${ }^{c} \mathbf{P r O x}$ and referred to the electron withdrawing effect of the three-membered ring [141]. Compared to semicrystalline $\mathbf{p}^{i} \mathbf{P r O x}, \mathbf{p}^{c} \mathbf{P r O x}$ is amorphous like $\mathbf{p}^{n} \mathbf{P r O x}$, but has a slightly higher cloud point (CP). Furthermore, by end-capping $\mathbf{p}^{c} \mathbf{P r O x}$ with methacrylic acid, a macromonomer for subsequent RAFT polymerizations could be synthesized. Hoogenboom, Schubert and co-workers reported the synthesis of $(\mathbf{E t})^{n} \mathbf{H p O x}$ and its subsequent homo- and copolymerization (the latter with EtOx) [142]. Characterization of the random copolymers composed of $(\mathbf{E t})^{n} \mathbf{H p O x}$ and $-\mathbf{E t O x}$ displayed a linear correlation between the glass-transition temperature and the content of $\mathbf{p}(\mathbf{E t})^{n} \mathbf{H p O x}$, due to the lower packing density of the flexible branched side-chains. Notably, $\mathbf{p}(\mathbf{E t})^{n} \mathbf{H p O x}$ was reported to be the amorphous poly(2-oxazoline) with the lowest glass-transition temperature. Schlaad and co-workers reported the crystallization of $\mathbf{p}^{i} \mathbf{B u O x}$ and $\mathbf{p}^{n} \mathbf{N o n O x}$ in ethanol-water solutions at room temperature with annealing below the upper critical solution temperature [143]. Parameters influencing the crystallization behavior were temperature, polymer concentration and solvent composition. Like $\mathbf{p}^{i} \mathbf{P r O x}$, also $\mathbf{p}^{i} \mathbf{B u O x}$ and $\mathbf{p}^{n} \mathbf{N o n O x}$ show self-assembly in solution, and the corresponding structures were induced by crystallization. Hoogenboom, Schubert et al. synthesized a library of random pEtOx-stat- ${ }^{n}$ PrOx copolymers that differed in composition and chain length [144]. They found that the cloud points of the copolymers decreased not only with increasing chain length, but also with increasing content of $\mathbf{p}^{n}$ PrOx. Furthermore, the thermal transitions of copolymers with cloud points of approx. $34{ }^{\circ} \mathrm{C}$ showed no hysteresis or concentration dependence, making them superior to poly( $N$-isopropylacrylamide). Hruby et al. synthesized pMeOx-block-(p ${ }^{i}$ PrOx-stat$\mathbf{p}^{n} \mathbf{B u O x}$-block-MeOx block copolymers of the ABA type with hydrophilic A blocks and a thermoresponsive B block [145]. These copoly(2-oxazoline)s showed water solubility below the cloud point temperature of block B. At higher temperatures, micelles formed, the size of which depended on the A to B block weight ratio. Employing thiol-ene reactions, a phenolic moiety was introduced to enable radionucleide labeling for usage in solid tumor diagnostics. In a later study, these investigations were expanded to $\mathbf{p}^{i}$ PrOx-stat-p ${ }^{n} \mathbf{B u O x}$, which molecularly dissolved below the cloud point temperature in water and were incorporated into micellar nanoparticles of Pluronic F127 after increasing the solution temperature beyond their transition temperature [146]. Furthermore, copolymerizations with ${ }^{n} \mathbf{B u}{ }^{=} \mathbf{O x}$ enabled subsequent covalent attachment of 2-(4-hydroxyphenyl)acetic acid (by thiol-ene reactions) and radionuclide labeling with iodine-125 of the aromatic moiety. Hoogenboom et al. investigated the effect of Hofmeister salts on the lower critical solution temperature of linear pEtOx, $\mathbf{p}^{n} \operatorname{PrOx}, \mathbf{p}^{i} \operatorname{PrOx}$, and poly(methacrylate)-graft-pEtOx [147]. It was 
shown that the response to the addition of Hofmeister salts depended significantly on the (degree of) hydrophilicity of the polymers, but hardly on their architecture.

\subsubsection{Optical Rotation of Polymers with Pending 2-Oxazolinyl Substituents}

Onimura et al. synthesized optically active $\mathbf{E t}^{\equiv}{ } \mathbf{P h O x}(\mathbf{B n})$ monomers and polymerized them using a rhodium catalyst, yielding a polyacetylene with pending 2-oxazoline groups [148]. Induced by the chiral 2-oxazoline groups in the side-chains, the polymers showed higher-order structure with predominantly one-handed screw (helical) sense. In another study, Onimura et al. used the palladiumand copper-catalyzed Sonogashira-Hagihara coupling polymerization to copolymerize optically active (2I)PhOx(Ph) or (2I)PhOx(Bz) with 1,4- or 1,3-diethynylbenzene [149]. Investigation of the optical properties revealed the formation of higher-order structures such as helices. The monomers $N$-[o-(4-phenyl-4,5-dihydro-1,3-oxazol-2-yl)phenyl]methacrylamide, $N$-[o-(4-iso-propyl-4,5-dihydro1,3-oxazol-2-yl)phenyl]methacrylamide, and $N$-[o-(4-iso-propyl-4,5-dihydro-1,3-oxazol-2-yl)phenyl]methacrylamide were synthesized and subsequently (radically) polymerized. Jiang et al. revealed the impact of the pending 2-oxazoline rings on the polymerization process and the optical properties of the polymers, suggesting the formation of higher-order polymer structures [150]. Jiang et al. prepared optically active polymers via ${ }^{n} \mathrm{BuLi}$-initiated anionic polymerization of $\mathrm{N}$-phenylmaleimides bearing 2-oxazolinyl substituents, namely PhOx(Et), PhOx( $\left.{ }^{i} \mathbf{P r}\right)$, and $\mathbf{P h O x}(\mathbf{P h})$ (Scheme 12) [151]. The polymers exhibited optical rotation that was referred not only to the optically active 2-oxazolinyl substituents, but also to the polymers' partial helical structures (excess of threo-diisotactic configuration in the main chain). Jiang et al. synthesized block copolymers of poly(ethylene glycol) and poly(maleimide) carrying the optically active 2-oxazolinyl substituent $\mathbf{P h O x}(\mathbf{P h})$ [152]. Copolymers with long blocks of poly(ethylene glycol) formed regular spherical micelles; the copolymers with short blocks of poly(ethylene glycol) formed larger-size aggregates. The variation in chiroptical properties correlated with the aggregated state of the block copolymers. Yashima et al. found pronounced differences in the $\mathrm{CD}$ and absorption spectra of a chiral regioregular polythiophene bearing the optically active 2-phenyl-5-ethyl-2-oxazolinyl substituent [153]. Upon addition of poor solvents to the polymer solutions, self-assembling of the polymer to chiral, supramolecular structures occured. Yashima et al. investigated the aggregation behavior of a regioregular optically active polythiophene, namely poly $\{(R)-3$-[4-(4-ethyl-2-oxazolin-2-yl)-phenyl]thiophene $\}$ with several metal salts like copper(I), copper(II), silver(I), zinc(II), and iron(II) perchlorate [154]. They stated that these polymers possessed a split-type induced circular dichroism due to the chirality of the main chain with the pending optically active 2-oxazolinyl substituents.

\subsubsection{Optical Rotation of Poly(2-oxazoline)s}

Schubert, Hoogenboom and co-workers investigated the connection between the crystalline structure and the formation of ordered chiral structures in the semicrystalline polymers $\mathbf{p}(R)-{ }^{n} \mathbf{B u O x}(\mathbf{E t}), \quad \mathbf{p}(S)-{ }^{n} \mathbf{B u O x}(\mathbf{E t})$ and $\mathbf{p}(R S)-{ }^{n} \mathbf{B u O x}(\mathbf{E t}) \quad$ (Scheme 12) [155]. The polymers derived from enantiopure monomers exhibited double melting peaks in DSC measurements and were argued to recrystallize during melting from a disordered chiral structure into a more perfect chiral structure. By contrast, the racemic polymer was found to be amorphous. Schubert, Hoogenboom and 
co-workers also copolymerized $\boldsymbol{R}$ - or $\boldsymbol{S}-{ }^{n} \mathbf{B u O x}(\mathrm{Et})$ and $\boldsymbol{R S}-{ }^{n} \mathbf{B u O x}(\mathbf{E t})$ [156]. No chiral amplification, either in solution or the solid state, could be detected for those copoly(2-oxazoline)s. Nonetheless, the optical rotation, solubility and thermal properties of the copolymers could be regulated by the enantiomeric excess.

Scheme 12. Structural formulae of poly(2-oxazoline)s with chiral carbon atoms in the main chain: $\mathbf{p}(R)-{ }^{n} \mathrm{BuOx}(\mathrm{Et}), \mathbf{p}(S)-{ }^{n} \mathrm{BuOx}(\mathrm{Et})$ and $\mathbf{p}(R S)-{ }^{n} \mathrm{BuOx}(\mathrm{Et})$ (top; for details, see reference [155]). Anionic polymerization of maleimides bearing optically active 2-oxazoline substituents (bottom; for details, see reference [151]).<smiles>CCC(C(=O)O)N(C)C(=O)CCCCCCCOC(=O)O</smiles><smiles>CCC(CCCCCCCCCOC(=O)O)N(C)C(=O)O</smiles>

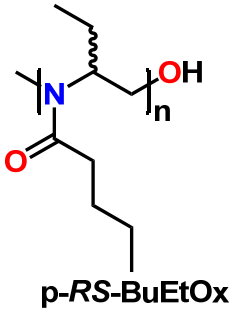<smiles>CC(C)[C@H](N)CO</smiles><smiles>CC(C)[C@@H]1COC(c2ccccc2N)=N1</smiles><smiles>CCOC(=O)COC(=O)CCOC(=O)CO</smiles><smiles>CC(C)[C@H]1COC(NC(=O)/C=C\C(=O)O)=N1</smiles>

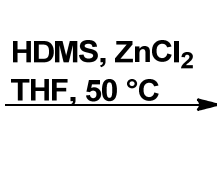<smiles>CC(C)[C@H]1COC(c2ccccc2N2C(=O)C=CC2=O)=N1</smiles><smiles>CC1C(=O)N(c2ccccc2C2COC3C(=N2)OC[C@@H]3C(C)C)C(=O)C1C</smiles>

\subsection{Block Copoly(2-oxazoline)s}

The usage of microwave-assisted polymerizations for the synthesis of well defined block copoly(2-oxazoline)s (Scheme 13) has been described by Schubert et al. extensively for the monomers MeOx, EtOx, PhOx, and ${ }^{n}$ NonOx. Preceded by a study of homopolymerizations [157], research examples comprise a 16-membered library of four chain-extended homo- and 12 diblock copoly(2-oxazoline)s [158], as well as the synthesis of the corresponding tri- [159] and tetrablock copoly(2-oxazoline)s [160].

Scheme 13. Structural formula of amphiphilic pEtOx-block-pNonOx.

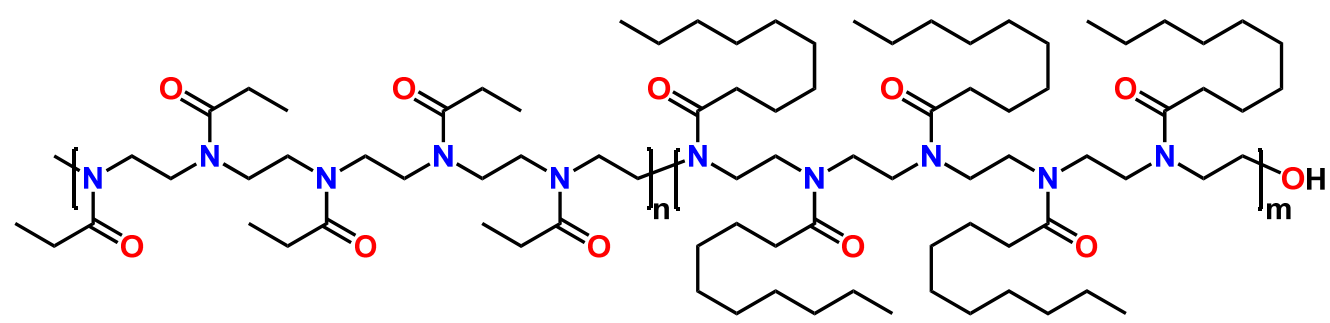




\subsubsection{Block Copoly(2-oxazoline)s Containing a Block of pPhOx}

Schubert et al. synthesized a series of gradient $\mathbf{p}^{n}$ NonOx-stat-pPhOx copolymers (due to the pronouncedly different reactivity ratios of ${ }^{n}$ NonOx and PhOx) [161]. Regarding the pronouncedly different polymerization rates of alkyl-substituted 2-oxazolines and their aromatic counterparts, Schubert and co-workers studied the kinetics and reactivity ratios of statistical microwave-assisted copolymerizations of PhOx with either MeOx or EtOx [162]. The formation of quasi-diblock copoly(2-oxazoline)s was proven. The mechanical properties of triblock copoly(2-oxazoline)s [163], in particular the elastic moduli, were found to correlate with triblock copolymer composition and chain architecture. In particular the surface energy strongly depended on the presence or absence of $\mathbf{p}^{n}$ NonOx blocks due to phase segregation and crystallization on the surface. The investigation of the micellar morphologies in binary water-ethanol mixtures revealed that spherical micelles were obtained in the case when $\mathbf{p}^{n}$ NonOx was the only solvophobic block; if $\mathbf{p P h O x}$ blocks were additionally present, spherical and cylindrical as well as vesicles were observed [164]. Trzebicka et al. investigated the self-association process of pEtOx-block-pPhOx block copolymers in aqueous media and on surfaces [165]. They revealed the correlation between copolymer composition and aggregation behavior: Highly hydrated particles were formed by copolymers with a (relatively) low amount of the hydrophobic block PhOx, whereas more stable aggregates of spherical micelles were formed by copolymers with longer blocks of PhOx. The micellization behavior of pEtOx-block-pPhOx and pMeOx-block-pPhOx quasi-diblock copolymers was discussed by Gohy and co-workers [166]. (Due to the different reactivity of MeOx/EtOx and PhOx during CROP, the copolymerization yielded quasi-block copolymers.) Micelles of the copolymers formed in spincast solutions due to the evaporation of the solvent; a correlation between the amount of pPhOx and the morphology and size of the micelles could be established. Tiller et al. synthesized amphiphilic pMeOx-block-pPhOxblock-pMeOx triblock copolymers in a two-step process using bisfunctional $\alpha, \alpha^{\prime}$-dibromo- $p$-xylene as initiator and examined their self-assembling behavior [167]. Three coexisting structures (unimolecular micelles, micellar aggregates, form-stable polymersomes with a glassy middle-block) were observed.

\subsubsection{Self-Assembly of Diblock Copoly(2-oxazoline)s}

Sato et al. found that amphiphilic pi PrOx-block-pEtOx formed "star" micelles (core-shell micelles containing a core of hydrophobic $\left.\mathbf{p}^{i} \operatorname{PrOx}\right)$ in water at $50{ }^{\circ} \mathrm{C}$ [168]. Those micelles formed large concentrated phase droplets after further aggregation, and finally droplet coalescence leading to bulk phase separation occurred. On the contrary, at $70{ }^{\circ} \mathrm{C}$, the pEtOx blocks did not coalesce into a liquid bulk phase, since both blocks were sufficiently hydrophobic. Schlaad, Taubert et al. studied the solution behavior of double-hydrophilic poly(ethylene oxide)-block-pMeOx [169]. Pulsed field gradient NMR spectroscopy confirmed the presence of aggregates, despite the block copolymer's double-hydrophilic character. Hoogenboom, Kjoniksen et al. investigated the aggregation behavior of pEtOx $_{80}$-block-p(EtOx $\mathbf{x}_{\mathbf{x}}$-stat- $\left.{ }^{n}{ }^{-}{ } \mathbf{O x}_{40-x}\right)$ with $x=0$, 4, or 8 [170]. Upon heating, the block copolymers exhibit two cloud points. The aggregates formed at the first cloud point restructured and fragmented into smaller micelle-like structures; at even higher temperatures, the block copolymer became double-hydrophobic and formed large compact aggregates. Gohy et al. investigated the micelle 
formation of various $\mathbf{p}^{n}$ NonOx-block-pEtOx copolymers on surfaces during the spincoating process [171]. Due to the evaporation of the solvent ethanol, the less soluble $\mathbf{p}^{n}$ NonOx blocks started to precipitate first. Depending on the relative content of the $\mathbf{p}^{n}$ NonOx blocks, the size and the morphology of the surface micelles could be varied. Jordan, Papadakis and co-workers investigated the micellar structures of amphiphilic diblock copolymers synthesized by sequential CROP of MeOx as hydrophilic and either ${ }^{n} \mathbf{N o n O x}$ as hydrophobic or $\left.\mathbf{( 9 F}\right)^{n} \mathbf{H x O x}$ as fluorophilic part [172]. The copoly(2-oxazoline)s formed core/shell micelles in aqueous media. While pMeOx-block-p ${ }^{n}$ NonOx formed spherical micelles, pMeOx-block-p(9F) ${ }^{n} \mathbf{H x O x}$ formed elongated assemblies; in water, those micelles coexisted but did not mix. Nuyken and co-workers synthesized a series of pyridine-bearing

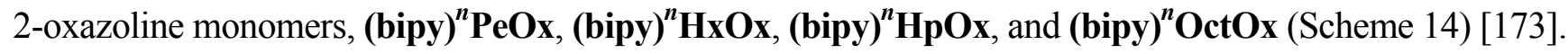
The diblock copolymers composed of a block of pMeOx and a block of the bipyridine-containing 2-oxazoline could be successfully used in ATRP as macroligands. In another study, Nuyken and co-workers synthesized amphiphilic blockcopolymers based on poly(2-oxazoline)s and introduced phosphine ligands by polymeranalogous P-C coupling between aryliodide bearing side-chains and bisaryl phosphine [174]. These micellar catalysts showed high catalytic activity during first experiments. Schubert, Gohy et al. synthesized amphiphilic pEtOx-block-pSoy ${ }^{=}=\mathbf{O x}$ that formed aqueous spherical micelles with a $\mathbf{p E t O x}$ corona and a $\mathbf{p S o y}=\mathbf{}=\mathbf{O x}$ core [175]. The core of the micelles was slightly crosslinked by UV irradiation. When changing the solvent from water to acetone the micelles' morphology formed short rods similar to rice grains due to the swelling of the crosslinked core. This effect was claimed to be useful for the encapsulation and the release of molecules.

\subsubsection{Self-Assembly of Triblock Copoly(2-oxazoline)s}

The aggregation behavior of di- and triblock as well as copoly(2-oxazoline)s composed of pMeOx and $\mathbf{p}^{n}$ NonOx was investigated by Jordan, Papadakis et al. [176]. They revealed that the architecture of the micelles formed by the copolymers characteristically correlated with their composition. Schubert and co-workers prepared $\mathbf{p}^{n}$ NonOx-block-pEtOx block copolymers to provide micelles suitable for the thermoreversible phase transfer between hydrophobic ionic liquids and water [177]. Schubert and co-workers prepared triblock amphihpilic and fluorophilic copolymers of the composition pEtOx-block-p(Et) ${ }^{n}$ PeOx-block-p(2F)PhOx via microwave-assisted polymerizations [178]. Two glass-transistions were detected, indicative of the immiscibility of the two types of blocks in the amphiphilic copoly(2-oxazoline). Kabanov et al. synthesized amphiphilic di- and triblock copolymers of the compositions pEtOx-block-p ${ }^{n}$ BuOx and pMeOx-block-p ${ }^{n}$ BuOx-block-pMeOx [179]. These block copolymers formed micelles in water and were used to solubilize otherwise water-insoluble drugs like Paclitaxel. Excellent drug loading efficacies were observed. Montemagno et al. synthesized amphiphilic pEtOx-block-poly(dimethylsiloxane)-block-pEtOx using telechelic poly(dimethylsiloxane) as macroinitiator for the CROP of EtOx [180]. In aqueous media, the triblock copolymer formed vesicles with a shell thickness of $4 \mathrm{~nm}$ and diameters in the range of 150-250 nm. Weberskirch and co-workers also described a procedure to prepare block copolymers containing blocks of 2-oxazoline derivatives with $N$-heterocyclic carben/palladium catalysts in the lipophilic segment, involving the monomers $\left(\mathbf{i m i d}_{2} \mathbf{P d I}_{2}\right)^{\boldsymbol{n}} \mathbf{B u O x},\left(\mathbf{i m i d}_{2} \mathbf{P d I}_{2}\right)^{\boldsymbol{n}} \mathbf{H x O x}$, and $\left.\left(\mathbf{i m i d}_{2} \mathbf{P d I}\right)^{n}\right)^{\boldsymbol{n}} \mathbf{O c t O x}$, (Scheme 14) [131,181]. Three different as-functionalized monomers, composed of a bis(imidazoline-2- 
ylidene)palladium(II) diiodide derivative covalently bound to the 2-oxazoline ring by alkyl spacers ( $n$-butyl, $n$-hexyl, $n$-octyl), were incorporated into the block copolymers, which displayed self-assembly in aqueous solution and were furthermore used in Heck and Suzuki coupling reactions. Kabanov, Luxenhofer et al. prepared pMeOx-block-p ${ }^{n}$ BuOx-block-pMeOx-based micelles that could be loaded with large amounts of various hydrophobic anticancer agents [182]. These multidrug loaded poly(2-oxazoline) micelles were also found to be more stable compared to single-drug loaded micelles and to exhibit synergistic effects useful against several tumor models.

Scheme 14. Structural formula of imidazole-functionalized poly(2-oxazoline)s as immobilized catalysts for Heck and Suzuki coupling reactions (top; for details, see reference [181]). Structural formula of bipyridine-functionalized poly(2-oxazoline)s that can be used as macroligands in atom-transfer radical polymerizations (bottom; for details, see reference [172]).
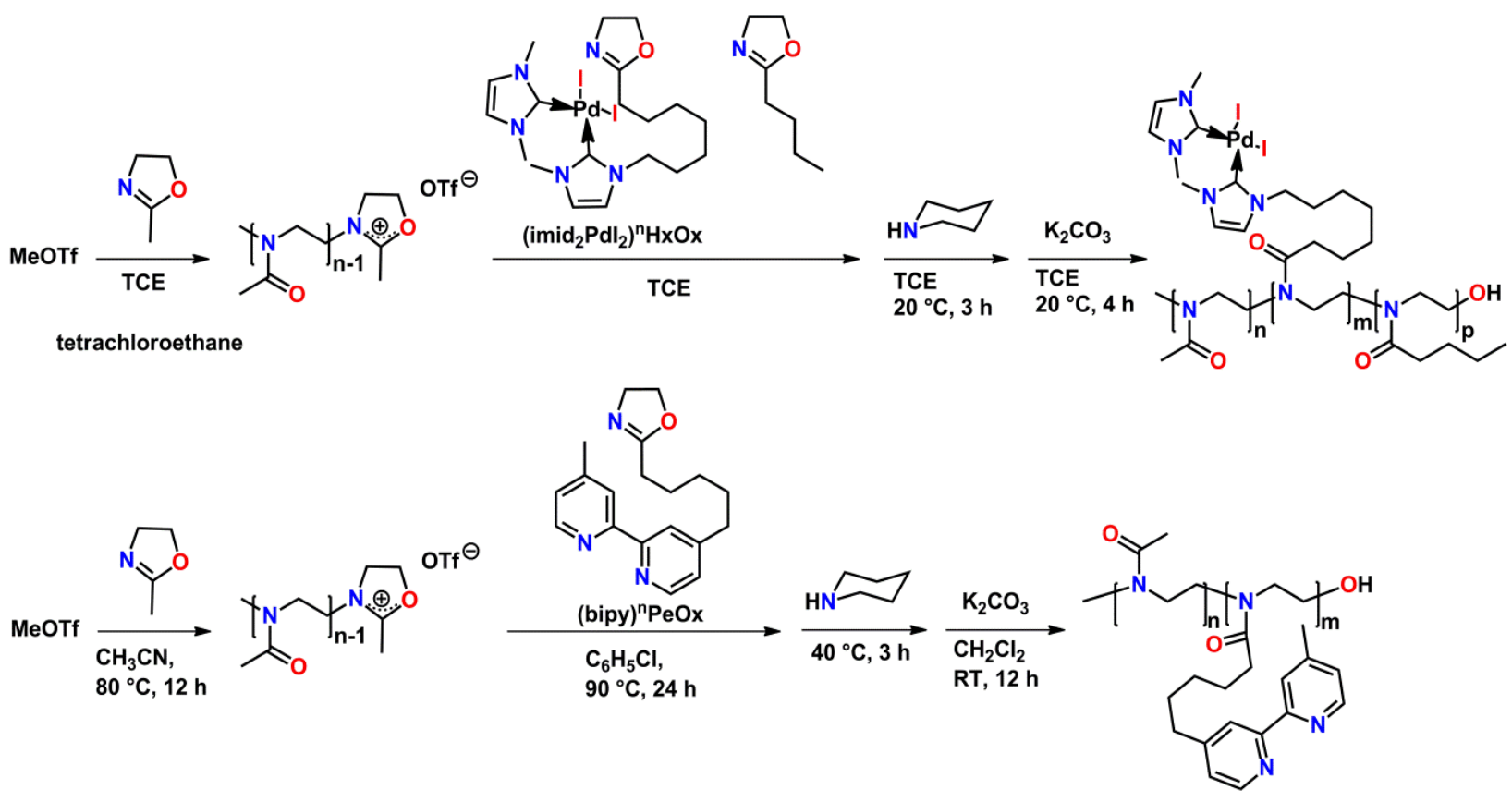

\section{Polymeranalogous Reactions}

\subsection{Polymeranalogous Reactions of poly(2-oxazoline)s Excluding (Partial) Hydrolysis}

\subsubsection{Click-Reactions Involving Olefinic Moieties}

Schubert, Hoogenboom and Kempe reported that, due to its double bonds in the side-chains, $\mathbf{p}^{n} \mathbf{D e c}^{=} \mathbf{O x}$ can be crosslinked and as well be modified by thiol-ene reactions with thiols such as $n$-dodecanethiol or 2,3,4,6-tetra-O-acetyl-1-thio-glucopyranose (Scheme 15) [183]. Nuyken and colleagues prepared random copolymers of the composition $\mathbf{p}(\mathbf{S H})$ EtOx-stat-pEtOx from the CROP of (SBz)EtOx and EtOx and subsequent deprotection of the thiol function [184]. The thiol-bearing copolymer was reacted with various ene-bearing molecules as well as with acrylamide- and maleimide-capped semitelechelic $\mathbf{p M e O x}$, yielding graft copolymers. Schubert et al. reported on the microwave-assisted CROP of $\mathbf{S o y}^{=}=\mathbf{O x}$ [185]; the monomer could be synthesized from the reaction of ethanol amine with soy bean oil, retaining the double bonds of the unsaturated fatty acid side-chains. 
Successful UV-induced crosslinking of the polymer was showcased. pEtOx-stat-p ${ }^{n} \mathbf{D e c}^{=} \mathbf{O x}$ was subjected to photoinduced thiol-ene click-chemistry with 2,3,4,6-tetra- $O$-acetyl-1-thio- $\beta$-D-glucopyranose, yielding glucosyl-functionalized copoly(2-oxazoline)s [186]. Hoogenboom, Schubert and co-workers investigated these thermoresponsive copolymers and found a linear correlation between the cloud point temperatures and the content of sugar groups; consequently the cloud points can be tuned as requested. Telechelic pEtOx-stat-p ${ }^{n}$ Dec $^{=} \mathbf{O x}$, end-functionalized with an azide and an anthracene functionality, respectively, in addition enabled for triple post-modification due to the three different orthogonal click-able functional groups: azide alkyne cycloaddition (azide), Diels-Alder cycloaddition (anthracene), and thiol-ene click chemistry ( $\left.\mathbf{p}^{n} \mathbf{D e c}^{=} \mathbf{O} \mathbf{x}\right)$ [187]. In this context, the reader's attention is brought to the work of Böhme and co-workers who synthesized multifunctional coupling agents bearing a 2-oxazoline, an azinone, and an allyl ether group [188]. Investigations using model compounds showed that the oxazoline group reacted selectively with carboxylic groups, while the oxazinone groups reacted selectively with amino groups. These reactions yielding allyloxy-functionalized poly(ester amide)s occurred at different temperatures, and modifications using these multifunctional coupling agents correspondingly could be carried out stepwise. Schlaad et al. synthesized $\mathbf{p}^{n} \mathbf{B u}={ }^{=} \mathbf{O x}$ homo- and $\mathbf{p E t O x}$-stat-p ${ }^{n} \mathbf{B u}{ }^{=} \mathbf{O x}$ copolymers [189]. These polymers were subjected to polymeranalogous thiol-ene click-reactions with mercaptans, yielding diol- perfluoro- $n$-octanyl-, and glucopyranosylfunctionalized poly(2-oxazoline)s. Schlaad et al. crystallized $\mathbf{p}^{i} \mathbf{P r O x}-\mathbf{s t a t}_{-} \mathbf{p}^{\boldsymbol{n}} \mathbf{B} \mathbf{u}^{=} \mathbf{O x}$ from aqueous solution above its cloud point, yielding thiol-ene functionalizable microspheres for carbohydrateprotein recognition [190]. Photoaddition of carbohydrates to the aggregates' surfaces was reported for 1-thio-glucose and 1-thio-galactose. Hydrophobic $\mathbf{p}^{n}$ NonOx-stat- $\mathbf{p}^{n} \mathbf{D e c}^{=} \mathbf{O x}$ was further functionalized by thiol-ene additions of 2-mercaptoethanol, yielding poly(2-oxazoline)-polyols, by Ronda et al. [191]. By the subsequent reaction with methylene-bis(phenyl-iso-cyanate), amorphous as well as semicrystalline polyurethane networks were obtained. Schlaad et al. generated a toolbox of thermoresponsive polymers with tunable cloud points by using thiol-ene reactions to functionalize $\mathbf{p}^{i} \mathbf{P r O x}-\mathbf{S t a t}_{-} \mathbf{p}^{n} \mathbf{B} \mathbf{u}{ }^{\bar{O}} \mathbf{O x}$ with various thiols such as 1-thioglycerol, 2-mercaptoethanol, 1-n-octanethiol, 3-mercaptopropionic acid, and 2,3,4,6-tetra-O-acetyl-1-thio- $\beta$-D-glucopyranose [192]. The relative content and type of functionalities bound to the polymer chain influenced the cloud points; hence, the glucopolymers synthesized were claimed to show potential for life sciences applications.

\subsubsection{Click-Reactions Involving Alkines}

Schubert and co-workers described the copper-catalyzed alkyne-azide cycloaddition reaction to synthesize a glucose-substituted 2-oxazoline monomer; well-defined copoly(2-oxazoline)s were prepared from the copolymerization thereof with either EtOx or ${ }^{n} \mathbf{D e c}^{=} \mathbf{O x}$ [193]. Thiol-ene click-reactions were described for the reaction of $\mathbf{p}^{n} \mathbf{D e c}{ }^{=} \mathbf{O x}$ with thiols such as $n$-dodecanethiol or 3-mercaptopropionic acid. Well-defined hydrophilic homo- and copolymers of the composition

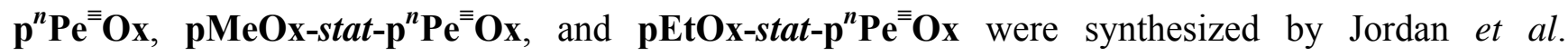
(Scheme 15) [194]. The subsequent copper-catalyzed Huisgen 1,3-dipolar cycloaddition of azides onto the polymers' alkyne side-chains quantitatively yielded triazoles. Functionalization and simultaneous crosslinking of $\mathbf{p}^{n} \mathbf{B u} \mathbf{u}^{\equiv} \mathbf{O x}-$ block-pEtOx micelles by thiol-yne photochemistry reactions with monofunctional thiols was reported by Schlaad et al. [195]. Simultaneous crosslinking occurred only if 
the solvent had induced the formation of micelles prior to the application of UV irradiation; if the copolymer was soluble in the solvent (e.g., tetrahydrofuran), thiol-yne reactions/polymeranalogous functionalization could be still observed while crosslinking of the dissolved polymer chains did not take place. Finn et al. reacted alkyne-functionalized poly(2-oxazoline)s of the compositions pMeOx, pEtOx, pMeOx-stat-p ${ }^{n} \mathbf{P e}^{\equiv} \mathbf{O x}$, and $\mathbf{p E t O x}-$ stat $\mathbf{p}^{n} \mathbf{P e}{ }^{\equiv} \mathbf{O x}$ with icosahedral virus-like particles bearing azide-functionalized surfaces [196]. While pMeOx and pEtOx enabled single-point attachment only in the copper-catalyzed reaction, the other two copolymers allowed multiple-point attachment (because of the $\mathbf{p}^{n} \mathbf{P e}^{\equiv} \mathbf{O x}$ units) and yielded fully crosslinked core-shell structures of high thermal stability.

Scheme 15. Reaction scheme for the covalent attachment of 2,3,4,6-tetra-O-acetyl-1-thioglucopyranose to $\mathbf{p D e c}{ }^{=} \mathbf{O x}$ by thiol-ene reactions (top; for details, see reference [183]). Reaction scheme of the Huisgen cycloaddition of $\mathbf{p M e O x}$-stat-p ${ }^{n} \mathbf{P e}^{\equiv}{ }^{\equiv \mathbf{O x}}$ and small-molecule azides (bottom; for details, see reference [194]).
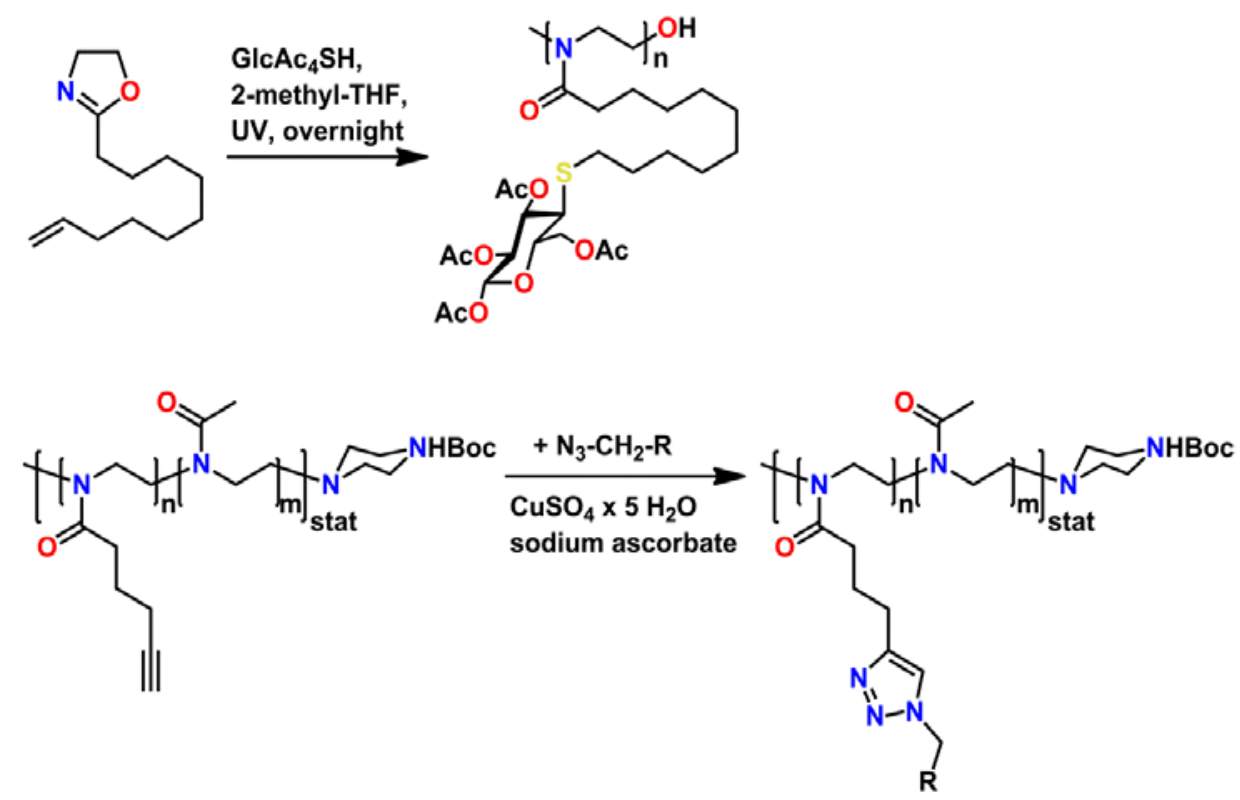

\subsubsection{Functional Groups with Protonable Functionalities/Acidic Protons in the Side-Chains}

Jordan et al. described a convenient procedure for the synthesis of amino-group bearing copoly(2-oxazoline)s, namely $\mathbf{p}\left(\mathbf{N H}_{2}\right)^{n}$ PeOx-stat-pEtOx that was obtained from the CROP of (NHBoc) ${ }^{n}$ PeOx (and EtOx) and deprotection of the copolymer [197]. The amino groups were subsequently reacted with various isothiocyanates, yielding crosslinked hydrogels in the case of bifunctional isothiocyanates. The copolymerization of EtOx with a non-protected amine, namely (NH $)$ PhOx, yielded an amino-bearing copolymer with however very high $\overline{\mathrm{M}}_{\mathrm{w}} / \overline{\mathrm{M}}_{\mathrm{n}}$ values in the range from 2 to 4, which was referred to as side-reactions of the free amino group during the polymerization [198]. The copolymers were found to be biocompatible materials suited for the immobilization of bioactive species. Jordan et al. published a one-pot strategy for the synthesis of poly(2-oxazoline)s bearing a protected aldehyde functionalitiy in the side-chain [199]. The protected aldehyde group, a dioxalan, of the copolymer $\mathbf{p M e O x - s t a t - p ( D i O x a l )})^{n} \mathbf{P r O x}$ could be deprotected with trifluoroacetic acid; the aldehyde side-chains of the recovered copolymer $\mathbf{p M e O x - s t a t - p ( C H O})^{n} \operatorname{PrOx}$ reacted 
quantitatively with amino-oxy compounds such as O-benzylhydroxylamine hydrochloride. Analogously, Luston et al. reported the branching side-reactions during the AB polyaddition of (OH)PhOx, which was referred to as the reaction of amide groups (formed during the polyaddition) with unreacted (OH)PhOx monomers [200]. The hydroxyl groups of amphiphilic pMeOx-block$\left[\mathbf{p}^{n} \mathbf{N o n O x}-\right.$ stat-p$\left.(\mathbf{O H})^{n} \mathbf{P e O x}\right]$ were reacted with hexafluoroglutaric anhydride and (in a multi-step reaction) attached to a ruthenium-based metathesis polymerization catalyst $[173,201]$. The metathesis polymerization of diethyl dipropargylmalonate yielded polymers with narrower molar mass distributions if the immobilized catalyst was used (compared to the non-immobilized catalyst). Aiming for the same class of immobilized catalysts, Weberskirch et al. also synthesized pMeOx-block$\left.\left[\mathbf{p}^{n} \text { NonOx-stat-p(COOH }\right)^{n} \mathbf{B u O x}\right]$, reacted the $(\mathbf{C O O H})^{n} \mathbf{B u O x}$ units with 2-isopropoxy-5hydroxystyrene, and bound the modified copolymer to a Grubbs-Hoveyda catalyst [202].

\subsubsection{Various Polymeranalogous Reactions}

Yan et al. attached pEtOx covalently to silicon wafers and gold slides employing the $\mathrm{CH}$-insertion reaction of photoactivated perfluorophenyl azide to form thin films [203]. The films' properties regarding protein resistance were investigated using bovine serum albumin and shown to positively correlate with the molar mass. Hoogenboom and co-workers reported the reduction of pMeOx, pEtOx, pPhOx, and $\mathbf{p}^{n}$ NonOx by borane/dimethylsulfide [204], yielding alkyl- and benzyl-substituted pEIs. The pEIs exhibited decreased melting and glass-transition temperatures after removal of the carbonyl functional group.

\subsection{Polymeranalogous Reactions Preceded by (Partial) Hydrolysis}

\subsubsection{Toxicity Studies of Poly(2-oxazoline)s and pEIs}

As in particular fully and partially hydrolyzed poly(2-oxazoline)s are under intensive investigation for their usage in biomedical applications, the toxicity of congeners of these compound classes is briefly discussed at the beginning of this chapter. Fischer et al. investigated the cytotoxicity and hemocompatibility of poly(ethylene glycol) and pEtOx under standard conditions and concluded that pEtOx presents a promising alternative for poly(ethylene glycol), since pEtOx possesses several advantages such as easier synthesis, low viscosity, and high stability [205]. The cytotoxicity of a library of poly(2-oxazoline) polymers, comprising polymers and copolymers of MeOx, EtOx, ${ }^{n}$ PrOx, ${ }^{i} \mathbf{P r O x},{ }^{n} \mathbf{B u O x},{ }^{n} \mathbf{P e}^{\equiv} \mathbf{O x}$, and ${ }^{n} \mathbf{N o n O x}$, was evaluated by Kabanov, Luxenhofer and co-workers who confirmed that this polymer class is not cytotoxic even at high concentrations [206]. The cellular uptake increased with the hydrophobic character of the polymers and was observed even at nanomolar concentrations. Hence, poly(2-oxazoline)s can be classified as candidates for the next generation of polymer therapeutics. Hoogenboom, Geest et al. examined the toxicity of partially hydrolyzed pEtOx and found that under physiological conditions no or hardly any decomposition of pEtOx occurred [207]; hence, partial hydrolysis does not limit the application of poly(2-oxazoline)s in biomedical applications. 


\subsubsection{Partial Hydrolysis: Copolymers Containing Units of pEI}

Schubert, Hoogenboom and co-workers investigated the acid-mediated hydrolysis of pMeOx and pEtOx [208]. They found that the hydrolysis kinetics did not show significant dependency on polymer concentrations or polymerization degrees. Hydrolysis of pEtOx was more time-consuming than of smaller pMeOx. Konishi et al. synthesized partially hydrolyzed pMeOx and pEtOx and amidized the corresponding copolymers with pyrene-1-carboxylic acid, yielding a chromophore-functionalized copolymer as base of a polymer-chain-induced tunable luminescence system [209]. Hsiue et al. synthesized pEtOx-block-pEI block copolymers from a synthetic strategy comprising the usage of potassium thioacetate as terminating agent for the CROP of EtOx (pEtOx-SAc), the full hydrolysis of the recovered polymer yielding semitelechelic pEI, and the conversion of the end-group to a pyridyl disulfide group (pEI-ssPy) [210]. Subsequently, pEtOx-SAc and pEI-ssPy were coupled using a disulfide exchange reaction. These diblock copolymers were able to condense DNA completely when reaching a polymer/DNA weight ratio of over 12. The polyplexes formed stable aggregates of $190 \mathrm{~nm}$ and were sensitive to $\mathrm{pH}$ changes. The pEtOx-block-pEI compounds exhibited low cytotoxicity and high transfection efficacy. Kim and co-workers synthesized pMeOx-stat-pEI from the partial alkaline hydrolysis of pMeOx and reacted it with sterically demanding multiwalled carbon nanotubes bearing carboxylic acid groups [211]. The thus-functionalized multiwalled carbon nanotubes had good solubility in various organic solvents. Hoogenboom and co-workers synthesized pMeOx-blockpPhOx and pMeOx-stat-pPhOx and subjected them to acidic or basic hydrolyses, recovering copolymers with different contents of pMeOx, pPhOx and pEI [212]. Using acidic hydrolysis, pMeOx and pPhOx units were readily hydrolyzed; using $\mathrm{NaOH}$ for hydrolysis, more selectivity was observed: pPhOx units were hardly cleaved at all. However, under alkaline conditions, the copolymers partially degraded. The partially hydrolyzed copolymers exhibited self-assembly to micelles in acidic environments and were readily soluble. In water or in alkaline solutions, the polymers were insoluble but formed spherical micelles at higher temperatures. pEI-stat-pPhOx copolymers were both, thermo- and pH-responsive. In another study, Hoogenboom et al. reported that pronouncedly selective hydrolyses of poly(2-oxazoline)s could be performed in water-ethanol solutions [213]. The block

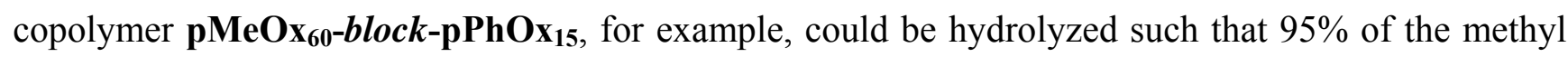
side-chains, but only $10 \%$ of the phenyl side-chains were cleaved.

\subsubsection{Fully Hydrolyzed Poly(2-oxazoline)s}

Menzel et al. prepared alkylated pEIs by performing the CROP of MeOx with $n$-octadecyltosylate as initiator and subsequent hydrolysis with $\mathrm{NaOH}$ in order to study the correlation between alkyl chain, polymerization degree and the conformation [214]. When cooling hot aqueous solutions of the copolymers, hydrogel formation occurred depending on the polymerization degree of the pEI parts. Hammond and co-workers presented a synthetic route for the synthesis of linear-dendritic rod diblock copolymers starting from tosylation of poly(ethylene glycol) monomethyl ether, which in the next step acted as initiator for the CROP of EtOx (Scheme 16) [215]. After acidic hydrolysis yielding a poly(ethylene glycol)-pEI diblock copolymer, branches were synthesized by alternating addition of methyl acrylate and ethylene diamine (referred to as half and full generations, terminated with ester groups and amine groups, respectively) up to generation 4.5. The diblock copolymer possessed 
semicrystallinity, which decreased with every generation due to the decreasing (relative) content of poly(ethylene oxide). Furthermore, end-group modifications were carried out using various alkyl groups aiming at enhancing the phase segregation. Generation 4 bearing $n$-dodecyl alkyl groups adopted a worm- or rod-like conformation.

Scheme 16. Reaction scheme for the synthesis of multiple-generation linear dendrimers with a pEI core by sequential (repeated) reaction with methyl acrylate and ethylene diamine (for details, see reference [215]).

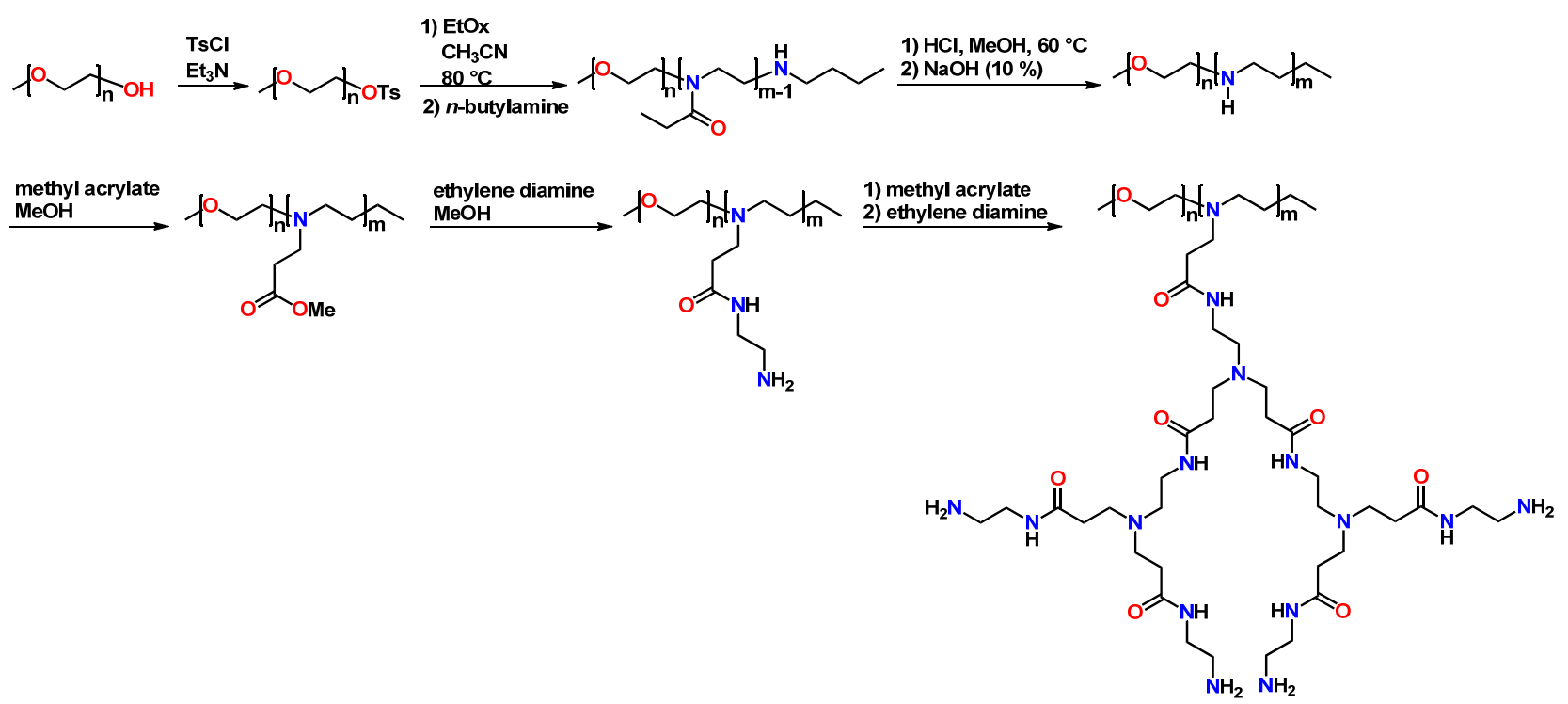

\subsubsection{Antimicrobial Activity of (Partially) Hydrolyzed Poly(2-oxazoline)s}

Yan and Ren developed an immobilization process for pEtOx and other polymers on perfluorophenyl azide-functionalized silicon wafers employing the $\mathrm{C}-\mathrm{H} / \mathrm{N}-\mathrm{H}$-insertion reaction of perfluorophenyl nitrenes, which were formed by the precursors during heating [216]. The layer thickness of the films could be varied if polymers with different molecular structures were used. Locklin et al. synthesized reacted linear pEI (derived from the acid-mediated hydrolysis of pEtOx and subsequent neutralization) with a mixture of 1-bromo- $n$-dodecane and 4-[(6-bromohexyl)oxy]benzophenone; the tertiary amines were subsequently quaternized with methyl iodide (Scheme 17) [217]. The benzophenone group in the side-chains of the copolymers enabled covalent attachment to substrates bearing $\mathrm{C}-\mathrm{H}$ bonds due to insertion of the benzophenone $\mathrm{C}=\mathrm{O}$ bond $\left(\mathrm{R}^{\prime} \mathrm{R}^{\prime \prime}-\mathrm{C}=\mathrm{O}+\mathrm{R}_{3}-\mathrm{CH} \rightarrow \mathrm{R}_{3}-\mathrm{C}-\mathrm{C}(\mathrm{OH}) \mathrm{R}^{\prime} \mathrm{R}^{\prime \prime}\right)$ during UV irradiation. The layers showed high biocidal activity. With a layer thickness of at least $50 \mathrm{~nm}$, almost all the tested bacteria comprising Escherichia coli and Staphylococcus aureus were killed. The alternative approach was reported as well [218]: pEtOx, pEI and various other polymers were covalently bound to surfaces modified by a benzophenone monolayer using a photochemical process. For the attachment of the polymers via their $\mathrm{C}-\mathrm{H}$ groups, $\mathrm{UV}$ irradiation was applied, and the $\mathrm{C}=\mathrm{O}$ functionality of the benzophenone derivative reacted with the polymers' $\mathrm{C}-\mathrm{H}$ bonds (insertion mechanism). These attached polymer layers were found to promote the growth of human endothelial cells. Moeller et al. used carbonate couplers for the one-step functionalization of pEI [219]. Quaternary ammonium groups, alkyl chains, allylic and benzylic groups were used for modification. 
These amphiphilic polymers were water-soluble and considered to be interesting materials for antimicrobial coatings and disinfectants. Their activity against gram-negative and gram-positive bacteria was tested; the colony forming units of Escherichia coli and Bacillus subtilis were reduced between $95 \%-99 \%$. Wiesbrock et al. investigated a small library of partially hydrolyzed pEtOx and pNonOx in terms of their antimicrobial activity after usage as additives to polyolefin mixtures [220]. They found that antimicrobial activity against gram-negative Escherichia coli and Pseudomonas aeruginosa as well as Candida albicans depended only on the degree of hydrolysis, while antimicrobial activity against gram-positive Staphylococcus aureus was only observed for hydrolyzed pNonOx.

Scheme 17. Reaction scheme for the fabrication of functionalized surfaces: hydrolysis of pEtOx, reaction of the recovered pEI with 1-bromododecane and a brominated benzophenone linker, and subsequent $\mathrm{C}-\mathrm{H}$ bond insertion (for details, see reference [217]).

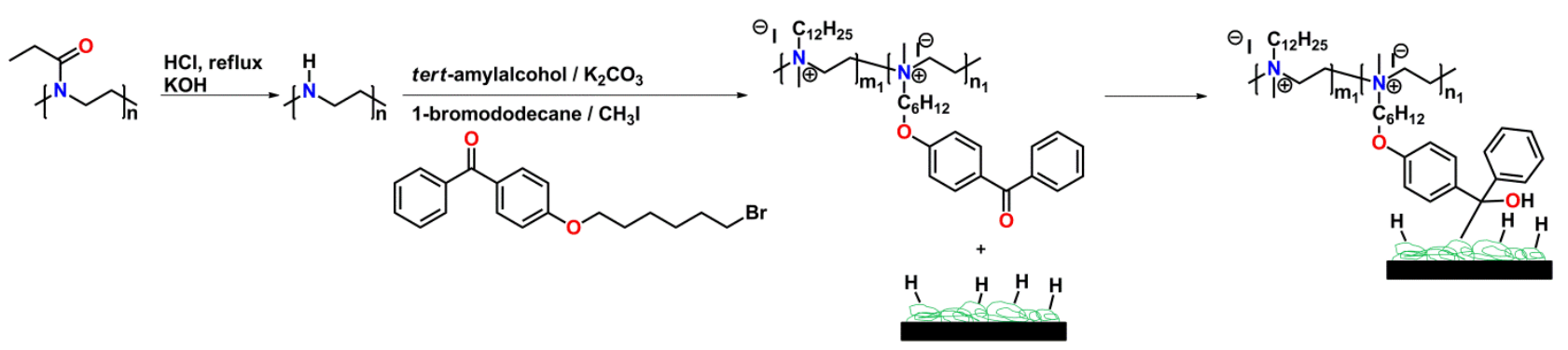

\section{Conclusions}

Within a comparatively short time, in fact five decades after the first report of the polymer class of poly(2-oxazoline)s, a plethora of synthetic strategies for the preparation of poly(2-oxazoline)s and related polymers and materials has been described in literature. Recent work in that field has been described in this review article, and the general current trends can be briefly summarized in a list of 10 key facts:

1. The synthesis and polymerization of a large number of 2-oxazoline monomers has been reported during the last decade, enabling for the straight-forward synthesis of homo- and copoly(2-oxazoline)s with tailor made properties.

2. Non-conjugated double bonds in the side-chains of poly(2-oxazoline)s do not need to be protected during the polymerization; alcohols, amines, aldehydes, and carboxylic acids in the poly(2-oxazoline) side-chains nonetheless need to be protected during the polymerization in order not to lose control of the polymerization and/or observe crosslinking of the polymer chains.

3. Polymeranalogous click-reactions such as the thiol-ene reaction and the Huisgen cycloaddition further expand the range of functionalized poly(2-oxazoline)s.

4. Despite the large number of 2-oxazoline monomers known, MeOx and EtOx are still in the main focus of investigations due to their water solubility and FDA approval; unambiguously, poly(2-oxazoline)s are considered as novel high-potential polymers for biomedic(in)al applications. 
5. In particular the choice and employment of dedicated functionalized initiators and terminating agents has been investigated recently, opening the pathway for semitelechelic and telechelic poly(2-oxazoline)s that have been successfully used as macroinitiators.

6. The hydrolysis of poly(2-oxazoline)s, yielding pEI and pEI-stat-poly(2-oxazoline) random copolymers, is currently under thorough investigation, aimed at the development of novel carrier materials for biological applications.

7. Telechelic poly(2-oxazoline)s and (partially) hydrolyzed poly(2-oxazoline)s display antimicrobial activity.

8. Due to the control, the so-called livingness or at least quasi-livingness, of the CROP of poly(2-oxazoline)s, also complex polymer structures and architectures such as dendrimers, combs, brushes, star-shape and hyperbranched designs can be synthesized.

9. The solubility and "solution behavior" of 2-oxazoline-based polymers and copolymers can be fine-tuned over a broad range, implying the formation of aggregates and their architecture (with relevance to biological applications) and paving the way to (micellar) catalysis with immobilized catalysts.

10. Benefiting from the straight-forward and highly-effective synthesis of tailor-made poly(2-oxazoline)s and (co-)poly(ethylene imine)s, these classes of polymers are about to establish themselves as "common" polymers for advanced/biological applications, with high relevance as well as in the areas of complexation and supramolecular assemblies.

In the authors' opinion, a fundamental data set for the class of poly(2-oxazoline)s has been compiled so far. As of now, the class of poly(2-oxazoline)s displays great versatility in terms of functionalization by careful choice of, e.g., the initiators/terminating agents, side-chains of the poly(2-oxazoline)s, heteropolymers in copolymers, and architectural design. Without any doubt, this class of polymers and corresponding materials will be further investigated by numerous research groups and further developments and synthetic advances in the area of poly(2-oxazoline)s will be achieved.

\section{Acknowledgments}

This literature research study was performed at the Polymer Competence Center Leoben GmbH (PCCL) and the Institute for Chemistry and Technology of Materials of the Graz University of Technology. PCCL is funded by the Austrian Government and the State Governments of Styria and Upper Austria within the framework of the Kplus-program of the Austrian Ministry of Traffic, Innovation, and Technology.

\section{Conflict of Interest}

The authors declare no conflict of interest.

\section{References}

1. Tomalia, D.A.; Sheetz, D.P. Homopolymerization of 2-alkyl- and 2-aryl-2-oxazolines. J. Polym. Sci. A Polym. Chem. 1966, 4, 2253-2265. 
2. Seeliger, W.; Aufderhaar, E.; Diepers, W.; Feinauer, R.; Nehring, R.; Thier, W.; Hellmann, H. Recent syntheses and reactions of cyclic imidic esters. Angew. Chem. Int. Ed. 1966, 5, 875-888.

3. Kagiya, T.; Narisawa, S.; Maeda, T.; Fukui, K. Ring-opening polymerisation of 2-substituted 2-oxazolines. J. Polym. Sci. B Polym. Lett. 1966, 4, 441-445.

4. Bassiri, T.G.; Levy, A.; Litt, M. Polymerization of cyclic imino ethers. I. Oxazolines. J. Polym. Sci. B Polym. Lett. 1967, 5, 871-879.

5. Ebner, C.; Bodner, T.; Stelzer, F.; Wiesbrock, F. One decade of microwave-assisted polymerizations: Quo vadis? Macromol. Rapid Commun. 2011, 32, 254-288.

6. Bodner, T.; Ellmaier, L.; Schenk, V.; Albering, J.; Wiesbrock, F. Delocalized $\pi$-electrons in 2-oxazoline rings resulting in negatively charged nitrogen atoms: Revealing the selectivity during the initiation of cationic ring-opening polymerizations. Polym. Int. 2011, 60, 1173-1179

7. Neu, M.; Fischer, D.; Kissel, T. Recent advances in rational gene transfer vector design based on poly(ethylene imine) and its derivatives. J. Gene Med. 2005, 7, 992-1009.

8. Jäger, M.; Schubert, S.; Ochrimenko, S.; Fischer, D.; Schubert, U.S. Branched and linear poly(ethylene imine)-based conjugates: Synthetic modification, characterization, and application. Chem. Soc. Rev. 2012, 41, 4755-4767.

9. Thünemann, A.F. Polyelectrolyte-surfactant complexes (synthesis, structure, and material aspects). Prog. Polym. Sci. 2002, 27, 1473-1572.

10. Kelly, A.M.; Wiesbrock, F. Strategies for the synthesis of poly(2-oxazoline)-based hydrogels. Macromol. Rapid Commun. 2012, 33, 1632-1647.

11. Guillerm, B.; Monge, S.; Lapinte, V.; Robin, J.-J. How to modulate the chemical structure of polyoxazolines by appropriate functionalization. Macromol. Rapid Commun. 2012, 33, $1600-1612$.

12. Luxenhofer, R.; Han, Y.; Schulz, A.; Tong, J.; He, Z.; Kabanov, A.V.; Jordan, R. Poly(2-oxazoline)s as polymer therapeutics. Macromol. Rapid Commun. 2012, 33, 1613-1631.

13. Hoogenboom, R. Poly(2-oxazoline)s: A polymer class with numerous potential applications. Angew. Chem. Int. Ed. 2009, 48, 7978-7994.

14. Hoogenboom, R.; Schlaad, H. Bioinspired poly(2-oxazoline)s. Polymers 2011, 3, 467-488.

15. Schlaad, H.; Diehl, C.; Gress, A.; Meyer, M.; Demirel, A.L.; Nur, Y.; Bertin, A. Poly(2-oxazoline)s as smart bioinspired polymers. Macromol. Rapid Commun. 2010, 31, $511-525$.

16. Kobayashi, S. Ethylenimine polymers. Prog. Polym. Sci. 1990, 15, 751-823.

17. Kobayashi, S.; Uyama, H. Poly(alkylenimine) derivatives: A variety of possible applications. Polym. News 1991, 16, 70-76.

18. Aoi, K.; Okada, M. Polymerization of oxazolines. Prog. Polym. Sci. 1996, 21, 151-208.

19. Kobayashi, S.; Uyama, H. Polymerization of cyclic imino ethers: From its discovery to the present state of the art. J. Polym. Sci. A Polym. Chem. 2002, 40, 192-209.

20. Adams, N.; Schubert, U.S. Poly(2-oxazolines) in biological and biomedical application contexts. Adv. Drug Deliv. Rev. 2007, 59, 1504-1520.

21. Hoogenboom, R.; Fijten, M.W.M.; Schubert, U.S. Parallel kinetic investigation of 2-oxazoline polymerizations with different initiators as basis for designed copolymer synthesis. J. Polym. Sci. A Polym. Chem. 2004, 42, 1830-1840. 
22. Kourti, M.-E.; Vougioukalakis, G.C.; Hadjichristidis, N.; Pitsikalis, M. Metallocene-mediated cationic ring-opening polymerization of 2-methyl- and 2-phenyl-oxazoline. J. Polym. Sci. A Polym. Chem. 2011, 49, 2520-2527.

23. Buzin, P.; Schwarz, G.; Kricheldorf, H.R. Cationic polymerizations of 2-alkyloxazolines catalyzed by bismuth salts. J. Polym. Sci. A Polym. Chem. 2008, 46, 4777-4784.

24. Paulus, R.M.; Becer, C.R.; Hoogenboom, R.; Schubert, U.S. Acetyl halide initiator screening for the cationic ring-opening polymerization of 2-ethyl-2-oxazoline. Macromol. Chem. Phys. 2008, 209, 794-800.

25. Guillerm, B.; Monge, S.; Lapinte, V.; Robin, J.-J. Novel investigations on kinetics and polymerization mechanism of oxazolines initiated by iodine. Macromolecules 2010, 43, 5964-5970.

26. Volet, G.; Amiel, C.; Auvray, L. Interfacial properties of a diblock amphiphilic copolymer: Poly(isobutylvinyl ether-b-2-methyl-2-oxazoline). Macromolecules 2003, 36, 3327-3336.

27. Glaied, O.; Delaite, C.; Hurtrez, G.; Joubert, M.; Dumas, P. Oxazoline-terminated macromonomers by the alkylation of 2-methyl-2-oxazoline. J. Polym. Sci. A Polym. Chem. 2005, 43, 2440-2447.

28. Reif, M.; Jordan, R. $\alpha, \omega$-Functionalized poly(2-oxazoline)s bearing hydroxyl and amino functions. Macromol. Chem. Phys. 2011, 212, 1815-1824.

29. Weber, C.; Becer, C.R.; Baumgaertel, A.; Hoogenboom, R.; Schubert, U.S. Preparation of methacrylate end-functionalized poly(2-ethyl-2-oxazoline) macromonomers. Des. Monomers Polym. 2009, 12, 149-165.

30. Park, C.; McAlvin, J.E.; Fraser, C.L.; Thomas, E.L. Iron cluster and microstructure formation in metal-centered star block copolymers: Amphiphilic iron tris(bipyridine)-centered polyoxazolines. Chem. Mater. 2002, 14, 1225-1230.

31. Kempe, K.; Vollrath, A.; Schaefer, H.W.; Poehlmann, T.G.; Biskup, C.; Hoogenboom, R.; Hornig, S.; Schubert, U.S. Multifunctional poly(2-oxazoline) nanoparticles for biological applications. Macromol. Rapid Commun. 2012, 31, 1869-1873.

32. Gaertner, F.C.; Luxenhofer, R.; Blechert, B.; Jordan, R.; Essler, M. Synthesis, biodistribution and excretion of radiolabeled poly(2-alkyl-2-oxazoline)s. J. Contr. Rel. 2007, 119, 291-300.

33. Obeid, R.; Park, J.-Y.; Advincula, R.C.; Winnik, F.M. Temperature-dependent interfacial properties of hydrophobically end-modified poly(2-isopropyl-2-oxazoline)s assemblies at the air/water interface and on solid substrates. J. Colloid Interface Sci. 2009, 340, 142-152.

34. Obeid, R.; Maltseva, E.; Thünemann, A.F.; Tanaka, F.; Winnik, F.M. Temperature response of self-assembled micelles of telechelic hydrophobically modified poly(2-alkyl-2-oxazoline)s in water. Macromolecules 2009, 42, 2204-2214.

35. Volet, G.; Chanthavong, V.; Wintgens, V.; Amiel, C. Synthesis of monoalkyl end-capped poly(2-methyl-2-oxazoline) and its micelle formation in aqueous solution. Macromolecules $\mathbf{2 0 0 5}$, 38, 5190-5197.

36. Volet, G.; Deschamps, A.-C.L.; Amiel, C. Association of hydrophobically $\alpha, \omega$-end-capped poly(2-methyl-2-oxazoline) in water. J. Polym. Sci. A Polym. Chem. 2010, 48, 2477-2485.

37. Volet, G.; Amiel, C. Polyoxazoline adsorption on silica nanoparticles mediated by host-guest interactions. Colloids Surf. B Biointerfaces 2012, 91, 269-273.

38. Volet, G.; Auvray, L.; Amiel, C. Monoalkyl poly(2-methyl-2-oxazoline) micelles. A small-angle neutron scattering study. J. Phys. Chem. B 2009, 113, 13536-13544. 
39. Li, J.; Yan, D.; Jiang, X.; Chen, Q. Formation of the crystalline inclusion complex between $\gamma$-cyclodextrin and poly( $N$-acetylethylenimine). Polymer 2002, 43, 2625-2629.

40. Huber, S.; Hutter, N.; Jordan, R. Effect of end group polarity upon the lower critical solution temperature of poly(2-isopropyl-2-oxazoline). Colloid Polym. Sci. 2008, 286, 1653-1661.

41. Correia, V.G.; Bonifácio, V.D.B.; Raje, V.P.; Casimiro, T.; Moutinho, G.; da Silva, C.L.; Pinho, M.G.; Aguiar-Ricardo, A. Oxazoline-based antimicrobial oligomers: Synthesis by CROP using supercritical $\mathrm{CO}_{2}$. Macromol. Biosci. 2011, 11, 1128-1137.

42. Waschinski, C.J.; Tiller, J.C. Poly(oxazoline)s with telechelic antimicrobial functions. Biomacromolecules 2005, 6, 235-243.

43. Waschinski, C.J.; Barnert, S.; Theobald, A.; Schubert, R.; Kleinschmidt, F.; Hoffmann, A.; Saalwächter, K.; Tiller, J.C. Insights in the antibacterial action of poly(methyloxazoline)s with a biocidal end group and varying satellite groups. Biomacromolecules 2008, 9, 1764-1771.

44. Waschinski, C.J.; Herdes, V.; Schueler, F.; Tiller, J.C. Influence of satellite groups on telechelic antimicrobial functions of polyoxazolines. Macromol. Biosci. 2005, 5, 149-156.

45. Chiper, M.; Hoogenboom, R.; Schubert, U.S. New terpyridine macroligands as potential synthons for supramolecular assemblies. Eur. Polym. J. 2010, 46, 260-269.

46. Mero, A.; Fang, Z.; Pasut, G.; Veronese, F.M.; Viegas, T.X. Selective conjugation of poly(2-ethyl 2-oxazoline) to granulocyte colony stimulating factor. J. Contr. Rel. 2012, 159, $353-361$.

47. Ogoshi, T.; Hiramitsu, S.; Yamagishi, T.; Nakamoto, Y. Columnar stacks of star- and tadpole-shaped polyoxazolines having triphenylene moiety and their applications for synthesis of wire-assembled gold nanoparticles. Macromolecules 2009, 42, 3042-3047.

48. Brissault, B.; Kichler, A.; Leborgne, C.; Jarroux, N.; Cheradame, H.; Guis, C. Amphiphilic poly[(propylene glycol)-block-(2-methyl-2-oxazoline)] copolymers for gene transfer in skeletal muscle. ChemMedChem 2007, 2, 1202-1207.

49. Stoenescu, R.; Meier, W. Vesicles with asymmetric membranes from amphiphilic ABC triblock copolymers. Chem. Commun. 2002, 3016-3017.

50. Fijten, M.W.M.; Haensch, C.; van Lankvelt, B.M.; Hoogenboom, R.; Schubert, U.S. Clickable poly(2-oxazoline)s as versatile building blocks. Macromol. Chem. Phys. 2008, 209, 1887-1895.

51. Haensch, C.; Erdmenger, T.; Fijten, M.W.M.; Hoeppener, S.; Schubert, U.S. Fast surface modification by microwave assisted click reactions on silicon substrates. Langmuir 2009, 25, 8019-8024.

52. Jerca, V.V.; Nicolescu, F.A.; Vasilescu, D.S.; Albu, A.M.; Vuluga, D.M. Synthesis and structure of 2-ethyl-2-oxazoline macromonomers with styryl end-groups. U.P.B. Sci. Bull. B 2009, 71, 29-36.

53. Volet, G.; Lav, T.-X.; Babinot, J.; Amiel, C. Click-chemistry: An alternative way to functionalize poly(2-methyl-2-oxazoline). Macromol. Chem. Phys. 2011, 212, 118-124.

54. Alemseghed, M.G.; Servello, J.; Hundt, N.; Sista, P.; Biewer, M.C.; Stefan, M.C. Amphiphilic block copolymers containing regioregular poly(3-hexylthiophene) and poly(2-ethyl-2-oxazoline). Macromol. Chem. Phys. 2010, 211, 1291-1297.

55. Glassner, M.; Kempe, K.; Schubert, U.S.; Hoogenboom, R.; Barner-Kowollik, C. One-pot synthesis of cyclopentadienyl endcapped poly(2-ethyl-2-oxazoline) and subsequent ambient temperature Diels-Alder conjugations. Chem. Commun. 2011, 47, 10620-10622. 
56. Lüdtke, K.; Jordan, R.; Hommes, P.; Nuyken, O.; Naumann, C.A. Lipopolymers from new 2-substituted-2-oxazolines for artificial cell membrane constructs. Macromol. Biosci. 2005, 5, 384-393.

57. Mero, A.; Pasut, G.; Dalla Via, L.; Fijten, M.W.M.; Schubert, U.S.; Hoogenboom, R.; Veronese, F.M. Synthesis and characterization of poly(2-ethyl 2-oxazoline)-conjugates with proteins and drugs: Suitable alternatives to PEG-conjugates? J. Contr. Rel. 2008, 125, 87-95.

58. Tong, J.; Luxenhofer, R.; Yi, X.; Jordan, R.; Kabanov, A.V. Protein modification with amphiphilic block copoly(2-oxazoline)s as a new platform for enhanced cellular delivery. Mol. Pharm. 2010, 7,. 984-992.

59. Konieczny, S.; Fik, C.P.; Averesch, N.J.H.; Tiller, J.C. Organosoluble enzyme conjugates with poly(2-oxazoline)s via pyromellitic acid dianhydride. J. Biotechnol. 2012, 159, 195-203.

60. Caponi, P.F.; Qiu, X.-P.; Vilela, F.; Winnik, F.M.; Ulijn, R.V. Phosphatase/temperature responsive poly(2-isopropyl-2-oxazoline). Polym. Chem. 2011, 2, 306-308.

61. Wang, C.-H.; Hwang, Y.-S.; Chiang, P.-R.; Shen, C.-R.; Hong, W.-H.; Hsiue, G.-H. Extended release of bevacizumab by thermosensitive biodegradable and biocompatible hydrogel. Biomacromolecules 2012, 13, 40-48.

62. Tarvainen, T.; Karjalainen, T.; Malin, M.; Peräkorpi, K.; Tuominen, J.; Seppälä, J.; Järvinen, K. Drug release profiles from and degradation of a novel biodegradable polymer, 2,2-bis(2-oxazoline) linked poly(ع-caprolactone). Eur. J. Pharm. Sci. 2002, 16, 323-331.

63. Pulkkinen, M.; Malin, M.; Tarvainen, T.; Saarimäki, T.; Seppälä, J.; Järvinen, K. Effects of block length on the enzymatic degradation and erosion of oxazoline linked poly-e-caprolactone. Eur. $J$. Pharm. Sci. 2007, 31, 119-128.

64. Tarvainen, T.; Malin, M.; Suutari, T.; Pöllänen, M.; Tuominen, J.; Seppälä, J.; Järvinen, K. Pancreatin enhanced erosion of and macromolecule release from 2,2-bis(2-oxazoline)-linked poly( $\varepsilon$-caprolactone). J. Contr. Rel. 2003, 86, 213-222.

65. Lee, S.C.; Kim, C.; Kwon, I.C.; Chung, H.; Jeong, S.Y. Polymeric micelles of poly(2-ethyl-2-oxazoline)-block-poly(e-caprolactone) copolymer as a carrier for paclitaxel. $J$. Contr. Rel. 2003, 89, 437-446.

66. Wang, X.; Li, X.; Zhou, Y.; Fan, C.; Li, W.; Ma, S.; Fan, Y.; Huang, Y.; Li, N.; Liu, Y. Synthesis, characterization and biocompatibility of poly(2-ethyl-2-oxazoline)-poly(D,L-lactide)poly(2-ethyl-2-oxazoline) hydrogels. Acta Biomater. 2007, 7, 4149-4159.

67. Tarvainen, T.; Karjalainen, T.; Malin, M.; Pohjolainen, S.; Tuominen, J.; Seppälä, J.; Järvinen, K. Degradation of and drug release from a novel 2,2'-bis(2-oxazoline) linked poly(lactic acid) polymer. J. Contr. Rel. 2002, 81, 251-261.

68. Hsiue, G.-H.; Wang, C.-H.; Lo, C.-L.; Wang, C.-H.; Li, J.-P.; Yang, J.-L. Environmental-sensitive micelles based on poly(2-ethyl-2-oxazoline)-b-poly(L-lactide) diblock copolymer for application in drug delivery. Int. J. Pharm. 2006, 317, 69-75.

69. Wang, C.-H.; Hsiue, G.-H. New amphiphilic poly(2-ethyl-2-oxazoline)/poly(L-lactide) triblock copolymers. Biomacromolecules 2003, 4, 1487-1490.

70. Wang, C.-H.; Wang, C.-H.; Hsiue, G.-H. Polymeric micelles with a pH-responsive structure as intracellular drug carriers. J. Contr. Rel. 2005, 108, 140-149. 
71. Obeid, R.; Scholz, C. Synthesis and self-assembly of well-defined poly(amino acid) endcapped poly(ethylene glycol) and poly(2-methyl-2-oxazoline). Biomacromolecules 2011, 12, 3797-3804.

72. Kuo, S.-W.; Lee, H.-F.; Huang, C.-F.; Huang, C.-J.; Chang, F.-C. Synthesis and self-assembly of helical polypeptide-random coil amphiphilic diblock copolymer. J. Polym. Sci. A Polym. Chem. 2008, 46, 3108-3119.

73. Meyer, M.; Schlaad, H. Poly(2-isopropyl-2-oxazoline)-poly(L-glutamate) block copolymers through ammonium-mediated NCA polymerization. Macromolecules 2006, 39, 3967-3970.

74. Yang, Y.; Kataoka, K.; Winnik, F.M. Synthesis of diblock copolymers consisting of hyaluronan and poly(2-ethyl-2-oxazoline). Macromolecules 2005, 38, 2043-2046.

75. Wang, C.-H.; Wang, W.T.; Hsiue, G.-H. Development of polyion complex micelles for encapsulating and delivering amphotericin B. Biomaterials 2009, 30, 3352-3358.

76. Lemechko, P.; Renard, E.; Volet, G.; Colin, C.S.; Guezennec, J.; Langlois, V. Functionalized oligoesters from poly(3-hydroxyalkanoate)s containing reactive end group for click chemistry: Application to novel copolymer synthesis with poly(2-methyl-2-oxazoline). React. Funct. Polym. 2012, 72, 160-167.

77. Celebi, O.; Lee, C.H.; Lin, Y.; McGrath, J.E.; Riffle, J.S. Synthesis and characterization of polyoxazoline-polysulfone triblock copolymers. Polymer 2011, 52, 4718-4726.

78. Isaacman, M.J.; Barron, K.A.; Theogarajan, L.S. Clickable amphiphilic triblock copolymers. J. Polym. Sci. A Polym. Chem. 2012, 50, 2319-2329.

79. Halacheva, S.; Price, G.J.; Garamus, V.M. Effects of temperature and polymer composition upon the aqueous solution properties of comblike linear poly(ethylene imine)/poly(2-ethyl-2oxazoline)-based polymers. Macromolecules 2011, 44, 7394-7404.

80. Nèry, L.; Lefebvre, H.; Fradet, A. Chain extension of carboxy-terminated aliphatic polyamides and polyesters by arylene and pyridylene bisoxazolines. Macromol. Chem. Phys. 2004, 205, 448-455.

81. Stadermann, J.; Komber, H.; Erber, M.; Däbritz, F.; Ritter, H.; Voit, B. Diblock copolymer formation via self-assembly of cyclodextrin and adamantyl end-functionalized polymers. Macromolecules 2011, 44, 3250-3259.

82. Li, Y.; Giles, M.D.; Liu, S.; Laurent, B.A.; Hoskins, J.N.; Cortez, M.A.; Sreerama, S.G.; Gibb, B.C.; Grayson, S.M. A versatile and modular approach to functionalisation of deep-cavity cavitands via "click" chemistry. Chem. Commun. 2011, 47, 9036-9038.

83. Ibrahim, S.; Voit, B. Synthesis and characterization of well-defined block copolymers by combining controlled radical and cationic polymerization. Macromol. Symp. 2009, 275-276, 59-66.

84. Becer, C.R.; Paulus, R.M.; Höppener, S.; Hoogenboom, R.; Fustin, C.-A.; Gohy, J.-F.; Schubert, U.S. Synthesis of poly(2-ethyl-2-oxazoline)-b-poly(styrene) copolymers via a dual initiator route combining cationic ring-opening polymerization and atom transfer radical polymerization. Macromolecules 2008, 41, 5210-5215.

85. Weber, C.; Krieg, A.; Paulus, R.M.; Lambermont-Thijs, H.M.L.; Becer, C.R.; Hoogenboom, R.; Schubert, U.S. Thermal properties of oligo(2-ethyl-2-oxazoline) containing comb and graft copolymers and their aqueous solutions. Macromol. Symp. 2011, 308, 17-24. 
86. Krieg, A.; Weber, C.; Hoogenboom, R.; Becer, C.R.; Schubert, U.S. Block copolymers of poly(2-oxazoline)s and poly(meth)acrylates: A crossover between cationic ring-opening polymerization (CROP) and reversible addition-fragmentation chain transfer (RAFT). ACS Macro. Lett. 2012, 1, 776-779.

87. Marx, L.; Volet, G.; Amiel, C. Well-defined polyoxazoline-based alkoxyamines as efficient macroinitiators in nitroxide-mediated radical polymerization of styrene. J. Polym. Sci. A Polym. Chem. 2011, 49, 4785-4793.

88. Jerca, V.V.; Nicolescu, F.A.; Vasilescu, D.S.; Vuluga, D.M. Synthesis of a new oxazoline macromonomer for dispersion polymerization. Polym. Bull. 2011, 66, 785-796.

89. Young, R.A.; Malins, E.L.; Becer, C.R. Investigations on the combination of cationic ring opening polymerization and single electron transfer living radical polymerization to synthesize 2-ethyl-2-oxazoline block copolymers. Aust. J. Chem. 2012, 65, 1132-1138.

90. Cabrera, A.; Böhme, L.M.; Schmidt-Naake, G. Modification of polyacrylonitrile particles and grafted films with oxazolines. Macromol. Chem. Phys. 2005, 206, 499-503.

91. Cabrera, A.; Schmidt-Naake, G. Cationic grafting of oxazolyl copolymers with 2-methyl and 2-phenyl oxazoline. Macromol. Chem. Phys. 2004, 205, 95-100.

92. Zhang, N.; Luxenhofer, R.; Jordan, R. Thermoresponsive poly(2-oxazoline) molecular brushes by living ionic polymerization: Kinetic investigations of pendant chain grafting and cloud point modulation by backbone and side chain length variation. Macromol. Chem. Phys. 2012, 213, 973-981.

93. Zhang, N.; Huber, S.; Schulz, A.; Luxenhofer, R.; Jordan, R. Cylindrical molecular brushes of poly(2-oxazoline)s from 2-isopropenyl-2-oxazoline. Macromolecules 2009, 42, 2215-2221.

94. Shi, J.-H.; Yang, B.-X.; Goh, S.H. Covalent functionalization of multiwalled carbon nanotubes with poly(styrene-co-acrylonitrile) by reactive melt blending. Eur. Polym. J. 2009, 45, $1002-1008$.

95. Jerca, V.V.; Nicolescu, F.A.; Baran, A.; Anghel, D.F.; Vasilescu, D.S.; Vuluga, D.M. Synthesis and characterization of side-chain oxazoline-methyl methacrylate copolymers bearing azo-dye. React. Funct. Polym. 2010, 70, 827-835.

96. Weber, C.; Neuwirth, T.; Kempe, K.; Ozkahraman, B.; Tamahkar, E.; Mert, H.; Becer, C.R.; Schubert, U.S. 2-Isopropenyl-2-oxazoline: A versatile monomer for functionalization of polymers obtained via RAFT. Macromolecules 2012, 45, 20-27.

97. Zhang, N.; Steenachers, M.; Luxenhofer, R.; Jordan, R. Bottle-brush brushes: Cylindrical molecular brushes of poly(2-oxazoline) on glassy carbon. Macromolecules 2009, 42, 5345-5351.

98. Zhang, N.; Pompe, T.; Amin, I.; Luxenhofer, R.; Werner, C.; Jordan, R. Tailored poly(2-oxazoline) polymer brushes to control protein adsorption and cell adhesion. Macromol. Biosci. 2012, 12, 926-936.

99. Hutter, N.A.; Reitinger, A.; Zhang, N.; Steenackers, M.; Williams, O.A.; Garrido, J.A.; Jordan, R. Microstructured poly(2-oxazoline) bottle-brush brushes on nanocrystalline diamond. Phys. Chem. Chem. Phys. 2010, 12, 4360-4366.

100. Lee, J.-H.; An, Y.-C.; Choi, D.-S.; Lee, M.-J.; Kim, K.-M.; Lim, J.-H. Fabrication of a nano-porous polyoxazoline-coated tip for scanning probe nanolithography. Macromol. Symp. 2007, 249-250, 307-311. 
101. Karagoz, B.; Gunes, D.; Bicak, N. Preparation of crosslinked poly(2-bromoethyl methacrylate) microspheres and decoration of their surfaces with functional polymer brushes. Macromol. Chem. Phys. 2010, 211, 1999-2007.

102. Yuan, J.; ten Brummelhuis, N.; Junginger, M.; Xie, Z.; Lu, Y.; Taubert, A.; Schlaad, H. Diversified applications of chemically modified 1,2-polybutadiene. Macromol. Rapid Commun. 2011, 32, 1157-1162.

103. Rueda, J.C.; Zschoche, S.; Komber, H.; Krahl, F.; Arndt, K.-F.; Voit, B. New thermo-sensitive graft copolymers based on a poly( $\mathrm{N}$-isopropylacrylamide) backbone and functional polyoxazoline grafts with random and diblock structure. Macromol. Chem. Phys. 2010, 211, 706-716.

104. Rueda, J.; Zschoche, S.; Komber, H.; Schmaljohann, D.; Voit, B. Synthesis and characterization of thermoresponsive graft copolymers of NIPAAm and 2-alkyl-2-oxazolines by the "grafting from" method. Macromolecules 2005, 38, 7330-7336.

105. Zschoche, S.; Rueda, J.C.; Binner, M.; Komber, H.; Janke, A.; Arndt, K.-F.; Lehmann, S.; Voit, B. Reversibly switchable $\mathrm{pH}$ - and thermoresponsive core-shell nanogels based on poly(NiPAAm)-graft-poly(2-carboxyethyl-2-oxazoline)s. Macromol. Chem. Phys. 2012, 213, $215-226$.

106. Zschoche, S.; Rueda, J.; Boyko, V.; Krahl, F.; Arndt, K.-F.; Voit, B. Thermo-responsive nanogels based on poly[NIPAAm-graft-(2-alkyl-2-oxazoline)]s crosslinked in the micellar state. Macromol. Chem. Phys. 2011, 211, 1035-1042.

107. Guillerm, B.; Darcos, V.; Lapinte, V.; Monge, S.; Coudane, J.; Robin, J.-J. Synthesis and evaluation of triazole-linked poly( $\varepsilon$-caprolactone)-graft-poly(2-methyl-2-oxazoline) copolymers as potential drug carriers. Chem. Commun. 2012, 48, 2879-2881.

108. Weber, C.; Becer, C.R.; Hoogenboom, R.; Schubert, U.S. Lower critical solution temperature behavior of comb and graft shaped poly[oligo(2-ethyl-2-oxazoline)methacrylate]s. Macromolecules 2009, 42, 2965-2971.

109. Weber, C.; Becer, C.R.; Guenther, W.; Hoogenboom, R.; Schubert, U.S. Dual responsive methacrylic acid and oligo(2-ethyl-2-oxazoline) containing graft copolymers. Macromolecules 2010, 43, 160-167.

110. Konradi, R.; Pidhatika, B.; Mühlebach, A.; Textor, M. Poly-2-methyl-2-oxazoline: A peptide-like polymer for protein-repellent surfaces. Langmuir 2008, 24, 613-616.

111. Poe, G.D.; McCormick, C.L. Synthesis, complex formation, and dilute-solution associative behavior of linear poly(methacrylic acid)-graft-poly(2-ethyl-2-oxazoline). J. Polym. Sci. A Polym. Chem. 2004, 42, 2520-2533.

112. Li, L.; Zheng, S. Poly(ethylene imine)-graft-poly(ethylene oxide) brush-like copolymers: Preparation, thermal properties, and selective supramolecular inclusion complexation with a-cyclodextrin. J. Polym. Sci. B Polym. Phys. 2008, 46, 2296-2306.

113. Pidhatika, B.; Möller, J.; Benetti, E.M.; Konradi, R.; Rakhmatullina, E.; Mühlebach, A.; Zimmermann, R.; Werner, C.; Vogel, V.; Textor, M. The role of the interplay between polymer architecture and bacterial surface properties on the microbial adhesion to polyoxazoline-based ultrathin films. Biomaterials 2010, 31, 9462-9472. 
114. Pidhatika, B.; Rodenstein, M.; Chen, Y.; Rakhmatullina, E.; Mühlebach, A.; Acikgöz, C.; Textor, M.; Konradi, R. Comparative stability studies of poly(2-methyl-2-oxazoline) and poly(ethylene glycol) brush coatings. Biointerphases 2012, 7, 1-15.

115. Agrawal, M.; Rueda, J.C.; Uhlmann, P.; Müller, M.; Simon, F.; Stamm, M. Facile approach to grafting of poly(2-oxazoline) brushes on macroscopic surfaces and applications thereof. ACS Appl. Mater. Interfaces 2012, 4, 1357-1364.

116. Rehfeldt, F.; Tanaka, M.; Pagnoni, L.; Jordan, R. Static and dynamic swelling of grafted poly(2-alkyl-2-oxazoline)s. Langmuir 2002, 18, 4908-4914.

117. Luxenhofer, R.; Bezen, M.; Jordan, R. Kinetic investigations on the polymerization of 2-oxazolines using pluritriflate initiators. Macromol. Rapid Commun. 2008, 29, 1509-1513.

118. Hoogenboom, R.; Fijten, M.W.M.; Kickelbick, G.; Schubert, U.S. Synthesis and crystal structures of multifunctional tosylates as basis for star-shaped poly(2-ethyl-2-oxazoline)s. Beilstein J. Org. Chem. 2010, 6, 773-783.

119. Kowalczuk, A.; Kronek, J.; Bosowska, K.; Trzebicka, B.; Dworak, A. Star poly(2-ethyl-2oxazoline)s-synthesis and thermosensitivity. Polym. Int. 2011, 60, 1001-1009.

120. Adeli, M.; Kalantari, M.; Zarnega, Z.; Kabiri, R. Cyclodextrin-based dendritic supramolecules; new multivalent nanocarriers. RSC Adv. 2012, 2, 2756-2758.

121. Adeli, M.; Zarnegar, Z. Linear-dendritic copolymers as nanocatalysts. J. Appl. Polym. Sci. 2009, 113, 2072-2080.

122. Adeli, M.; Zarnegar, Z.; Kabiri, R. Amphiphilic star copolymers containing cyclodextrin core and their application as nanocarrier. Eur. Polym. J. 2008, 44, 1921-1930.

123. Heller, M.; Schubert, U.S. Terpyridines as supramolecular initiators for living polymerization methods. Macromol. Symp. 2002, 177, 87-96.

124. Fiore, G.L.; Edwards, J.M.; Payne, S.J.; Klinkenberg, J.L.; Gioeli, D.G.; Demas, J.N.; Fraser, C.L. Ruthenium(II) tris(bipyridine)-centered poly(ethylenimine) for gene delivery. Biomacromolecules 2007, 8, 2829-2835.

125. Lambermont-Thijs, H.M.L.; Fijten, M.W.M.; Schubert, U.S.; Hoogenboom, R. Star-shaped poly(2-oxazoline)s by dendrimer endcapping. Aust. J. Chem. 2011, 64, 1026-1032.

126. Jeerupan, J.; Ogoshi, T.; Hiramitsu, S.; Umeda, K.; Nemoto, T.; Konishi, G.; Yamagishi, T.; Nakamoto, Y. Star-shaped poly(2-methyl-2-oxazoline) using by reactive bromoethyl group modified calix[4]resorcinarene as a macrocyclic initiator. Polym. Bull. 2008, 59, 731-737.

127. Wen, Y.; Jiang, X.; Liu, R.; Yin, J. Amphipathic hyperbranched polymeric thioxanthone photoinitiators (AHPTXs): Synthesis, characterization and photoinitiated polymerization. Polymer 2009, 50, 3917-3923.

128. Clausnitzer, C.; Voit, B.; Komber, H.; Voigt, D. Poly(ether amide) dendrimers via nucleophilic ring-opening addition reactions of phenol groups toward oxazolines: Synthesis and characterization. Macromolecules 2003, 36, 7065-7074.

129. Däbritz, F.; Lederer, A.; Komber, H.; Voit, B. Synthesis and characterization of two classes of hyperstar polymers bearing hyperbranched cores grafted with linear arms. J. Polym. Sci. A Polym. Chem. 2012, 50, 1979-1990. 
130. Guerrero-Sanchez, C.; Lobert, M.; Hoogenboom, R.; Schubert, U.S. Microwave-assisted homogeneous polymerizations in water-soluble ionic liquids: An alternative and green approach for polymer synthesis. Macromol. Rapid Commun. 2007, 28, 456-464.

131. De Macedo, C.V.; da Silva, M.S.; Casimiro, T.; Cabrita, E.J.; Aguiar-Ricardo, A. Boron trifluoride catalyzed polymerisation of 2-substituted-2-oxazolines in supercritical carbon dioxide. Green Chem. 2007, 9, 948-953.

132. Kempe, K.; Lobert, M.; Hoogenboom, R.; Schubert, U.S. Screening the synthesis of 2-substituted-2-oxazolines. J. Comb. Chem. 2009, 11, 274-280.

133. Kempe, K.; Lobert, M.; Hoogenboom, R.; Schubert, U.S. Synthesis and characterization of a series of diverse poly(2-oxazoline)s. J. Polym. Sci. A Polym. Chem. 2009, 47, 3829-3838.

134. Rettler, E.F.-J.; Kranenburg, J.M.; Lambermont-Thijs, H.M.L.; Hoogenboom, R.; Schubert, U.S. Thermal, mechanical, and surface properties of poly(2- $N$-alkyl-2-oxazoline)s. Macromol. Chem. Phys. 2012, 211, 2443-2448.

135. Lambermont-Thijs, H.M.L.; van Kuringen, H.P.C.; van der Put, J.P.W.; Schubert, U.S.; Hoogenboom, R. Temperature induced solubility transitions of various poly(2-oxazoline)s in ethanol-water solvent mixtures. Polymers 2010, 2, 188-199.

136. Cortez, M.A.; Grayson, S.M. Thiol-ene click functionalization and subsequent polymerization of 2-oxazoline monomers. Macromolecules 2010, 43, 4081-4090.

137. Takasu, A.; Kojima, H. Synthesis and ring-opening polymerizations of novel S-glycooxazolines. J. Polym. Sci. A Polym. Chem. 2010, 48, 5953-5960.

138. Diab, C.; Akiyama, Y.; Kataoka, K.; Winnik, F.M. Microcalorimetric study of the temperature-induced phase separation in aqueous solutions of poly(2-isopropyl-2-oxazolines). Macromolecules 2004, 37, 2556-2562.

139. Katsumoto, V.; Tsuchiizu, A.; Qiu, X.-P.; Winnik, F.M. Dissecting the mechanism of the heat-induced phase separation and crystallization of poly(2-isopropyl-2-oxazoline) in water through vibrational spectroscopy and molecular orbital calculations. Macromolecules 2012, 45, 3531-3541.

140. Demirel, A.L.; Meyer, M.; Schlaad, H. Formation of polyamide nanofibers by directional crystallization in aqueous solution. Angew. Chem. Int. Ed. 2007, 46, 8622-8624.

141. Bloksma, M.M.; Weber, C.; Perevyazko, I.Y.; Kuse, A.; Baumgärtel, A.; Vollrath, A.; Hoogenboom, R.; Schubert, U.S. Poly(2-cyclopropyl-2-oxazoline): From rate acceleration by cyclopropyl to thermoresponsive properties. Macromolecules 2011, 44, 4057-4064.

142. Kempe, K.; Jacobs, S.; Lambermont-Thijs, H.M.L.; Fijten, M.M.W.M.; Hoogenboom, R.; Schubert, U.S. Rational design of an amorphous poly(2-oxazoline) with a low glass-transition temperature: Monomer synthesis, copolymerization, and properties. Macromolecules 2010, 43, 4098-4104.

143. Diehl, C.; Dambowsky, I.; Hoogenboom, R.; Schlaad, H. Self-assembly of poly(2-alkyl-2oxazoline)s by crystallization in ethanol-water mixtures below the upper critical solution temperature. Macromol. Rapid Commun. 2011, 32, 1753-1758. 
144. Hoogenboom, R.; Thijs, H.M.L.; Jochems, M.J.H.C.; van Lankvelt, B.M.; Fijten, M.W.M.; Schubert, U.S. Tuning the LCST of poly(2-oxazoline)s by varying composition and molecular weight: Alternatives to poly( $N$-isopropylacrylamide)? Chem. Commun. 2008, doi:10.1039/B813140F.

145. Hruby, M.; Filippov, S.K.; Panek, J.; Novakova, M.; Mackova, H.; Kucka, J.; Vetvicka, D.; Ulbrich, K. Polyoxazoline thermoresponsive micelles as radionuclide delivery systems. Macromol. Biosci. 2010, 10, 916-924.

146. Pánek, J.; Filippov, S.K.; Hrubý, M.; Rabyk, M.; Bogomolova, A.; Kučka, J.; Štěpánek, P. Thermoresponsive nanoparticles based on poly(2-alkyl-2-oxazoline)s and pluronic F127. Macromol. Rapid Commun. 2012, 1683-1689.

147. Bloksma, M.M.; Bakker, D.J.; Weber, C.; Hoogenboom, R.; Schubert, U.S. The effect of Hofmeister salts on the LCST transition of poly(2-oxazoline)s with varying hydrophilicity. Macromol. Rapid Commun. 2010, 31, 724-728.

148. Rattanatraicharoen, P.; Shintaku, K.; Yamabuki, K.; Oishi, T.; Onimura, K. Synthesis and chiroptical properties of helical poly(phenylacetylene) bearing optically active chiral oxazoline pendants. Polymer 2012, 53, 2567-2573.

149. Rattanatraicharoen, P.; Yamabuki, K.; Oishi, T.; Onimura, K. Synthesis and characterization of optically active poly(phenylene-ethynylene)s containing chiral oxazoline derivatives. Polym. J. 2012, 44, 224-231.

150. Fu, Z.; Xi, X.; Jiang, L.; Shen, Z. Optically active polymethacrylamides bearing a bulky oxazoline pendant: Synthesis and characterization. React. Funct. Polym. 2007, 67, 636-643.

151. Xi, X.; Jiang, L.; Sun, W.; Shen, Z. Synthesis and anionic polymerization of optically active N-phenylmaleimides bearing bulky oxazoline substituents. Eur. Polym. J. 2005, 41, 2592-2601.

152. Lou, L.; Jiang, L.; Sun, W.; Shen, Z. A novel optically active diblock copolymer composed of poly(ethylene glycol) and poly[N-\{o-(4-phenyl-4,5-dihydro-1,3-oxazol-2-yl)phenyl $\}$ maleimide]: Synthesis, micellization behavior, and chiroptical property. J. Polym. Sci. A Polym. Chem. 2008, 46, 1025-1033.

153. Goto, H.; Okamoto, Y.; Yashima, E. Solvent-induced chiroptical changes in supramolecular assemblies of an optically active, regioregular polythiophene. Macromolecules 2002, 35, $4590-4601$.

154. Goto, H.; Okamoto, Y.; Yashima, E. Metal-induced supramolecular chirality in an optically active polythiophene aggregate. Chem. Eur. J. 2002, 8, 4027-4036.

155. Bloksma, M.M.; Hendrix, M.M.R.M.; Schubert, U.S.; Hoogenboom, R. Ordered chiral structures in the crystals of main-chain chiral poly(2-oxazoline)s. Macromolecules 2010, 43, 4654-4659.

156. Bloksma, M.M.; Schubert, U.S.; Hoogenboom, R. Main-chain chiral copoly(2-oxazoline)s. Polym. Chem. 2011, 2, 203-208.

157. Wiesbrock, F.; Hoogenboom, R.; Leenen, M.A.M.; Meier, M.A.R; Schubert, U.S. Investigation of the living cationic ring-opening polymerization of 2-methyl-, 2-ethyl-, 2-nonyl-, and 2-phenyl-2-oxazoline in a single-mode microwave reactor. Macromolecules 2005, 38, 5025-5034. 
158. Wiesbrock, F.; Hoogenboom, R.; Leenen, M.; van Nispen, S.F.G.M.; van der Loop, M.; Abeln, C.H.; van den Berg, A.M.J.; Schubert, U.S. Microwave assisted synthesis of a $4^{2}$-membered library of diblock copoly(2-oxazoline)s and chain-extended homo poly(2-oxazoline)s and their thermal characterization. Macromolecules 2005, 38, 7957-7966.

159. Hoogenboom, R.; Wiesbrock, F.; Huang, H.; Leenen, M.A.; Thijs, H.M.; van Nispen, S.F.; van der Loop, M.; Fustin, C.-A.; Jonas, A.M.; Gohy, J.-F.; Schubert, U.S. Microwave-assisted cationic ring-opening polymerization of 2-oxazolines: A powerful method for the synthesis of amphiphilic triblock copolymers. Macromolecules 2006, 39, 4719-4725.

160. Wiesbrock, F.; Hoogenboom, R.; Leenen, M.A.; Thijs, H.M.; Huang, H.; Fustin, C.-A.; Guillet, P.; Gohy, J.-F.; Schubert, U.S. Synthesis and aqueous micellization of amphiphilic tetrablock copoly(2-oxazoline)s. Macromolecules 2007, 40, 2837-2843.

161. Lambermont-Thijs, H.M.L.; Jochems, M.J.H.C.; Hoogenboom, R.; Schubert, U.S. Synthesis and properties of gradient copolymers based on 2-phenyl-2-oxazoline and 2-nonyl-2-oxazoline. J. Polym. Sci. A Polym. Chem. 2009, 47, 6433-6440.

162. Hoogenboom, R.; Thijs, H.M.L.; Fijten, M.W.M.; Van Lankvelt, B.M.; Schubert, U.S. One-pot synthesis of 2-phenyl-2-oxazoline-containing quasi-diblock copoly(2-oxazoline)s under microwave irradiation. J. Polym. Sci. A Polym. Chem. 2007, 45, 416-422.

163. Kranenburg, J.M.; Thijs, H.M.L.; Tweedie, C.A.; Hoeppener, S.; Wiesbrock, F.; Hoogenboom, R.; Van Vliet, K.J.; Schubert, U.S. Correlating the mechanical and surface properties with the composition of triblock copoly(2-oxazoline)s. J. Mater. Chem. 2009, 19, 222-229.

164. Fustin, C.-A.; Thijs-Lambermont, H.M.L.; Hoeppener, S.; Hoogenboom, R.; Schubert, U.S.; Gohy, J.-F. Multiple micellar morphologies from tri- and tetrablock copoly(2-oxazoline)s in binary water-ethanol mixtures. J. Polym. Sci. A Polym. Chem. 2010, 48, 3095-3102.

165. Trzebicka, B.; Koseva, N.; Mitova, V.; Dworak, A. Organization of poly(2-ethyl-2-oxazoline)block-poly(2-phenyl-2-oxazoline) copolymers in water solution. Polymer 2010, 51, 2486-2493.

166. Fustin, C.-A.; Lefèvre, N.; Hoogenboom, R.; Schubert, U.S.; Gohy, J.-F. Micellization of poly(2-oxazoline)-based quasi-diblock copolymers on surfaces. Macromol. Chem. Phys. 2007, 208, 2026-2031.

167. Kumm, C.; Fik, C.P.; Meuris, M.; Dropalla, G.J.; Geltenpoth, H.; Sickmann, A.; Tiller, J.C. Well-defined amphiphilic poly(2-oxazoline) ABA-triblock copolymers and their aggregation behavior in aqueous solution. Macromol. Rapid Commun. 2012, 1677-1682.

168. Takahashi, R.; Sato, T.; Terao, K.; Qiu, X.-P.; Winnik, F.M. Self-association of a thermosensitive poly(alkyl-2-oxazoline) block copolymer in aqueous solution. Macromolecules 2012, 45, 6111-6119.

169. Casse, O.; Shkilnyy, A.; Linders, J.; Mayer, C.; Häussinger, D.; Völkel, A.; Thünemann, A.F.; Dimova, R.; Cölfen, H.; Meier, W.; et al. Solution behavior of double-hydrophilic block copolymers in dilute aqueous solution. Macromolecules 2012, 45, 4772-4777.

170. Trinh, L.T.T.; Lambermont-Thijs, H.M.L.; Schubert, U.S.; Hoogenboom, R.; Kjoniksen, A.-L. Thermoresponsive poly(2-oxazoline) block copolymers exhibiting two cloud points: Complex multistep assembly behavior. Macromolecules 2012, 45, 4337-4345. 
171. Fustin, C.A.; Lefèvre, N.; Hoogenboom, R.; Schubert, U.S.; Gohy, J.-F. Surface micellization of poly(2-oxazoline)s based copolymers containing a crystallizable block. J. Colloid Interface Sci. 2009, 332, 91-95.

172. Ivanova, R.; Komenda, T.; Bonné, T.B.; Lüdtke, K.; Mortensen, K.; Pranzas, P.K.; Jordan, R.; Papadakis, C.M. Micellar structures of hydrophilic/lipophilic and hydrophilic/fluorophilic poly(2-oxazoline) diblock copolymers in water. Macromol. Chem. Phys. 2008, 209, 2248-2258.

173. Kotre, T.; Zarka, M.T.; Krause, J.O.; Buchmeiser, M.R.; Weberskirch, R.; Nuyken, O. Design and application of amphiphilic polymeric supports for micellar catalysis. Macromol. Symp. 2004, 217, 203-214.

174. Nuyken, O.; Persigehl, P.; Weberskirch, R. Amphiphilic poly(oxazoline)s-synthesis and application for micellar catalysis. Macromol. Symp. 2002, 177, 163-173.

175. Huang, H.; Hoogenboom, R.; Leenen, M.A.M.; Guillet, P.; Jonas, A.M.; Schubert, U.S.; Gohy, J.-F. Solvent-induced morphological transition in core-cross-linked block copolymer micelles. J. Am. Chem. Soc. 2006, 128, 3784-3788.

176. Bonné, T.B.; Lüdtke, K.; Jordan, R.; Papadakis, C.M. Effect of polymer architecture of amphiphilic poly(2-oxazoline) copolymers on the aggregation and aggregate structure. Macromol. Chem. Phys. 2007, 208, 1402-1408.

177. Guerrero-Sanchez, C.; Gohy, J.-F.; D’Haese, C.; Thijs, H.; Hoogenboom, R.; Schubert, U.S. Controlled thermoreversible transfer of poly(oxazoline) micelles between an ionic liquid and water. Chem. Commun. 2008, 2753-2755.

178. Kempe, K.; Baumgaertel, A.; Hoogenboom, R.; Schubert, U.S. Design of new amphiphilic triblock copoly(2-oxazoline)s containing a fluorinated segment. J. Polym. Sci. A Polym. Chem. 2010, 48, 5100-5108.

179. Luxenhofer, R.; Schulz, A.; Roques, C.; Li, S.; Bronich, T.K.; Batrakova, E.V.; Jordan, R.; Kabanov, A.V. Doubly amphiphilic poly(2-oxazoline)s as high-capacity delivery system for hydrophobic drugs. Biomaterials 2010, 31, 4972-4979.

180. Choi, H.-J.; Brooks, E.; Montemagno, C.D. Synthesis and characterization of nanoscale biomimetic polymer vesicles and polymer membranes for bioelectronics applications. Nanotechnology 2005, 16, 143-149.

181. Schönfelder, D.; Fischer, K.; Schmidt, M.; Nuyken, O.; Weberskirch, R. Poly(2-oxazoline)s functionalized with palladium carbene complexes: Soluble, amphiphilic polymer supports for $\mathrm{C}-\mathrm{C}$ coupling reactions in water. Macromolecules 2005, 38, 254-262.

182. Han, Y.; He, Z.; Schulz, A.; Bronich, T.K.; Jordan, R.; Luxenhofer, R.; Kabanov, A.V. Synergistic combinations of multiple chemotherapeutic agents in high capacity poly(2-oxazoline) micelles. Mol. Pharm. 2012, 9, 2302-2313.

183. Kempe, K.; Hoogenboom, R.; Schubert, U.S. A green approach for the synthesis and thiol-ene modification of alkene functionalized poly(2-oxazoline)s. Macromol. Rapid Commun. 2011, 32, 1484-1489.

184. Cesana, S.; Kurek, A.; Baur, M.A.; Auernheimer, J.; Nuyken, O. Polymer-bound thiol groups on poly(2-oxazoline)s. Macromol. Rapid Commun. 2007, 28, 608-615.

185. Hoogenboom, R.; Schubert, U.S. Microwave-assisted cationic ring-opening polymerization of a soy-based 2-oxazoline monomer. Green Chem. 2006, 8, 895-899. 
186. Kempe, K.; Neuwirth, T.; Czaplewska, J.; Gottschaldt, M.; Hoogenboom, R.; Schubert, U.S. Poly(2-oxazoline) glycopolymers with tunable LCST behavior. Polym. Chem. 2011, 2, 1737-1743.

187. Kempe, K.; Hoogenboom, R.; Jaeger, M.; Schubert, U.S. Three-fold metal-free efficient "click" reactions onto a multifunctional poly(2-oxazoline) designer scaffold. Macromolecules 2011, 44, 6424-6432.

188. Jakisch, L.; Komber, H.; Böhme, F. Multifunctional coupling agents: Synthesis and model reactions. J. Polym. Sci. A Polym. Chem. 2003, 41, 655-667.

189. Gress, A.; Völkel, A.; Schlaad, H. Thio-click modification of poly[2-(3-butenyl)-2-oxazoline]. Macromolecules 2007, 40, 7928-7933.

190. Diehl, C.; Schlaad, H. Polyoxazoline-based crystalline microspheres for carbohydrate-protein recognition. Chem. Eur. J. 2009, 15, 11469-11472.

191. Del Rio, E.; Lligadas, G.; Ronda, J.C.; Galià, M.; Cádiz, V. Poly-2-oxazoline-derived polyurethanes: A versatile synthetic approach to renewable polyurethane thermosets. J. Polym. Sci. A Polym. Chem. 2011, 49, 3069-3079.

192. Diehl, C.; Schlaad, H. Thermo-responsive polyoxazolines with widely tuneable LCST. Macromol. Biosci. 2009, 9, 157-161.

193. Kempe, K.; Weber, C.; Babiuch, K.; Gottschaldt, M.; Hoogenboom, R.; Schubert, U.S. Responsive glycol-poly(2-oxazoline)s: Synthesis, cloud point tuning, and lectin binding. Biomacromolecules 2011, 12, 2591-2600.

194. Luxenhofer, R.; Jordan, R. Click chemistry with poly(2-oxazoline)s. Macromolecules 2006, 39, 3509-3516.

195. Ten Brummelhuis, N.; Schlaad, H. Stimuli-responsive star polymers through thiol-yne core functionalization/crosslinking of block copolymer micelles. Polym. Chem. 2011, 2, 1180-1184.

196. Manzenrieder, F.; Luxenhofer, R.; Retzlaff, M.; Jordan, R.; Finn, M.G. Stabilization of virus-like particles with poly(2-oxazoline)s. Angew. Chem. Int. Ed. 2011, 50, 2601-2605.

197. Cesana, S.; Auernheimer, J.; Jordan, R.; Kessler, H.; Nuyken, O. First poly(2-oxazoline)s with pendant amino groups. Macromol. Chem. Phys. 2006, 207, 183-192.

198. Kronek, J.; Luston, J.; Kronekova, Z.; Paulovicova, E.; Farkas, P.; Petrencikova, N.; Paulovicova, L.; Janigova, I. Synthesis and bioimmunological efficiency of poly(2-oxazoline)s containing a free amino group. J. Mater. Sci. Mater. Med. 2010, 21, 879-886.

199. Taubmann, C.; Luxenhofer, R.; Cesana, S.; Jordan, R. First aldehyde-functionalized poly(2oxazoline)s for chemoselective ligands. Macromol. Biosci. 2005, 5, 603-612.

200. Luston, J.; Kronek, J.; Böhme, F. Synthesis and polymerization reactions of cyclic imino ethers. I. Ring-opening homopolyaddition of AB-type hydroxyphenyl-substituted 2-oxazolines. J. Polym. Sci. A Polym. Chem. 2006, 44, 343-355.

201. Krause, J.O.; Zarka, M.T.; Anders, U.; Weberskirch, R.; Nuyken, O.; Buchmeiser, M.R. Simple synthesis of poly(acetylene) latex particles in aqueous media. Angew. Chem. Int. Ed. 2003, 42, 5965-5969.

202. Zarka, M.T.; Nuyken, O.; Weberskirch, R. Polymer-bound, amphiphilic Hoveyda-Grubbs-type catalyst for ring-closing metathesis in water. Macromol. Rapid Commun. 2004, 25, 858-862. 
203. Wang, H.; Li, L.; Tong, Q.; Yan, M. Evaluation of photochemically immobilized poly(2-ethyl-2-oxazoline) thin films as protein-resistant surfaces. Appl. Mater. Interfaces 2011, 3, 3463-3471.

204. Lambermont-Thijs, H.M.L.; Bonami, L.; Du Prez, F.E.; Hoogenboom, R. Linear poly(alkyl ethylene imne) with varying side chain length: Synthesis and physical properties. Polym. Chem. 2010, 1, 747-754.

205. Bauer, M.; Lautenschlaeger, C.; Kempe, K.; Tauhardt, L.; Schubert, U.S.; Fischer, D. Poly(2-ethyl-2-oxazoline) as alternative for the stealth polymer poly(ethylene glycol): Comparison of in vitro cytotoxicity and hemocompatibility. Macromol. Biosci. 2012, 12, 986-998.

206. Luxenhofer, R.; Sahay, G.; Schulz, A.; Alakhova, D.; Bronich, T.K.; Jordan, R.; Kabanov, A.V. Structure-property relationship in cytotoxicity and cell uptake of poly(2-oxazoline) amphiphiles. J. Contr. Rel. 2011, 153, 73-82.

207. Van Kuringen, H.P.C.; Lenoir, J.; Adriaens, E.; Bender, J.; de Geest, B.G.; Hoogenboom, R. Partial hydrolysis of poly(2-ethyl-2-oxazoline) and potential implications for biomedical applications. Macromol. Biosci. 2012, 12, 1114-1123.

208. Lambermont-Thijs, H.M.L.; van der Woerdt, F.S.; Baumgaertel, A.; Bonami, L.; Du Prez, F.E.; Schubert, U.S.; Hoogenboom, R. Linear poly(ethylene imine)s by acidic hydrolysis of poly(2-oxazoline)s: Kinetic screening, thermal properties, and temperature-induced solubility transitions. Macromolecules 2010, 43, 927-933.

209. Niko, Y.; Konishi, G. Polymer-chain-induced tunable luminescence properties: Amphiphilic poly(2-oxazoline)s possessing a N,N,-dialkylpyrene-1-carboxamide chromophore in the side chain. Macromolecules 2012, 45, 2327-2337.

210. Hsiue, G.-H.; Chiang, H.-Z.; Wang, C.-H.; Juang, T.-M. Nonviral gene carriers based on diblock copolymers of poly(2-ethyl-2-oxazoline) and linear polyethylenimine. Bioconjug. Chem. 2006, 17, 781-786.

211. Jeon, J.-H.; Lee, S.-H.; Lim, J.-H.; Kim, K.-M. Synthesis and characterization of novel hybrid polyoxazoline-grafted multiwalled carbon nanotubes. J. Appl. Polym. Sci. 2010, 116, 2937-2943.

212. Lambermont-Thijs, H.M.L.; Heuts, J.P.A.; Hoeppener, S.; Hoogenboom, R.; Schubert, U.S. Selective partial hydrolysis of amphiphilic copoly(2-oxazoline)s as basis for temperature and $\mathrm{pH}$ responsive micelles. Polym. Chem. 2011, 2, 313-322.

213. Van Kuringen, H.P.C.; de la Rosa, V.R.; Fijten, M.W.M.; Heuts, J.P.A.; Hoogenboom, R. Enhanced selectivity for the hydrolysis of block copoly(2-oxazoline)s in ethanol-water resulting in linear poly(ethylene imine) copolymers. Macromol. Rapid Commun. 2012, 33, 827-832.

214. Navarro, S.; Shkilnyy, A.; Tiersch, B.; Taubert, A.; Menzel, H. Preparation, characterization, and thermal gelation of amphiphilic alkyl-poly(ethyleneimine). Langmuir 2009, 25, 10558-10566.

215. Santini, C.M.B.; Johnson, M.A.; Boedicker, J.Q.; Hatton, T.A.; Hammond, P.T. Synthesis and bulk assembly behavior of linear-dendritic rod diblock copolymers. J. Polym. Sci. A Polym. Chem. 2004, 42, 2784-2814.

216. Yan, M.; Ren, J. Covalent immobilization of ultrathin polymer films by thermal activation of perfluorophenyl azide. Chem. Mater. 2004, 16, 1627-1632. 
217. Dhende, V.P.; Samanta, S.; Jones, D.M.; Hardin, I.R.; Locklin, J. One-step photochemical synthesis of permanent, nonleaching, ultrathin antimicrobial coatings for textiles and plastics. ACS Appl. Mater. Interfaces 2011, 3, 2830-2837.

218. Chang, B.-J.; Prucker, O.; Groh, E.; Wallrath, A.; Dahm, M.; Rühe, J. Surface-attached polymer monolayers for the control of endothelial cell adhesion. Colloids Surf. A Physicochem. Eng. Asp. 2002, 198-200, 519-526.

219. Pasquier, N.; Keul, H.; Heine, E.; Moeller, M. From multifunctionalized poly(ethylene imine)s toward antimicrobial coatings. Biomacromolecules 2007, 8, 2874-2882.

220. Kelly, A.; Kaltenhauser, V.; Mühlbacher, I.; Rametsteiner, K.; Kren, H.; Slugovc, C.; Stelzer, F.; Wiesbrock, F. Poly(2-oxazoline)-derived contact biocides: Contributions to the understanding of antimicrobial activity. Macromol. Biosci. 2013, 13, 116-125.

(C) 2013 by the authors; licensee MDPI, Basel, Switzerland. This article is an open access article distributed under the terms and conditions of the Creative Commons Attribution license (http://creativecommons.org/licenses/by/3.0/). 